\title{
Processes, microstructure and properties of vanadium microalloyed steels
}

\section{T. N. Baker*}

Vanadium as an important alloying element in steels was initially associated with the properties achieved following tempering. Interest in the microstructure was stimulated by the advent of transmission electron microscopes with a resolution of $\sim 1 \mathrm{~nm}$ together with selected area electron diffraction techniques. A second timely development was that of controlled rolling, particularly of plate and sheet products. The scope of this review will include the historical background on quenched and tempered vanadium steels, precipitation during isothermal aging, conventional controlled rolling and during thin slab direct charging and the development of strength and toughness in vanadium microalloyed steels. The characterisation of microstructure, in particular the methods for the analysis of the chemical composition of precipitates has progressed since the availability of X-ray energy dispersive analysis in the 1970s, and the role played by electron energy loss spectroscopy in providing quantitative analysis of carbon and nitrogen in vanadium microalloyed steels will be presented. There are still many topics involving vanadium microalloyed steels that are controversial. These include the nucleation sequence of homogeneous precipitates of vanadium carbonitride and whether this occurs coherently, the composition of the vanadium precipitates, the nucleation mechanism for interphase precipitation, the importance of strain induced precipitation in austenite of vanadium carbonitride, the contributions of both interphase precipitation and random precipitation in ferrite to the yield strength, and the role of the process route parameters in developing properties. These topics will be considered in this paper which concentrates on hot rolled vanadium microalloyed steels placed in the context of pertinent research on other alloys.

Keywords: Vanadium, Microalloy Steels, Processes, Microstructure, Properties

\section{Introduction}

No recent comprehensive review on vanadium in microalloyed steels, also known as high strength low alloy (HSLA) steels, appears to have been published, but there are several accounts dealing with specific aspects, such as the physical metallurgy of vanadium steels complied by Woodhead ${ }^{1}$ and the role of vanadium in microalloyed steels. ${ }^{2}$ This latter review provides an excellent account, up to 1999, in particular of the research undertaken at the Swedish Institute for Metals Research in Stockholm, where high quality work on vanadium steels has spanned several decades. ${ }^{2}$ Also many papers, together with the book by Gladman, ${ }^{3}$ cover the effects of vanadium, alongside those of niobium and titanium additions, on the microstructure and properties of microalloyed steels. One of the most cited reviews of the earlier work on microalloyed steels,

Metallurgy and Engineering Materials Group, Department of Mechanical Engineering, University of Strathclyde, Glasgow, G1 1XN, UK

*Corresponding author, email tnb@mecheng.strath.ac.uk which includes vanadium steels, is that by Pickering, ${ }^{4}$ which considered the situation up to 1975. Despite the amount of published work on the effect of vanadium on microalloyed steels over the past 40 plus years, there are still many topics that are controversial. These include the nucleation sequence of homogeneous precipitates of vanadium carbonitride and whether this occurs coherently, the composition of the vanadium precipitates, the nucleation mechanism for interphase precipitation, the importance of strain induced precipitation in austenite of vanadium carbonitride, the contributions of both interface precipitation and random precipitation in ferrite to the yield strength, and the role of the process route parameters in developing properties. These topics will be considered in this paper which concentrates on hot rolled vanadium microalloyed steels placed in the context of pertinent research on other alloys. The scope of this review will include the historical background on quenched and tempered vanadium steels, isothermal aging, precipitation during conventional controlled rolling and during thin slab direct charged and the development of strength and toughness in vanadium microalloyed steels. 


\section{Historical background}

Vanadium was discovered by a Mexican chemist, A. M. del Rio, in 1801, but the letter describing his methods of extraction, sent to the Institute de France for confirmation was lost in a shipwreck, and the claim subsequently withdrawn. As described by Langneborg et al. ${ }^{2}$ in their excellent summary of the early history of vanadium, the Swede, N. G. Sefström is credited with the discovery of the element vanadium in 1830. This led J. J. Berzelius to undertake research on vanadium compounds. However, it was not until some 30 years later that the element was isolated by Sir Henry Roscoe. The first use of the element in steels appears to be associated with Professor Arnold of Sheffield Firth College, who was in 1889, to become the first Professor of Metallurgy in the newly constituted University College of Sheffield, which in 1905 became the University of Sheffield. His work initiated a whole range of tool and die steels based on vanadium. ${ }^{2}$ Another early reference to alloying with vanadium is given in 1929 by Knowlton, in his book on the 'Heat treatment, uses and properties of steel'. ${ }^{5} \mathrm{He}$ writes, 'vanadium in small amounts acts as a scavenger in removing impurities thus producing a sounder stronger steel. The exact effect of vanadium which is left in the steel may be open to some dispute, although it undoubtedly has some beneficial effects'. It was later shown that the hardness of these steels was attributed to the high temperature stability conferred by vanadium carbide. Abram ${ }^{6}$ studied a $0 \cdot 30 \mathrm{C}-2 \cdot 60 \mathrm{Ni}-0 \cdot 75 \mathrm{Cr}-$ $0 \cdot 50 \mathrm{Mo}(\mathrm{wt}-\%)$ steel, oil quenched from $900^{\circ} \mathrm{C}$ and showed that the strength decreased as the tempering temperature increased, whereas when $0 \cdot 30 \mathrm{wt}-\% \mathrm{~V}$ was present, while the tensile strength remained practically constant, the yield stress increased. Abram ${ }^{6}$ ascribes these observations to the solution of vanadium carbide in austenite, its retention in the ferrite on quenching and its precipitation on tempering, a view similar to that upheld today.

As an alloying element in steel, vanadium was used extensively in Cr-Mo-V steels, developed for high temperature creep resistance, particularly for the early gas turbine engines ${ }^{7}$ through the precipitation of transition metal carbides, following heat treatment involving tempering. ${ }^{8,9}$ Other important applications of vanadium alloy steels, developed during the first two thirds of the twentieth century were for high temperature power plant, rail steels and in cast iron. However, as described by Langneborg et al., ${ }^{2}$ the most important use of vanadium in steels is as an alloying element in microalloyed steels, which commenced in the 1950s. In addition to being a major alloying element in microalloyed steels, vanadium is also an important alloying element in titanium alloys, and over $50 \%$ of the Ti alloys manufactured fall into the Ti-6Al-4V category. ${ }^{10}$

\section{Vanadium carbide and nitride}

Vanadium is a strong carbide and nitride former. The lattice parameters of the $\mathrm{B} 1(\mathrm{Fm} 3 \mathrm{~m}) \mathrm{NaCl}$ type compounds of vanadium are for the carbide, $0.41285 \mathrm{~nm}$ for $\mathrm{VC}_{0.75}$ to $0.41686 \mathrm{~nm}$ for $\mathrm{VC}_{0.92}$ and $0.4066 \mathrm{~nm}$ for $\mathrm{VN}_{0.72}$ to $0.41398 \mathrm{~nm}$ for $\mathrm{VN} .^{11,12}$ Woodhead $^{1}$ was among the earliest workers to point out, that due to the closeness of the lattice parameters, it is quite impossible to categorise a compound as a vanadium carbide or nitride from selected area electron diffraction (SAED) patterns. However, the orientation relationship that exists between $\mathrm{V}(\mathrm{C}, \mathrm{N})$ and ferrite can be used to determine whether the $\mathrm{V}(\mathrm{C}, \mathrm{N})$ had precipitated in austenite or in ferrite. ${ }^{13}$ When $\mathrm{V}(\mathrm{C}, \mathrm{N})$ is related to ferrite by the Baker-Nutting $(\mathrm{B}-\mathrm{N})$ orientation relationship ${ }^{14}$

$$
\begin{aligned}
& \{100\} \alpha-\mathrm{Fe} \|\{100\} \mathrm{V}_{4} \mathrm{C}_{3} \\
& \langle 011\rangle \alpha-\mathrm{Fe} \|\langle 010\rangle \mathrm{V}_{4} \mathrm{C}_{3}
\end{aligned}
$$

this means that $\mathrm{V}(\mathrm{C}, \mathrm{N})$ has precipitated in ferrite. However, when $\mathrm{V}(\mathrm{C}, \mathrm{N})$ is related to ferrite by the Kurdjumov-Sachs orientation relationship ${ }^{15}$

$$
\begin{aligned}
& \{110\} \alpha-\mathrm{Fe} \|\{111\} \mathrm{V}_{4} \mathrm{C}_{3} \\
& \langle 111\rangle \alpha-\mathrm{Fe} \|\langle 110\rangle \mathrm{V}_{4} \mathrm{C}_{3}
\end{aligned}
$$

this means that the $\mathrm{V}(\mathrm{C}, \mathrm{N})$ had precipitated in austenite.

\section{Solubility of vanadium carbide and nitride in austenite and ferrite}

The solubility of vanadium carbide in austenite is significantly higher than the other microalloy carbides and nitrides. Gladman ${ }^{3}$ considered that in low carbon steels containing $\leqslant 0 \cdot 15 \mathrm{wt}-\% \mathrm{C}$ with vanadium contents up to $0.15 \mathrm{wt}-\%$, the carbide should be completely dissolved at austenite temperatures as low as $900^{\circ} \mathrm{C}$. $\mathrm{He}$ has also pointed out a problem with the solubility product for vanadium carbide due to perceived differences in stoichiometry. Some authors assume that the chemical formula is $\mathrm{VC}$ while others use $\mathrm{V}_{4} \mathrm{C}_{3}$. Gladman $^{3}$ makes a case for taking the data of Narita ${ }^{16}$ for the solubility of VC in austenite. On the other hand, Turkdogen ${ }^{17}$ prefers that of Wriedt and $\mathrm{Hu}^{18}$ for $\mathrm{V}_{4} \mathrm{C}_{3}$. Their $\mathrm{Fe}-\mathrm{V}-\mathrm{C}$ alloys were equilibrated at temperatures of 918,993 and $1150^{\circ} \mathrm{C}$, quenched in water and examined by both SEM and TEM to determine the $\gamma /$ $(\gamma+$ carbide $)$ phase boundaries. ${ }^{18}$ Turkdogen ${ }^{17}$ also finds that the data derived by Wada et al. ${ }^{19}$ is close to that of Wriedt and $\mathrm{Hu}^{18}$ Fortunately, both Gladman and Turkdogen support their choice of data by pointing out that the experimental data of Savost'yanova and Shvartsman ${ }^{20}$ is in close agreement. A collection of solubility data for vanadium carbide in austenite and ferrite is collated in Table 1,13,21-24 and compared in Fig. 1. Depending on which pair of equations for austenite $(\gamma)$ and ferrite $(\alpha)$ are taken, the difference in $\mathrm{VC}$ solubility varies from 5 to 100 times.

A good collection of VN solubility equations has been made by Rose. ${ }^{25}$ Figure 2 shows the results of calculations for the three different equations available for the solution temperatures of $\mathrm{VN}$ in both $\gamma$ and $\alpha$, and given in Table 2. Taking the average values for the three sets of constants $\mathrm{A}$ and $\mathrm{B}$ for each phase in the equation

$$
\log K_{\mathrm{s}}=A / T+B
$$

where $K_{\mathrm{s}}$ is the solubility product $[\mathrm{V}][\mathrm{N}]$ and $T$ the temperature (in $\mathrm{K}$ ), it is found that the difference at $760^{\circ} \mathrm{C}$ in the solubility of $\mathrm{VN}$ in $\gamma$ is 1.73 times that in $\alpha$, which is significant, but not substantial.

From Figs. 1 and 2, it can be seen that the solubility in terms of the $\log K_{\mathrm{s}}$ values at $850^{\circ} \mathrm{C}$ of vanadium carbide and vanadium nitride in austenite and ferrite, decrease approximately in the order $-1,-2,-3 \cdot 8$, 
$\mathrm{T},{ }^{\circ} \mathrm{C}$

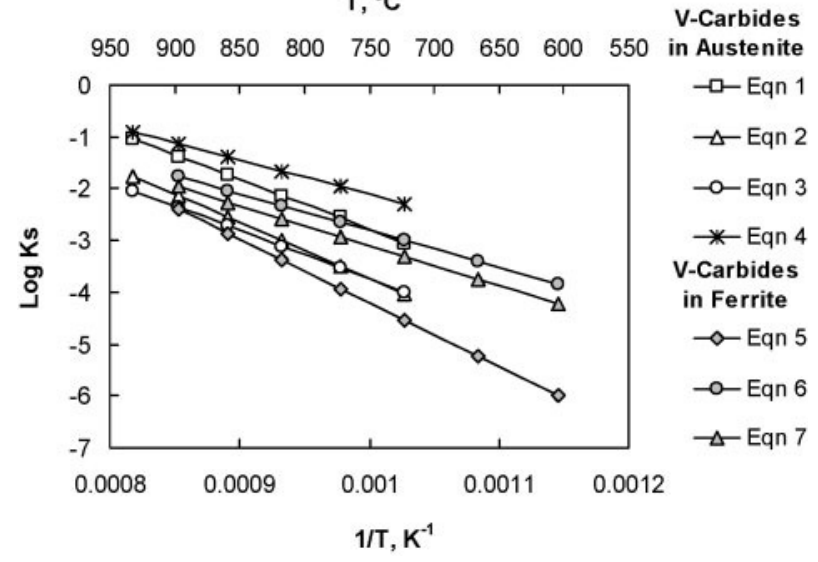

1 Solubility of vanadium carbide in austenite and ferrite

\section{$\mathrm{T},{ }^{\circ} \mathrm{C}$}

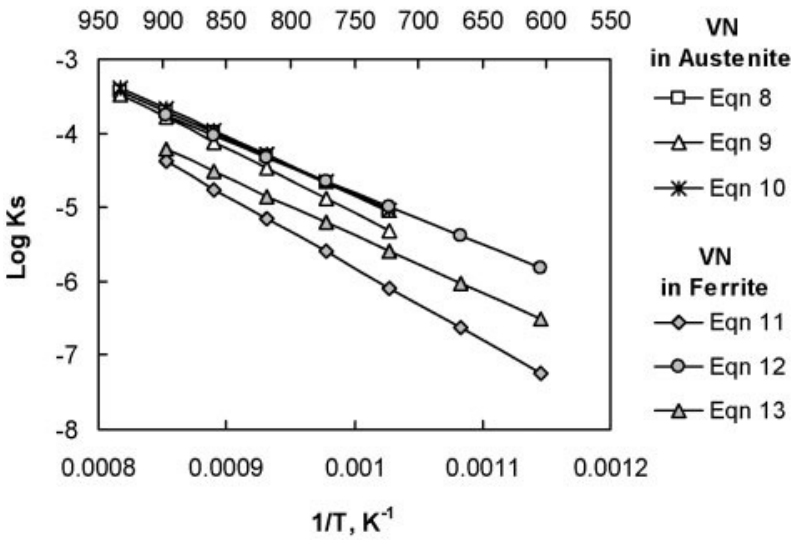

2 Solubility of vanadium nitride in austenite and ferrite ${ }^{154}$

$-4 \cdot 8$. This shows the substantially higher solubility of the carbide than the nitride and the significant decrease in solubility in ferrite compared with austenite. A more detailed discussion of the solubility of $\mathrm{VC}$ and $\mathrm{VN}$ in austenite and VC in ferrite is provided by Gladman. ${ }^{3}$ For comparison, a selection made by Aronsson $^{28}$ of solubility of the transition metal carbides and nitrides in austenite, of importance in microalloyed steels, is given in Fig. 3, where it is apparent that vanadium carbide and nitride are the most soluble carbide and nitride of each group. Strid and Easterling ${ }^{29}$ have also collected relevant solubility data.

An important aspect of most transition metal carbides and nitrides, is that with few exceptions, they are mutually soluble, as is shown by the data presented by Goldschmidt. ${ }^{30}$ It has been suggested that this mutually solubility occurs when the atomic size difference between the two carbide or nitride forming elements is not greater than $13 \%$. Houghton ${ }^{31}$ was among the first

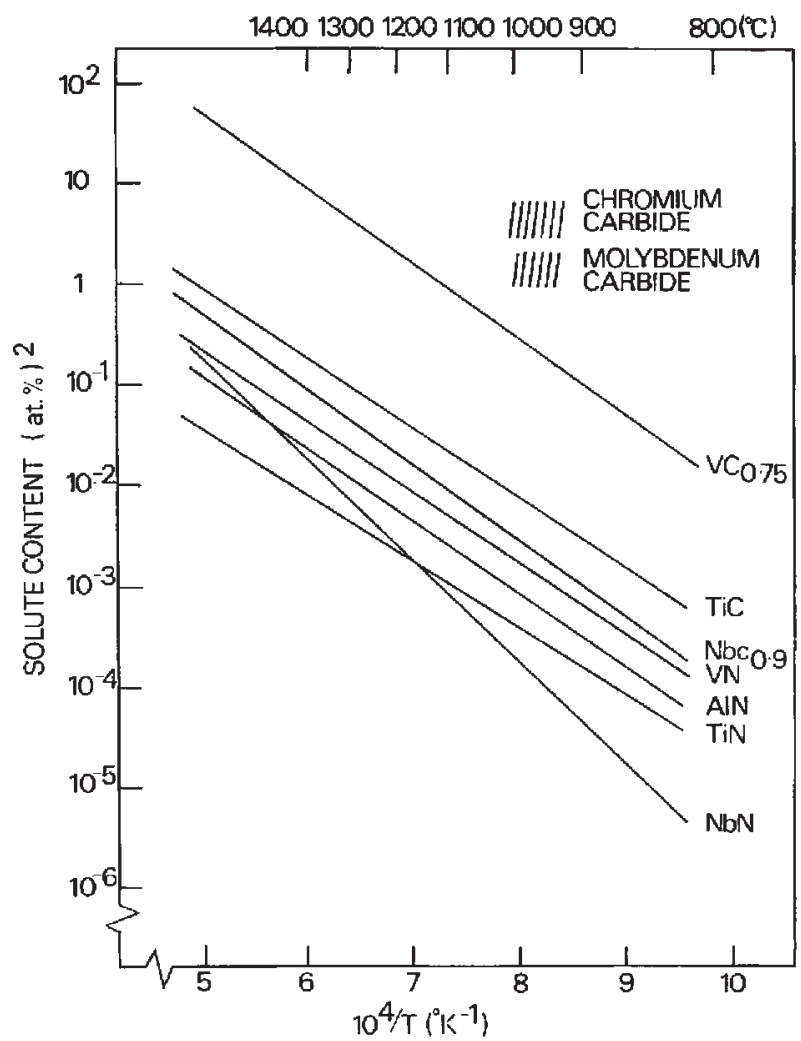

3 Solubility products, in atomic per cent, of carbides and nitrides in austenite as function of temperature ${ }^{28}$

to acknowledge the effect of mutual solubility of carbides and nitrides in microalloyed steels. He presented a quasi-regular solution thermodynamic model which described the precipitation of complex carbides and nitrides from austenite for two extreme cases:

(i) no mixing between precipitates

(ii) complete miscibility while maintaining in both cases equilibrium between precipitates and solutes in austenite.

His results were then compared with those of other models, whose predictions are in general intermediate between (i) and (ii).

While the binary solubility equation approach is a useful guide, sophisticated methods have been evolved using dedicated software, which take into account the

Table 2 Solubility of vanadium nitride in austenite and ferrite $^{154}$

Austenite Ferrite

\begin{tabular}{lllllllll}
\hline Equation & A & B & Ref. & Equation & A & B & Ref. \\
\hline 8 & -7700 & 2.86 & 17 & 11 & -9700 & 3.90 & 17 \\
9 & -8700 & 3.63 & 16 & 12 & -7061 & 2.26 & 27 \\
10 & -7840 & 3.02 & 26 & 13 & -7830 & 2.45 & 24 \\
\hline
\end{tabular}

Table 1 Solubility of vanadium carbide in austenite and ferrite

\begin{tabular}{|c|c|c|c|c|c|c|c|c|}
\hline \multicolumn{5}{|l|}{ Austenite } & \multicolumn{4}{|l|}{ Ferrite } \\
\hline Equation & A & B & Type & Ref. & Equation & A & B & Ref. \\
\hline 1 & -9500 & $6 \cdot 72$ & VC & 16 & 5 & -12265 & 8.05 & 23 \\
\hline 2 & -10800 & $7 \cdot 06$ & $\mathrm{~V}_{4} \mathrm{C}_{3}$ & 21 & 6 & -7050 & $4 \cdot 24$ & 22 \\
\hline 3 & -9400 & $5 \cdot 65$ & $\mathrm{~V}_{4} \mathrm{C}_{3}$ & 22 & 7 & -7667 & 4.57 & 1 \\
\hline 4 & -6560 & $4 \cdot 45$ & $\mathrm{~V}_{4} \mathrm{C}_{3}$ & 18 & & & & \\
\hline
\end{tabular}


influence on solubility of additional elements in the steels composition. However, this software should be used with caution. A good account of the background to several of these methods is given by Gladman. ${ }^{3}$ The most recent examination of the solubility of $\mathrm{Fe}-\mathrm{V}-\mathrm{C}$, $\mathrm{Fe}-\mathrm{V}-\mathrm{N}$ and $\mathrm{Fe}-\mathrm{V}-\mathrm{C}-\mathrm{N}$ has been undertaken by Popov and Gorbachev ${ }^{32,33}$ who also provide a review of many of the previous models developed for these systems. Their work is based on an analysis of the thermodynamic data of the three systems and calculations of phase equilibria using the Calphad method. One important conclusion is that in low alloy steels, a very strong influence is exerted by the nitrogen content on the composition and solubility of vanadium carbonitrides. ${ }^{32}$

When added to an $\mathrm{Fe}-\mathrm{C}$ alloy, vanadium is known to be a strong ferrite stabiliser which increases the solubility of carbon in ferrite and decreases the solubility of carbon in austenite. Thus the $\alpha$-phase field is more extensive in the $\mathrm{Fe}-\mathrm{C}-\mathrm{V}$ than in the $\mathrm{Fe}-\mathrm{C}$ phase diagram. One result of the enlarged $\alpha$-phase field is that the temperature $T_{\mathrm{o}}$ at which the free energies of austenite and ferrite are equal is raised by the addition of vanadium. Consequently, at the same isothermal transformation temperature below $T_{\mathrm{o}}$ for a plain carbon steel, the driving force in vanadium steels is greater than in plain carbon steels, thus the rate of ferrite separation is greater. ${ }^{34}$

\section{Tempering of vanadium steels}

Before the advent of microalloyed steel, the traditional route to achieving high strength in carbon steels was by quenching to form martensite, and then subsequently reheating or tempering at an intermediate temperature, usually between 550 and $650^{\circ} \mathrm{C}$, to precipitate a fine dispersion of carbides. This increased the toughness without too great a loss in strength. ${ }^{35}$ The role of carbides in low alloy creep resisting steels was reviewed by Woodhead and Quarrell ${ }^{8}$ in 1965. They found that the $\mathrm{Fe}-\mathrm{V}-\mathrm{C}$ system was by no means established, but that during tempering, unlike the cases of $\mathrm{Cr}$ or Mo, only one carbide formed, which was usually not the stoichiometric composition, $\mathrm{VC}$, but closer to $\mathrm{V}_{4} \mathrm{C}_{3}$. Also the mechanism of the formation of the carbides was hotly debated as being either 'due to transformation in situ, when the alloying element gradually concentrates in the $\mathrm{M}_{3} \mathrm{C}$, where $\mathrm{M}$ is $\mathrm{Fe}, \mathrm{Mo}, \mathrm{Cr}, \mathrm{V}, \mathrm{W}$, until the individual particles transform as a whole, or by separate nucleation, when the $\mathrm{M}_{3} \mathrm{C}$ dissolves in the ferrite and the alloy carbide precipitates'. The sequence of precipitation during the tempering of complex alloys containing, for example, $0 \cdot 2 \mathrm{wt}-\% \mathrm{C}, 3 \mathrm{wt}-\% \mathrm{Cr}$, $0.7 \mathrm{wt}-\% \mathrm{Mo}, 0.7 \mathrm{wt}-\% \mathrm{~V}$ and $0.5 \mathrm{wt}-\% \mathrm{~W}$ was known to be difficult to predict. The first detectable carbide was not an iron carbide, but $\mathrm{V}_{4} \mathrm{C}_{3}{ }^{8}{ }^{8}$ Typical compositions and properties given for vanadium structural steels in a review by Sage et al. ${ }^{36}$ are $0.17 \mathrm{wt}-\% \mathrm{C}, 1.5 \mathrm{wt}-\% \mathrm{Mn}$, $0 \cdot 3$ wt- $\% \mathrm{Si}, 0 \cdot 7$ wt- $\% \mathrm{Cr}, \quad 0 \cdot 28 \mathrm{wt}-\% \mathrm{Mo}, \quad 0 \cdot 1 \mathrm{wt}-\% \mathrm{~V}$, which after normalising and tempering in thickness of $\sim 10 \mathrm{~mm}$, had a yield strength $\sigma_{\mathrm{y}}$ of $460 \mathrm{MPa}$, an ultimate tensile strength of 587-679 $\mathrm{MPa}$, elongation $15 \%$ and impact energy at $0^{\circ} \mathrm{C}$ of $27 \mathrm{~J}$. Because of its stability, even at temperatures approaching $700^{\circ} \mathrm{C}$, vanadium is an important constituent in steels for elevated temperature service such as $0.5 \mathrm{Cr}, 0.5 \mathrm{Mo}$, $0 \cdot 5 \mathrm{~V}$ and $3 \mathrm{Cr}, 1 \mathrm{Mo}, 0 \cdot 25 \mathrm{~V}$ steels, which exhibit

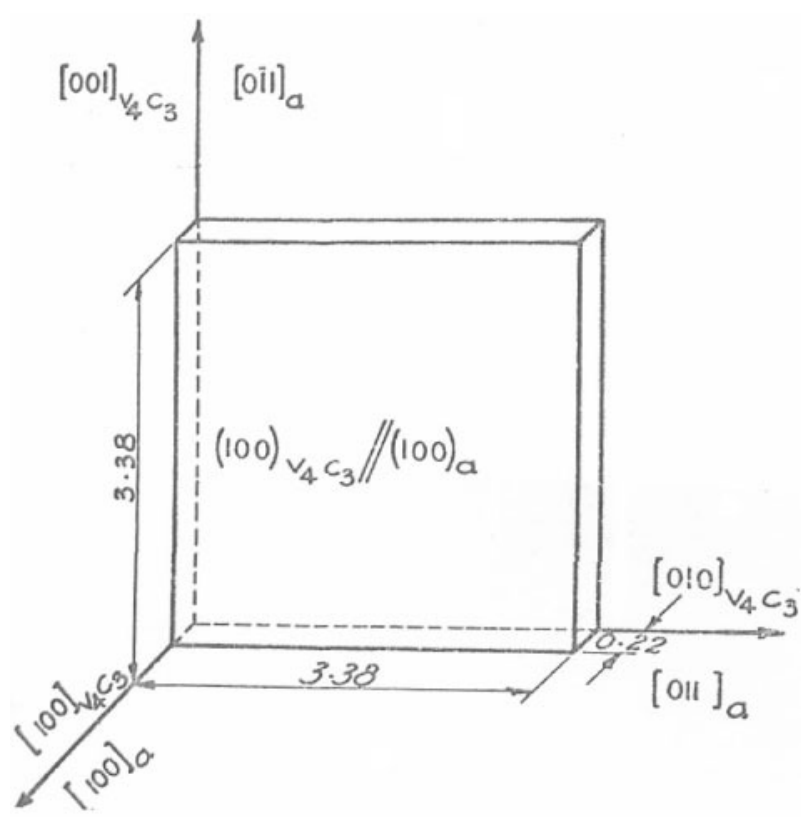

4 Relationship between $\mathrm{V}_{4} \mathrm{C}_{3}$ and $\alpha$-Fe (Ref. 43)

extensive vanadium carbide precipitation. ${ }^{35}$ Much of the first detailed microstructural work on alloy steels was concerned with the tempering of low alloy steels containing $1 \mathrm{wt}-\% \mathrm{~V}$, sometimes with chromium and molybdenum. ${ }^{14,37-39}$ This was supplemented by TEM using the newly developed technique of thin foil examination.

The early studies of the secondary hardening of vanadium steels using carbon extraction replicas ${ }^{40,41}$ showed that depending on the composition and tempering time, the maximum hardness was developed between 550 and $650^{\circ} \mathrm{C}$, and that in this temperature range, cementite and vanadium carbide co-existed. Other workers showed that $\mathrm{V}_{4} \mathrm{C}_{3}$ could precipitate as low as $450^{\circ} \mathrm{C}$ with a morphology described variously as rodlets, ${ }^{37,38}$ discs $^{37}$ and platelets. ${ }^{14}$ The orientation relationship given above and published by Baker and Nutting, ${ }^{14}$ was originally obtained between $\mathrm{V}_{4} \mathrm{C}_{3}$ and ferrite. Figure 4 shows diagrammatically, the mismatch between the two lattices as perceived by Tekin and Kelly, ${ }^{42,43}$ giving a $31 \%$ mismatch perpendicular to the plate and $3 \%$ parallel to the plate This orientation relation has subsequently been found to hold for nearly all carbides and nitrides precipitated in ferrite. Tekin and Kelly ${ }^{42,43}$ first detected vanadium carbide well before peak hardness, i.e. after $15 \mathrm{~h}$ at $450^{\circ} \mathrm{C}$ in a $0 \cdot 2 \mathrm{C}-1 \cdot 0 \mathrm{~V}(\mathrm{wt}-\%)$ steel. They found that 'at this stage, the reflections were arced. After $500^{\circ} \mathrm{C}$ tempering, the arced reflections were more pronounced and the dislocations appeared 'dotted' as if small precipitates had formed on them'. Following $550^{\circ} \mathrm{C}$ tempering, they used the arced reflections in SAED patterns to image precipitates in dark field, and revealed a number of small particles lying in 'strings'. By comparing the bright and dark field micrographs, the 'strings' of precipitates could be related to dislocations in the matrix. After tempering at 550 or $600^{\circ} \mathrm{C}$, they observed $\mathrm{V}_{4} \mathrm{C}_{3}$ spots streaked along $\langle 100\rangle_{\mathrm{V} 4 \mathrm{C} 3}$ directions in the matrix with no streaking of the matrix spots, the $\mathrm{V}_{4} \mathrm{C}_{3}$ reflections being well away from those of $\alpha$-Fe, and were considered to be due to thin $\mathrm{V}_{4} \mathrm{C}_{3}$ plates lying in the $\{100\} \alpha$-Fe planes 
and not due to any type of GP formation. This observation was confirmed by Raynor et $a l^{44}$ and Tanino and Nishida. ${ }^{45}$ The latter proposed that the secondary hardness found in vanadium steels was due to the suppression of dislocation climb and the reduction of the growth rate of ferrite grains, by vanadium in solution and finely dispersed carbides. Both sets of authors $^{44,45}$ used SAED to confirm the B-N orientation relationship and to 'identify' the platelet precipitates as vanadium carbides.

While most of the detailed microstructural work on vanadium steels goes back to the 1960s, the topic has been revisited more recently by Mayata et al. ${ }^{46}$ As part of their study of the coarsening kinetics of mixed $\mathrm{V}$ and $\mathrm{Nb}$ bearing $\mathrm{MC}$ type carbides, they undertook both TEM and direct lattice imaging of carbides in thin foils. They found that in a $0 \cdot 2 \mathrm{~V}-0 \cdot 03 \mathrm{Nb}$ (wt- $\%$ ) steel, tempered for $1800 \mathrm{~s}$ at $720^{\circ} \mathrm{C}$, precipitation was mainly associated with dislocations, but with a $0.1 \mathrm{wt}-\% \mathrm{Nb}$ steel tempered under the same conditions, coherency strain fields were observed. It is noticeable that some of their micrographs show both double lobe strain field contrast and precipitates associated with dislocations. Unfortunately, they ${ }^{46}$ did not analyse the strain field contrast in detail, as undertaken by others, or determine the chemical composition of the precipitates. However, they did find that a reduction in vanadium content and an increase in niobium content retarded the coarsening of the MC carbide. Also their lattice parameter values continuously increased with increasing niobium partition to the MC carbide, resulting in an increase in the misfit coherency. The critical coherency diameter of the MC carbide was estimated as being in the range $3 \cdot 3-$ $5.0 \mathrm{~nm}$, and decreased with increasing niobium content and reducing vanadium content. No similar work appears to have been undertaken to study the effect of tempering steels to nucleate vanadium carbonitrdes, where the particle composition was specifically analysed.

More recently, tempering of alloy steels has been shown to be of importance for another reason, as the carbides provide hydrogen trapping sites to enhance the resistance to static fracture of power plant components, springs and bolts. $\mathrm{V}_{4} \mathrm{C}_{3}$ is far more effective in enhancing the resistance to hydrogen embrittlement than, for example $\mathrm{Mo}_{2} \mathrm{C}$, due to its much higher hydrogen trapping capacity. ${ }^{47}$

While most of the research discussed above falls into the category of fundamental work, a number of investigations have been concerned with improving industrial processing in which multimicroalloying was used. For example, Jana et $a l .{ }^{48}$ studied the influence of tempering sand cast steels, quenched after austenitising at $950^{\circ} \mathrm{C}$, then tempered for $1 \mathrm{~h}$ in the range $200-700^{\circ} \mathrm{C}$. The $0 \cdot 15 \mathrm{C}-0.85 \mathrm{Mn}-0 \cdot 40 \mathrm{Cr} \quad(\mathrm{wt}-\%)$ steels were microalloyed with $0 \cdot 1 \mathrm{wt}-\% \mathrm{~V}+0 \cdot 01 \mathrm{wt}-\% \mathrm{Ti}$ or $0 \cdot 1 \mathrm{wt}-\% \mathrm{~V}+$ 0.034 wt $-\% \mathrm{Nb}+0.01 \mathrm{wt} \% \mathrm{Ti}$. Unfortunately, the nitrogen content was not given in their paper. The $\mathrm{V}-\mathrm{Nb}-\mathrm{Ti}$ steel showed the greatest improvement in strength, but only after tempering above $500^{\circ} \mathrm{C}$. They observed dendritic precipitates with a core and cap morphology and fine precipitates on dislocations, but were not able to characterise these particles ${ }^{48}$

The role of microalloying additions of $\mathrm{Nb}, \mathrm{Ti}$ and $\mathrm{V}$ between 0.001 and $0.03 \mathrm{wt}-\%$ in quenched and tempered steel containing $\sim 0.16 \mathrm{wt}-\% \mathrm{C}, 0.5 \mathrm{wt}-\% \mathrm{Cr}$,
$0 \cdot 38 \mathrm{wt}-\%$ Mo and $1 \cdot 3 \mathrm{wt}-\% \mathrm{Ni}$ has been investigated by Robertson. ${ }^{49}$ Two steels had additions of $\mathrm{Nb}$, Ti and $\mathrm{V}$, a third, Ti and V, and a fourth only $0.014 \mathrm{wt}-\% \mathrm{Ti}$. Following earlier processing ${ }^{49}$ a final austenitising treatment was carried out at $915^{\circ} \mathrm{C}$ followed by water quenching and tempering. After tempering at different times, the reduction in HV from the as quenched value, indicated that the steels containing $\mathrm{V}$ and $\mathrm{Nb}$ displayed the greatest temper resistance. Transmission electron microscopy together with energy dispersive X-ray (EDX) spectra showed that in the steels containing $\mathrm{Ti}+\mathrm{V}$ and $\mathrm{Ti}$ alone, $\mathrm{Ti}$ precipitated as $10-100 \mathrm{~nm}$ cuboids of TiN. However, in the $\mathrm{Ti}+\mathrm{Nb}+\mathrm{V}$ steel, the cuboids contained $\mathrm{Ti}$ and $\mathrm{Nb}$ and were considered to be based on $(\mathrm{Ti}, \mathrm{Nb})(\mathrm{C}, \mathrm{N})$. Vanadium was not found in these particles and it was not possible to detect any of the elements, including $\mathrm{V}$, in any of the finest precipitates. However, it was considered that vanadium containing particles played an important role in conferring temper resistance.

The development of substantial secondary hardness depends on steel compositions, which today, are regarded as outside those of microalloyed steels, in that the carbon levels were up to $0 \cdot 2 \mathrm{wt}-\%$ and vanadium contents as high as $2 \cdot 0 \mathrm{wt}-\%$. However, the main microstructural features observed, in terms of the morphology and precipitate crystal structure parameters, would appear to be similar to those observed using modern steel processing routes and compositions. It is of interest that many of the studies linking microstructure to properties of tempered steels were associated with the development of TEM. The methods used to examine fine precipitates on carbon extraction replicas and subsequently thin foils, together with the use of SAED techniques to determine crystallographic data, first saw the light of day in this area of steels research.

\section{Precipitation in vanadium steels}

In the present paper, particle strengthening involving the bypassing of an incoherent or hard particle by a dislocation, as proposed by Orowan ${ }^{50}$ and by Hirsch, ${ }^{51}$ will be described as dispersion strengthening. On the other hand, particles which are coherent with the matrix can be cut by dislocations, and this mechanism will be described as precipitation hardening, after the distinction made amongst others, by Ardell. ${ }^{52}$

A detailed review of precipitation in iron alloys, but omitting tempering, was undertaken by Edmonds and Honeycombe $^{53}$ citing 260 references, and provides a valuable source of knowledge in this area, up to the late 1970 s. It includes information pertinent to this review, and deals in particular, with the mechanisms of precipitation of vanadium carbide.

The precipitation of carbonitride particles can occur at different stages during the manufacture and fabrication of microalloyed steels. Lui and Jonas ${ }^{54}$ considered three main stages. Type I precipitates are formed in the slag during the liquid phase, and or after solidification, on the liquid/solid interface and in delta ferrite. These latter precipitates, or as they are often called, inclusions, nucleate during casting, and are very stable. While they are too large to influence the recrystallisation of austenite, the smallest may effectively retard grain coarsening in austenite during reheating before the final rolling passes or during a welding cycle. The precipitates 


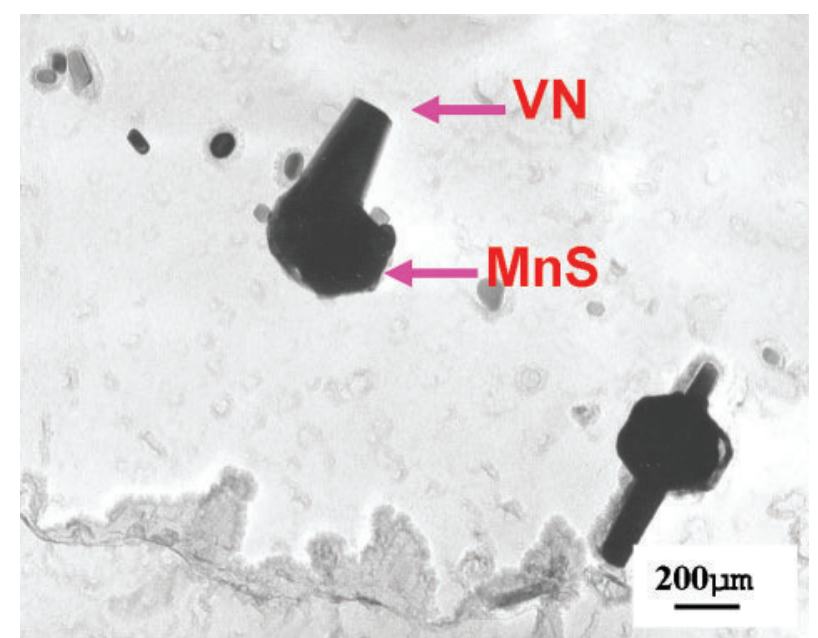

5 VN particles nucleating on MnS inclusions ${ }^{176}$

are normally oxides or sulphides, but in some steels can be nitrides such as aluminium nitride, and very occasionally, carbonitrides. In general, vanadium has not been reported as an element in inclusions present after casting. Richardson and Jeffes ${ }^{55}$ have shown that the standard free energy of $\mathrm{CaO}, \mathrm{Al}_{2} \mathrm{O}_{3}$ and $\mathrm{SiO}_{2}$ are more negative than $\mathrm{V}_{2} \mathrm{O}_{4}$, indicating that the former are more stable. These particular oxides contain the major elements usually found in most inclusions in microalloyed steels, together with MnS. Heterogeneous precipitation in austenite, particularly of VN, has been reported $^{56,57}$ on AlN, MnS (Fig. 5) and TiN. This produces a complex precipitate which may fall within the size range of particles capable of grain refining austenite, but often they are $>100 \mu \mathrm{m}$, a size which is normally regarded as too large. The particles then serve only to remove vanadium from use both in grain and dispersion strengthening. ${ }^{2}$ Type II precipitates form in austenite during processing subsequent to casting. In particular, vanadium containing precipitates are formed in austenite after solution treatment and during hot deformation (for example, during controlled rolling) as the temperature decreases. The precipitates are strain induced and can retard recovery and recrystallisation of austenite. Dislocations and austenite grain boundaries are the normal nucleation sites in microalloyed steels, the former being particularly active in niobium steels, but much less so in steels with vanadium additions. ${ }^{2}$ Figure 6, taken from the work of Cuddy, ${ }^{58}$ shows the effect of different elements on the austenite recrystallisation stop temperature. Here it can be seen that vanadium has far less influence than either niobium or titanium. Reservations have been expressed about the interpretation of the data given in Fig. 6. One possible solution has been provided by DeArdo, ${ }^{59,60}$ and is illustrated in Fig. 7, which shows that of the possible precipitating systems, only $\mathrm{NbC}$ can have high supersaturations over a large portion of a typical hot rolling temperature range.

There have been a number of studies of precipitation in and recrystallisation of deformed austenite in HSLA steels microalloyed with vanadium. ${ }^{61-65}$ White and Owen ${ }^{63}$ showed unambiguously, that during isothermal experiments at 900 and $1000^{\circ} \mathrm{C}$, precipitation of $\mathrm{V}(\mathrm{C}, \mathrm{N})$ alone, before or during recrystallisation, can stop further

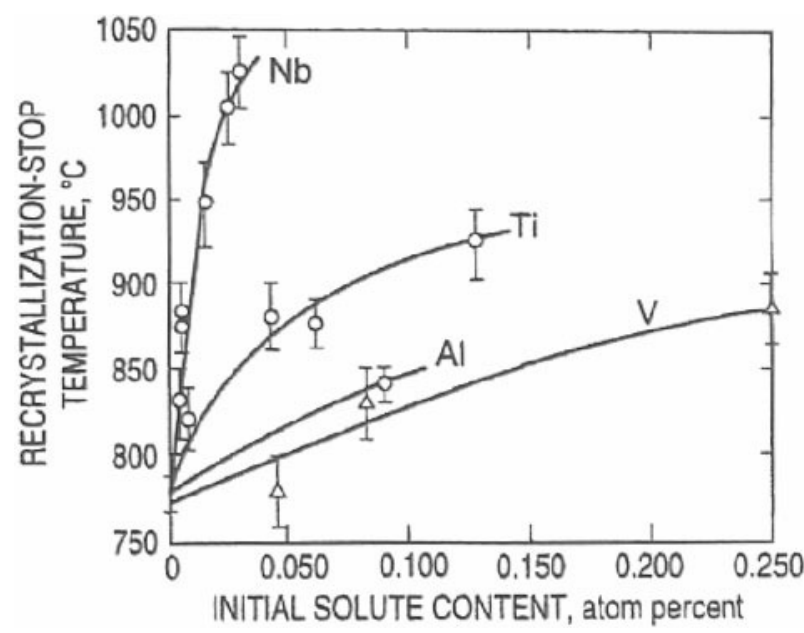

6 Effect of different elements on austenite recrystallisation stop temperature ${ }^{58}$

recrystallisation. Crooks et al., ${ }^{64}$ expanded this work by comparing vanadium with vanadium niobium steels.

Vanadium has been shown to have an effect on static recrystallisation kinetics after simulating warm deformation conditions. ${ }^{66}$ In this situation, it is considered that during reheating before forging at temperatures $800-870^{\circ} \mathrm{C}$, which are in the lower range for hot rolling, undissolved $\mathrm{V}(\mathrm{C}, \mathrm{N})$ precipitates remain. These promote a fine austenite grain size and interact with the recrystallisation process leading to longer recrystallisation times than those recorded with plain carbon steels. ${ }^{65}$ At $1025^{\circ} \mathrm{C}$, the highest deformation temperature used in this work, there was some evidence of retardation of recrystallisation, which was attributed to solute drag due to segregation of vanadium atoms at austenite grain boundaries. ${ }^{66} \mathrm{He}$ and Edmonds ${ }^{67}$ have provided evidence of segregation of vanadium atoms at austenite grain boundaries in an experimental microalloyed steel containing $0.48 \mathrm{wt}-\% \mathrm{~V}$. They used secondary ion mass spectrometry to produce maps showing concentrations of vanadium which they had not been able to locate with high resolution TEM. Under their heat treatment conditions, no precipitates were observed to be associated with these boundaries. However, the solute drag

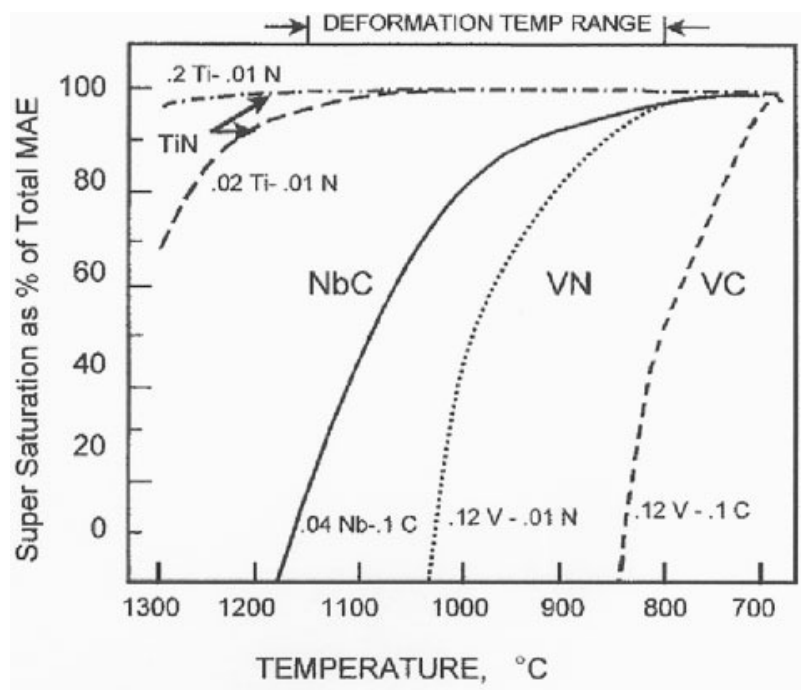

7 Precipitation potential of various microalloying compounds $^{59}$ (MAE: microalloying elements) 


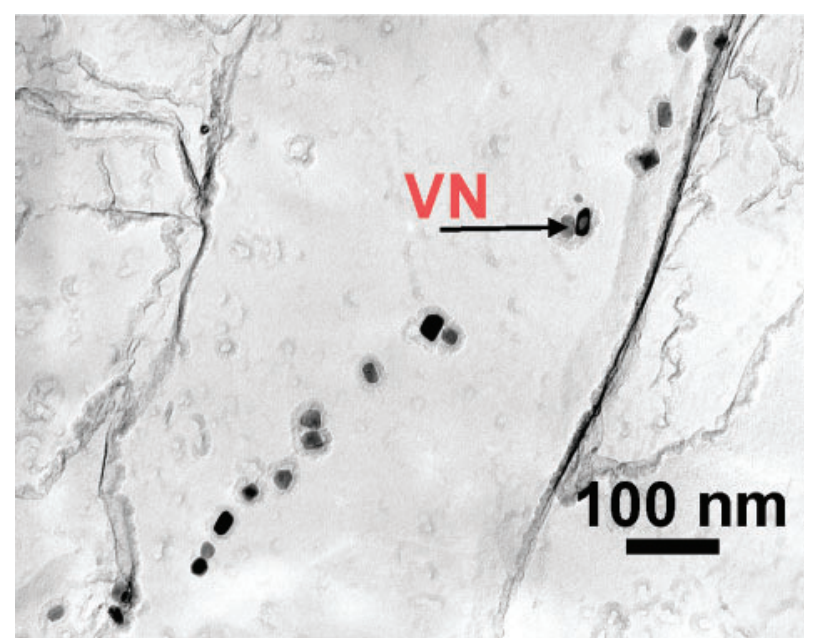

$8 \mathrm{~V}(\mathrm{C}, \mathrm{N})$ cuboid particles outlining prior austenite grain boundaries $^{56}$

effect on recrystallisation kinetics due to vanadium atoms has been shown to be very small compared to that of niobium. Andrade et al. ${ }^{68}$ defined a solute retardation parameter (SRP) for static recovery and recrystallisation. They calculated that $\mathrm{Nb}$ as a single addition, with an SRP of 409, was the most potent element, followed by Mo, 37 and lastly V, 10. The rank order of SRP is the same as that found under dynamic softening conditions, but the relative contribution of $\mathrm{Nb}$ is more profound for the static condition. ${ }^{54}$ However, in multi-alloyed steels the SRP attributable to each element was smaller than when it was present alone. Therefore during multipass rolling of conventional vanadium microalloyed steels, very little solute drag or strain induced $\mathrm{V}(\mathrm{C}, \mathrm{N})$ precipitation occurs, compared with, for example, precipitation of $\mathrm{Nb}(\mathrm{C}, \mathrm{N})$ in niobium microalloyed steels, which can occur over the full deformation temperature range. ${ }^{59,60}$ However particularly when the carbon or nitrogen levels are high, for example at levels of $0 \cdot 15 \mathrm{wt}-\% \mathrm{C}$ or $0.015 \mathrm{wt}-\% \mathrm{~N}$ respectively, Lagneborg et $a l^{2}$ reported evidence for some strain induced precipitation of $\mathrm{V}(\mathrm{C}, \mathrm{N})$. It is concluded from the above, that at high temperatures, $\sim 1200^{\circ} \mathrm{C}$, vanadium in solution has little observable effect on recrystallisation by solute drag, but at lower temperatures $\sim 950^{\circ} \mathrm{C}$, $\mathrm{V}(\mathrm{C}, \mathrm{N})$ precipitation retards recrystallisation by pinning austenite grain boundaries, a process which is enhanced with increasing $\mathrm{N}$ content, through a greater volume fraction of $\mathrm{V}(\mathrm{C}, \mathrm{N})$ particles. In hot rolling processes, $\mathrm{V}(\mathrm{C}, \mathrm{N})$ has been observed in many cases outlining prior austenite grain boundaries, such as those seen in thin slab direct charged (TSDC) processed steels (Fig. 8). ${ }^{56}$ Here the size range was 10 to $40 \mathrm{~nm}$, with an average size of $22 \mathrm{~nm}$.

Finally, type III precipitates are formed during or after the austenite to ferrite phase transformation, nucleating on the $\gamma / \sigma$ interface and in ferrite. ${ }^{54}$ Dispersion strengthening in ferrite normally occurs under these conditions and a fine particle dispersion, $\leqslant 15 \mathrm{~nm}$ is usually observed. The precipitation of type III alloy carbonitrides, which accompanies the $\gamma \rightarrow \alpha$ transformation has been summarised by Honeycombe ${ }^{69,70}$ in terms of the morphologies of carbonitrides which have been recorded as continuous fibres/laths, interphase precipitation (planar or curved) and random matrix precipitation from supersaturated ferrite.

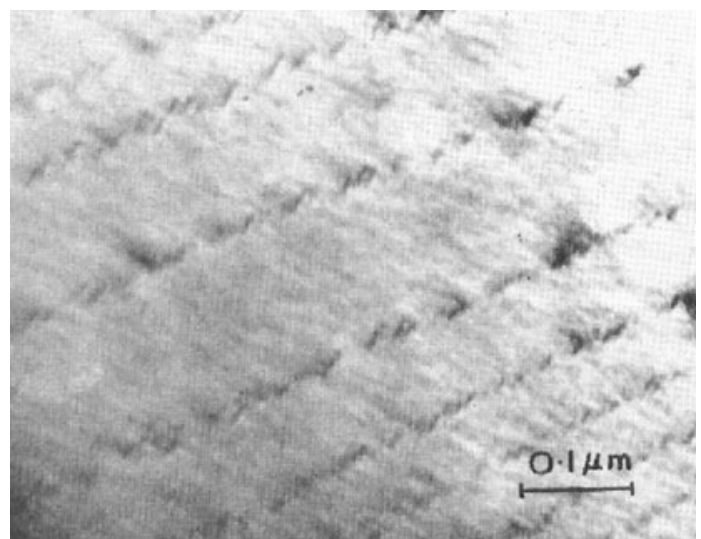

9 Interphase precipitation where particles have grown and developed common habit at angle to direction of growth $^{77}$

\section{Continuous fibres/laths}

It has been observed that carbides can grow perpendicular to the $\gamma / \alpha$ interface producing fibrous aggregates of ferrite and carbide similar to pearlite, but on a much finer scale. ${ }^{70}$ These features have been reported in isothermally transformed ${ }^{70-76}$ and laboratory controlled rolled $^{77}$ vanadium steels, but not those containing niobium or titanium. The fibres tend to occur when cooling is slow or on holding at a high temperature in the two phase $\gamma / \alpha$. The formation is considered to be a distorted form of eutectoid $\gamma \rightarrow \alpha+\mathrm{V}(\mathrm{C}, \mathrm{N})$ transformation. ${ }^{2,70}$ In hot rolled microalloyed steels, fibres are not a dominant feature and are not expected to make a significant contribution to mechanical or toughness properties.

\section{Interphase precipitation (planar or curved)}

Planar interphase precipitation has been reported extensively in the literature and accompanies the decomposition of austenite to ferrite. It is due to the lower solubility of carbides and nitrides, and other elements, such as copper, silver and gold in ferrite than in austenite. A particular feature of interphase precipitates is that they grow with a single habit, ${ }^{77-80}$ in the B-N orientation relationship (Fig. 9). This type of precipitation has been observed in steels containing molybdenum, ${ }^{72,81}$ chromium $^{82}$ copper $^{83}$ and silver, ${ }^{84}$ as well as the main microalloying elements, niobium, ${ }^{85-88}$ vanadium $^{75,76,80,89-91}$ and titanium, ${ }^{92}$ and has been reviewed in detail by Edmonds and Honeycombe. ${ }^{53}$

In many vanadium steels which have undergone isothermal transformation, interphase precipitation shows a random arrangement of individual particles within a sheet formed parallel to the $\gamma / \sigma$ interface by repeated nucleation, as the transformation front moves through austenite. Two main models have been proposed to explain interphase precipitation; the ledge mechanism and solute diffusion control. ${ }^{2,53,93}$ The ledge mechanism for planar interfaces, depends on the precipitates nucleating on low energy, coherent or semicoherent broad faces of the ledges, just behind the highly mobile high energy risers, which appear as stepped discontinuities in the planar interface. ${ }^{94}$ The second approach, the solute depletion model, developed at the 


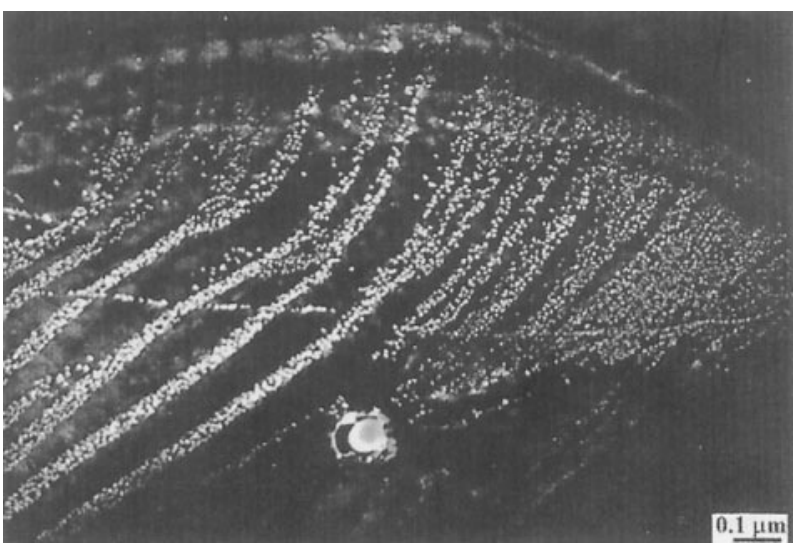

10 Interphase precipitation appears as irregularly spaced, often curved sheets of $\mathrm{V}(\mathrm{C}, \mathrm{N})$ particles $^{226}$

Swedish Institute for Metals Research by Roberts ${ }^{95}$ has been extended and discussed by Langneborg and Zajac. ${ }^{96}$

Interphase precipitation in vanadium steels has more recently been reviewed in detail by Khalid and Edmonds. ${ }^{97}$ They also studied the nucleation of VC associated with the $\gamma \rightarrow \alpha$ phase transformation in steels containing a range of carbon levels from 0.23 to $0.82 \mathrm{wt}-\%$ using both TEM and atom probe field ion microscopy (APFIM). Their results showed that interphase precipitation of $\mathrm{VC}$ or $\mathrm{VCN}$, occurred in all their steels in both proeutectoid ferrite and pearlitic ferrite, and that heterogeneous nucleation of $\mathrm{VC}$ or $\mathrm{VCN}$ is associated with the structural features of the interface. This disproves the earlier hypothesis suggesting that precipitation occurred behind the interface, in ferrite and was based on the large difference in solubility of VC and $\mathrm{VN}$ in $\gamma$ and $\alpha$ phases, together with these compounds having a B-N orientation relationship with ferrite. ${ }^{72,98}$ Lagneborg et al. $^{2}$ have also summarised the models proposed to explain interphase precipitation as well as the effect of different variables, such as transformation temperature, cooling rate and steel composition. For example, it has been observed that 'at high transformation temperatures, $\sim 800^{\circ} \mathrm{C}$, for $0 \cdot 1 \mathrm{wt}-\% \mathrm{C}$, $0 \cdot 10 \mathrm{wt}-\% \mathrm{~V}$ steels, the interphase precipitation appears as irregularly spaced, often curved sheets of $\mathrm{V}(\mathrm{C}, \mathrm{N})$ particles (Fig. 10). With decreasing temperatures, the incidence of the curved rows of precipitates diminishes and the dominant mode is regularly spaced, planar sheets of particles. Below $700^{\circ} \mathrm{C}$, the interphase precipitation is commonly found to be incomplete, and random precipitation from supersaturated ferrite after the $\gamma \rightarrow \alpha$ phase transformation takes over progressively with decreasing temperature'. ${ }^{2}$ While the above discussion is concerned with carbides, Ballinger and Honeycombe $^{76,99}$ observed nitride interphase precipitates in vanadium microalloyed steels. They found that for a given transformation temperature, the intersheet spacings of alloys $\mathrm{FeVCN}$ and $\mathrm{FeVN}$ were much smaller than those of FeVC, and that the nitrides and carbonitride particles did not coarsen to the same extent as carbides.

\section{Random precipitation from supersaturated ferrite}

Homogeneous precipitation of carbides, nitrides and carbonitrides in ferrite, has been proposed by K. H. Jack to follow a sequence analogous to that occurring during the ageing of $\mathrm{Al}-4 \% \mathrm{Cu} .{ }^{100}$ This sequence is zones $\rightarrow$ intermediate phase $(\mathrm{s}) \rightarrow$ equilibrium phase. While the early stages of precipitation of have been the subject of many investigations, the proposed solute segregation or clustering to develop zones, is still far from being universally accepted for precipitation in commercially processed steels. ${ }^{53}$ Most of this work was carried out on alloys other than $\mathrm{Fe}-\mathrm{V}-\mathrm{N}$, but provides valuable evidence which is equally true for the vanadium alloy. The constant activity nitriding work of Speirs ${ }^{101}$ and Driver ${ }^{102}$ provides strong evidence for homogeneous precipitation of coherent metastable disc shaped zones on $\{100\}$ matrix ferrite planes of the Fe-Mo-N system, which showed the 'tweed' appearance in electron micrographs and streaking of the matrix electron diffraction patterns in the $\langle 100\rangle_{\alpha}$ directions. The TEM and later FIM experiments show that $\mathrm{Fe}, \mathrm{Mo}$ and $\mathrm{N}$ atoms are assembled in mixed substitutional interstitial atom zones produced by clustering, similar to GP zones in Al$\mathrm{Cu}$ alloys. The zones were $10-15 \mathrm{~nm}$ in diameter and $0.6-0.9 \mathrm{~nm}$ in thickness, with an interparticle spacing of $5-15 \mathrm{~nm}$ and a density of $10^{15}-10^{17} \mathrm{~cm}^{-3}$. Coherency strain fields were developed between the zones and the matrix which were interstitial in character, indicating that the matrix was compressed on either side of the platelet. The zones were shown to have lattice dimensions normal to the plate face which were $\sim 10 \pm 5 \%$ greater than the ferrite matrix. Extensive FIM have been used to study GP zones in $\mathrm{Fe}-\mathrm{N}$ alloys. Here, images of a single $\{100\}$ layer zone contained randomly distributed nitrogen atoms and double layer zones, in which nitrogen atoms locally ordered as in the $\alpha^{\prime \prime}-\mathrm{Fe}_{16} \quad \mathrm{~N}_{2}$ structure, were obtained. ${ }^{103}$ This followed the previous work on the structure of Fe-Ti-N by D. H. Jack, ${ }^{104}$ who explored the tweed structure by high resolution TEM and computer imaging. He estimated the zone thickness from diffraction streaking, included two iron atom planes which together with the Ti-N plane, gave a three layer zone with two $0 \cdot 194 \mathrm{~nm}$ interplanar spacings. There was no evidence for dislocation formation accompanying the formation of coherent plates. Also, both TEM and modelling evidence pointed to a periodic distribution of plates which strongly suggested a spinodal decomposition mechanism close to the spinodal point, or classical coherent homogeneous nucleation accompanied by periodic alignment as a result of tetragonal distortion. More recently, Chechenin et al. ${ }^{105}$ used a variety of techniques to study nitrided iron alloys which provided evidence for the formation of mixed $\mathrm{Fe}-$ Ti-N GP zones observed after the early stages of nitriding. As in previous work, ${ }^{104}$ it was concluded that the GP-like cluster may contain more $\mathrm{N}$ atoms than $\mathrm{Ti}$ atoms. The presence of these coherent clusters enhances the dilation of the matrix.

Zones have also been reported following nitriding of other ferritic alloys such as $\mathrm{Fe}-\mathrm{Nb}, \mathrm{Fe}-\mathrm{Cr}, \mathrm{Fe}-\mathrm{Ti}, \mathrm{Fe}-\mathrm{V}$ and Fe-W. ${ }^{105}$ Phillips $^{106}$ and Pope et al. ${ }^{107}$ showed that ion nitriding or constant activity nitriding respectively, of $\mathrm{Fe}-\mathrm{V}$ alloys gave a high hardness due to the fine dispersion of discs $\sim 1 \mathrm{~nm}$ thick and 4-6 nm diameter, precipitated on $\{100\}_{\alpha}$. However, the latter authors were also unable to decide from the experimental evidence whether the first stage of homogeneous precipitation consisted of very thin $\mathrm{VN}$ platelets or of $\mathrm{Fe}-\mathrm{V}-\mathrm{N}$ disc 
shaped clusters. To date, zones have not been indisputably identified in hot rolled microalloyed steels.

The carbides, nitrides and carbonitrides of the transition metals which precipitate homogeneously from supersaturated ferrite matrix are predicted to be coherent in their earliest stages of existence. Estimates of the particle misfit strain to which coherency is retained are given in Table 3 based on the cube-on-edge orientation relationship given above, ${ }^{14}$ and the ratio of $\varepsilon_{2 / \varepsilon_{1}}$ for VC, $\sim 15$ is that shown in Fig. 4 .

Table 3 shows that vanadium carbide and nitride have the smaller calculated misfits, and therefore retain coherency to a larger particle size than other transition metal carbides and nitrides. This is based on the premise that coherency is initially lost when the difference in the lattice spacing between the particle and the matrix at their interface exceeds $50 \%$, and an interface dislocation takes up the mismatch which is too great to be accommodated by elastic strain fields.

$\mathrm{V}_{4} \mathrm{C}_{3}$ can form as platelets lying on $\{100\} \alpha$-Fe planes. The 'configuration' of $\mathrm{V}$ and $\mathrm{Fe}$ atoms in $\{100\} \alpha-\mathrm{Fe}$ planes indicates excellent coherency between [200] $\mathrm{V}_{4} \mathrm{C}_{3}$ and [110] $\alpha$-Fe with $\sim 3 \%$ mismatch. However, in the planes [001] $\mathrm{V}_{4} \mathrm{C}_{3}$ and [001] $\alpha$-Fe perpendicular, the lattice misfit is $\sim 30 \%$. This theoretically limits coherency in the two planes to dimensions of $\sim 6 \mathrm{~nm}$ and $\sim 0.4 \mathrm{~nm}$ respectively, which is why the precipitates are frequently reported in the platelet morphology. ${ }^{77,79,89}$

Thin foil observations of strain fields associated with precipitation of carbides, nitrides and carbonitrides, has been reported for vanadium containing steels. ${ }^{79,89,108}$ Unlike those observations reported for $\mathrm{Cu}-\mathrm{Co}$ (Ref. 109) and Al-Cu (Ref. 110) alloys, where spherical coherent precipitates produce the double lobe contrast. Sass et al. ${ }^{111}$ studied the strain fields arising from nonspherical particles and observed a 'notch' or arrowhead shape with a line of no contrast, and/or an asymmetric image, both features being matched by appropriate computer simulated maps. Their micrographs of material containing cuboidal NiTi particles, show very similar contrast to that developed with platelets of vanadium carbide, ${ }^{108}$ identified in a steel of composition $0 \cdot 10 \mathrm{C}-1 \cdot 5 \mathrm{Mn}-0 \cdot 13 \mathrm{~V}-0 \cdot 006 \mathrm{~N}$ (wt- $\%$ ) (Fig. 11). The steel was solution treated at $1325 \mathrm{~K}$ for $1 \mathrm{~h}$ and then cooled at rates in the range $2 \mathrm{Ks}^{-1}$ to $3 \times 10^{-2} \mathrm{~K} \mathrm{~s}^{-1}$. The density of strain fields increased with decreasing cooling rate. Problems arising from the perturbation of the optical properties of the objective lens due to the large amount of ferromagnetic material in the thin foil, severely restricted contrast experiments which depended on extensive tilting of the specimens. As a result it was not possible to distinguish strain fields arising from coherency from those developed as a result of thermal

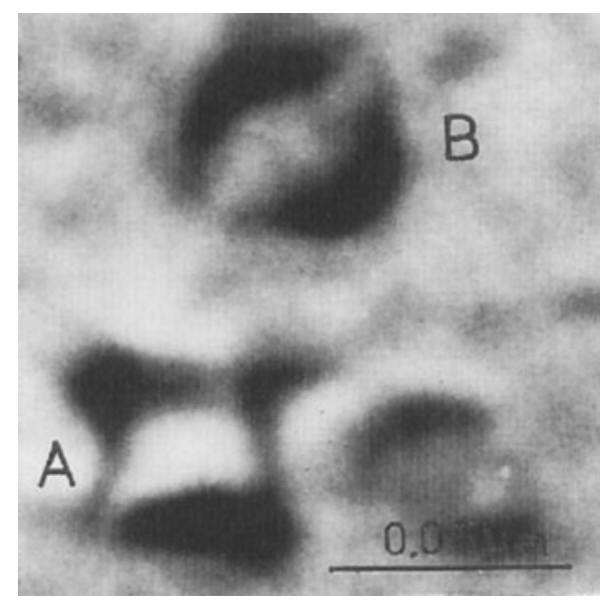

11 Bright field TEM micrograph, with $g_{110}$, of steel containing asymmetrical double arrowhead strain fields at $A$ and $B$ associated with vanadium carbide platelets ${ }^{108}$

strain. The controversy over coherent versus incoherent plate-like precipitates of $\mathrm{V}_{4} \mathrm{C}_{3}$ centres around the streaking observed on diffraction patterns. The streaking is due to the relaxation of one of the Laue conditions, which can occur when a thin platelet is oriented with the thin dimension approximately perpendicular to the electron beam direction. If the matrix spots are streaked, then the beam is diffracted from the lattice planes of the precipitate with a similar interplanar spacing to the matrix. On the other hand, when the streaking occurs well away from the matrix spots, the interplanar spacing of precipitate planes giving rise to diffraction is different from that of the matrix, and confirms that the precipitate is incoherent. Davenport ${ }^{112}$ examined apparent contradictory statements given in a number of publications. ${ }^{42,43,113}$ He showed that in his vanadium steels, the arced reflections originated from an epitaxial oxide $\left(\mathrm{Fe}_{3} \mathrm{O}_{4}\right)$ layer on the surface of the foil, as identified by Keown and Dyson ${ }^{114}$ and not from $\langle 111\rangle$ $\mathrm{V}_{4} \mathrm{C}_{3}$ zones as previously thought. Furthermore, Davenport $^{112}$ pointed out that the $d_{440 \text { oxide }}=$ $0.1484 \mathrm{~nm}, \quad d_{220 \mathrm{~V}_{4} \mathrm{C}_{3}}=0.1474 \mathrm{~nm}$ and $d_{220 \alpha-\mathrm{Fe}}=$ $0 \cdot 143 \mathrm{~nm}$. Tekin and Kelly, ${ }^{42,43}$ used arced reflections, well away from the matrix $\alpha$-Fe reflections, to study the early stages of precipitation of $\mathrm{V}_{4} \mathrm{C}_{3}$, and their published diffraction patterns show these to be the $d_{220 \mathrm{Fe}_{3} \mathrm{O}_{4}}$ reflections. By careful choice of reciprocal lattice planes and tilting about [110] direction, Davenport ${ }^{112}$ was able to separate the $\mathrm{V}_{4} \mathrm{C}_{3}$ relrods streak, produced by a thin precipitate causing a relaxation of one Laue condition, and the $\alpha$-Fe reflection. However, the exact mode of formation in the initial stages of precipitation is still debateable. Early TEM work on tempered steels led to

Table 3 Estimates of precipitate/ $\alpha$-Fe misfit for microalloyed carbides and nitrides*

\begin{tabular}{|c|c|c|c|c|}
\hline Compound & 'a' ASTM, nm & $\varepsilon_{1}$ & $\varepsilon_{2}$ & $\varepsilon_{2} / \varepsilon_{1}$ \\
\hline $\mathrm{NbC}$ & 0.4470 & 0.0650 & 0.292 & 4.49 \\
\hline $\mathrm{NbN}$ & $0 \cdot 4388$ & 0.0526 & 0.279 & $5 \cdot 29$ \\
\hline $\mathrm{TiC}$ & 0.43285 & 0.0435 & 0.270 & $6 \cdot 32$ \\
\hline TiN & 0.4240 & 0.0293 & 0.254 & 8.65 \\
\hline VC & 0.4154 & 0.0162 & $0 \cdot 245$ & $15 \cdot 15$ \\
\hline VN & 0.4130 & 0.0124 & $0 \cdot 241$ & $19 \cdot 42$ \\
\hline
\end{tabular}

${ }^{*} \varepsilon_{1}$ is the misfit at interface between $(110)_{\alpha-F e}$ and $(200)_{\text {compound }}$ while $\varepsilon_{2}$ is the misfit at interface between $(100)_{\alpha-F e}$ and $(100)_{\text {compound }}$ in accordance with Ref. 14. 
the suggestion that $\mathrm{V}_{4} \mathrm{C}_{3}$ in steels formed coherently. ${ }^{37,39}$ Smith and Nutting ${ }^{37}$ considered the possibility that the precipitation might be preceded by the formation of vanadium enriched zones, similar to GP zones observed in $\mathrm{Al}-4 \% \mathrm{Cu}$ alloys. ${ }^{115}$ This was later considered to be unlikely due the high affinity of $\mathrm{V}$ for $\mathrm{C}^{116}$ Others claimed that GP zones form in bcc iron alloys ${ }^{117-119}$ and it was suggested ${ }^{113,120}$ that spherical zones rich in vanadium $^{121}$ occur before the precipitation of $\mathrm{V}_{4} \mathrm{C}_{3}$. However, it is highly unlikely that coherent precipitation will be the only type of precipitates in tempered steels due to high density of quenched- in dislocations providing ample sites for heterogeneous nucleation. ${ }^{42,43,121,122}$ Obtaining evidence for this hypothesis resulted in a substantial amount of electron microscopy and electron diffraction commencing in the 1960s. ${ }^{35,37,42}$ Several papers have reported arced $\mathrm{V}_{4} \mathrm{C}_{3}$ reflections. Smith ${ }^{123}$ pointed out that arcing also implied random as well as preferred orientation and argued that this observation coupled with that of high dislocation densities could be explained by the presence of precipitation on dislocations. This was confirmed by thin foil studies. Morales et $a l^{124}$ used TEM techniques to study carbonitride precipitation in commercial vanadium steels containing $0.37 \mathrm{wt}-\% \mathrm{C}$. They reported that carbonitride particles were found in both the pro-eutectoid and the pearlitic ferrite phases. However, they found no evidence of strain field contrast and argued that the particles must be incoherent, despite the size of the smallest, $\sim 2 \mathrm{~nm}$, which are predicted by others to be coherent. Most of the particles examined were from interphase precipitation. Morales et al. ${ }^{124}$ are of the opinion that all the strengthening particles in this steel precipitated in austenite.

Much of the work involving pearlitic transformations has been concerned with the partitioning of solute, and it has been shown by APFIM studies, that in a continuously cooled pearlitic steel, $\mathrm{Cr}, \mathrm{Mn}$ and $\mathrm{V}$ were found to partition to the pearlitic cementite, whereas $\mathrm{Si}$ partitioned to ferrite. ${ }^{125}$ Furthermore, He and Edmonds found that VC precipitated in pearlitic ferrite. ${ }^{67}$

In most ferrite grains, the random dispersions of small $\mathrm{V}(\mathrm{C}, \mathrm{N})$ precipitates in hot rolled steels have the morphology of thin plates. They display variants of the $\mathrm{B}-\mathrm{N}$ orientation relationship. ${ }^{14}$

\section{Effect of vanadium on ferrite grain size and (martensite-austenite) MA phase}

The development of a fine ferrite grain size in the range $5-10 \mu \mathrm{m}$, is essential in producing an HSLA steel with high strength and good toughness. Vanadium carbide, nitride and carbonitride particles are known to pin austenite grain boundaries (Fig. 8), and on transformation, a fine ferrite grain structure develops. In addition, there is strong evidence to show that small quantities of vanadium in structural steels produce a significant refinement in the final ferrite microstructure, through both enhancement of the nucleation of grain boundary ferrite and by intragranular nucleation of ferrite. ${ }^{126}$ Hernandaz et al. ${ }^{126}$ evaluated both mechanisms for two vanadium steels, and their experiments 'confirmed that refinement was due to the enhancement of ferrite nucleation through particle simulated nucleation mechanisms, while the second mechanism, the influence of vanadium in slowing down the austenite-ferrite transformation kinetics, was of minor consequence. Intragranular nucleation of ferrite takes place at relatively late stages during transformation and contributes to the refinement of the microstructure by increasing the number of grains'. This additional nucleation arises from the formation of ferrite idiomorphs on particles inside the austenite grains. These idiomorphic particles were observed to include $\mathrm{TiO}_{3}$, $\mathrm{CuS}$, and in vanadium HSLA steels, complex $\mathrm{MnS}+\mathrm{V}(\mathrm{C}, \mathrm{N})$ particles, similar to those seen in Fig. 5. The contribution of this additional ferrite was calculated to produce a 2 to $3 \mu \mathrm{m}$ reduction in the final ferrite grain size. The role of complex $\mathrm{MnS}+\mathrm{V}(\mathrm{C}, \mathrm{N})$ particles in nucleating intragranular ferrite was also considered by Ishikawa et al. ${ }^{127} \mathrm{~A}$ reduction in the nucleus/matrix interfacial energy was highlighted as important. Of three steels containing:

(i) $0.25 \mathrm{wt}-\% \mathrm{C}, 0.023 \mathrm{wt}-\mathrm{\%} \mathrm{N}$

(ii) $0.25 \mathrm{wt}-\% \mathrm{C}, 0.13 \mathrm{wt}-\% \mathrm{~V}, 0.002 \mathrm{wt}-\% \mathrm{~N}$

(iii) $0.25 \mathrm{wt}-\% \mathrm{C}, 0 \cdot 13 \mathrm{wt}-\% \mathrm{~V}, 0 \cdot 021 \mathrm{wt}-\% \mathrm{~N}$,

only steel (iii) contained intragranular ferrite idiomorphs nucleated on vanadium nitride precipitates in the austenite matrix. The VN particles were in turn nucleated on MnS inclusions. SAED showed that the intragranular ferrite had a B-N orientation relationship with the VN particles precipitated on $\mathrm{MnS}$, both types of particles being 'identified' by TEM/SAED. However, the chemical composition of the precipitates was not established, so the fraction of carbon in the 'vanadium nitride' particles is unknown and its importance or otherwise, not clear.Kimura et al. ${ }^{128}$ studied the intragranular ferrite nucleation associated with VN precipitates, and found that increasing the nitrogen content from 0.003 to $0.013 \mathrm{wt}-\%$, in $0 \cdot 13 \mathrm{wt}-\% \mathrm{C}, 1 \cdot 4 \mathrm{wt}-\% \mathrm{Mn}$, $0.06 \mathrm{wt}-\% \mathrm{~V}$ steels reheated at $1200^{\circ} \mathrm{C}$, cooled to $950^{\circ} \mathrm{C}$ at $1 \mathrm{~K} \mathrm{~s}^{-1}$, and then cooled to room temperature at $0 \cdot 1 \mathrm{~K} \mathrm{~s}^{-1}$, decreased the ferrite grain size while increasing the number density. The increase in the nitrogen content apparently enhanced the intragranular ferrite. However, the grain boundary ferrite transformation behaviour of the $\mathrm{V}-\mathrm{N}$ steels was almost the same as that of a conventional TMCP steel. The ferrite transformation occurred first $>700^{\circ} \mathrm{C}$ on the austenite grain boundaries. At $700^{\circ} \mathrm{C}$, VN particles began to precipitate, gradually grew in size between 650 and $600^{\circ} \mathrm{C}$ achieving a size to influence intragranular ferrite nucleation. The intragranular ferrite transformation followed the grain boundary ferrite because it was not observed until temperatures were $<675^{\circ} \mathrm{C}$. One explanation proposed for the effective heterogeneous nucleation of ferrite by inclusions was that a low lattice mismatch, associated with a low interfacial energy, promoted nucleation. This is certainly the case with $\mathrm{VN}$ particles and ferrite (Table 3). Support for this proposal is found in the work of Furuhara et al., ${ }^{129}$ who calculated the chemical component of the interphase boundary energy between austenite or ferrite and $\mathrm{VC}, \mathrm{VN}$ and $\mathrm{MnS}$. They showed that $\mathrm{VC}$ and $\mathrm{VN}$ had a low interfacial energy with respect to ferrite, but relatively high interfacial energies with respect to austenite for the $(001)_{\mathrm{V}(\mathrm{C}, \mathrm{N})}$ boundary compared with MnS. These results supported their experimental observations that $\mathrm{MnS}$ alone was not an effective nucleation site for ferrite idiomorphs. $\mathrm{MnS}+$ $\mathrm{VC}$, showed a slight improvement, but $\mathrm{MnS}+\mathrm{VN}$ 
provided the most effective site. ${ }^{129}$ While a fine polygonal ferrite microstructure was the ultimate aim for processed HSLA steels, the development of an acicular ferrite microstructure in plate steels has been explored. For HSLA steels cooled at high rates, about 4-11 $\mathrm{K} \mathrm{s}^{-1}$, acicular ferrite forms. This is a microstructure comprising fine interwoven ferrite laths or plates associated with improved toughness over other forms of transformation products and first recognised in HSLA steels weld metal and heat affected zone (HAZ). The mechanism of acicular ferrite nucleation, initially considered to be due to weld metal oxide inclusions and other nucleants, has been discussed in many papers, including that by Lee et al. ${ }^{130}$ However, the exact mechanism remains unclear. ${ }^{67}$ There is evidence that additions of vanadium may promote the formation of an acicular ferrite microstructure and improve toughness. ${ }^{131}$ More recent work by $\mathrm{He}$ and Edmonds ${ }^{67}$ studied a series of $\mathrm{V}-\mathrm{N}$ steels, and considered in particular, the effect of composition and heat treatment on microstructure, including the ratio of oxygen and nitrogen concentration of inclusions. They 'did not find any significant evidence that inclusion assisted nucleation was the sole determining factor in producing acicular ferrite. No evidence could be found to relate vanadium alloying to significant vanadium nitride precipitation, either separately, or associated with the inclusions'. However, 'evidence for vanadium segregation in the microstructure was found'. The presence of the martensite retained austenite phase (MA phase) is well known to have a deleterious effect on weld metal toughness. ${ }^{132}$ Hart and Mitchell ${ }^{133}$ showed that steels with up to $0 \cdot 20 \mathrm{wt}-\% \mathrm{~V}$ had no adverse effect on the weld metal HAZ. A detailed assessment of the size and area fraction of the MA phase in microalloyed steels was undertaken by Li et al. ${ }^{134}$ It was shown that with an addition of $0.05 \mathrm{wt}-\% \mathrm{~V}$, the fraction of MA phase was low, but increased with a $0 \cdot 11 \mathrm{wt}-\% \mathrm{~V}$ addition, resulting in a deterioration of the intercritical grain coarsening HAZ.

\section{High nitrogen vanadium steels}

Most of the early work on microalloy steels in the UK was aimed at austenite grain refinement and dispersion strengthening through the precipitation of carbides. ${ }^{1,85,91,135-137}$ However in Germany a different approach was followed, in which high nitrogen vanadium steels with $>0.01 \mathrm{wt}-\% \mathrm{~N}$, and aluminium-vanadium nitrogen steels were explored as a means of producing weldable structural steels. It was expected that the main vanadium compounds would be high nitrogen carbonitrides rather than carbides. The early work is summarised by Wiester et al. ${ }^{138}$ They determined, by chemical means, the concentrations of vanadium and aluminium combined with nitrogen. At the lowest levels used in their laboratory casts, $0.011 \mathrm{wt}-\% \mathrm{Al}$, after a normalising treatment of $30 \mathrm{~min}$ at $930^{\circ} \mathrm{C}$, following a solution treatment at $1350^{\circ} \mathrm{C}$ for times up to $2 \mathrm{~h}$, found that almost all the $0.018 \mathrm{wt}-\% \mathrm{~N}$ was combined with the $0 \cdot 14 \mathrm{wt}-\% \mathrm{~V}$ in the steel. Konig et $a l^{139}$ investigated precipitation in steels with 0.2 wt- $\% \mathrm{C}, 1 \cdot 5 \mathrm{wt}-\% \mathrm{Mn}, 0 \cdot 018-0.025$ wt- $\% \mathrm{~N}, 0 \cdot 010$ $0 \cdot 152 \mathrm{wt}-\% \mathrm{Al}$ and $0 \cdot 02-0 \cdot 47 \mathrm{wt}-\% \mathrm{~V}$. Using chemical techniques, they analysed carbides and nitrides extracted electolytically from their alloys, to determine the total nitrogen and nitrogen combined with aluminium, and were able to show that with increasing annealing temperatures, between $500^{\circ} \mathrm{C}$ and $1350^{\circ} \mathrm{C}$, aluminium nitride formed at the expense of vanadium nitride. In alloys without aluminium additions, only $60 \%$ of the nitrogen combined with vanadium in the as cast alloy, and the percentage of $\mathrm{VN}$ formed reached a maximum after annealing at $750^{\circ} \mathrm{C}$, decreasing above $800^{\circ} \mathrm{C}$ and approaching zero around $1100^{\circ} \mathrm{C}$.A second series of experiments, undertaken by Konig et al. ${ }^{139}$ examined the situation after austenitising at $1350^{\circ} \mathrm{C}$ and transferring directly to a furnace in the range $500-1350^{\circ} \mathrm{C}$. The samples were then water quenched after holding for times of 1,3 or $6 \mathrm{~h}$. In the $\mathrm{V}-\mathrm{Al}$ steel, the VN content was found to be small after holding in the austenitic phase, but increased with decreasing temperature, reaching a peak value after $1 \mathrm{~h}$ holding in the ferrite phase at $600^{\circ} \mathrm{C}$. The steels containing vanadium, but without aluminium, showed peaks in the percentage precipitation at $1100^{\circ} \mathrm{C}$ in austenite and at $700^{\circ} \mathrm{C}$ in ferrite, both peaks apparently being unaffected by the holding time of between 1 and $6 \mathrm{~h}^{139}$ Further research was undertaken by Vogels et al. ${ }^{140}$ who decarburised their alloys to eliminate possible effects from carbides. They explored both direct cooling and hot rolling conditions. A rapid combination of vanadium and nitrogen was found after oil quenching from $1350^{\circ} \mathrm{C}$ to room temperature. Electron micrographs of precipitates extracted on to carbon replicas was presented as proof that vanadium nitride precipitated in the as rolled steel. The higher stability of nitrides than carbides was also one of the main reasons for the approach used by Baker ${ }^{77,141}$ in his attempt to promote the precipitation of vanadium nitrides in controlled rolled vanadium steels by restricting the carbon content to $\sim 0.03 \%$ with $>0 \cdot 01 \% \mathrm{~N}$ and up to $0 \cdot 11 \% \mathrm{~V}$. All of the morphologies of precipitate described above were observed in his work, but the yield strength, despite some finishing rolling temperatures being in the ferrite phase field, was low. This research was an early study of the relationship between steel composition, processing, particularly varying the finishing rolling temperature, microstructure and properties of microalloyed steels.

The effect of nitrogen on the transformation kinetics in vanadium steels was investigated by Ballinger and Honeycombe. $^{76,99}$ Their choice of composition was dictated by the ability to theoretically take all the VN into solution at $1400^{\circ} \mathrm{C}$. They compared three alloys, FeVC, FeVCN and FeVN. All contained $\sim 0.27$ wt- $\%$ V, with a maximum $\mathrm{N}$ of $0.032 \mathrm{wt}-\%$ and maximum of $0 \cdot 05 \mathrm{wt}-\% \mathrm{C}$. The alloys were isothermally transformed over the temperature range 700 to $850^{\circ} \mathrm{C}$. Fibres, interphase and random precipitation nucleated on dislocations were observed, as were microtwins, first reported by Baker, ${ }^{142}$ which were associated with high nitrogen vanadium steels. Also finer precipitate dispersions were observed in the nitrogen containing alloys. These were explained by the observation that nitrogen accelerated the $\gamma \rightarrow \alpha$ transformation over the entire temperature range in the $\mathrm{FeVCN}$ and $\mathrm{FeVN}$ alloys compared with the FeVC alloy. The coarsening of VC particles in ferrite was reported by Schwartz and $\mathrm{Ralph}^{143}$ in an $\mathrm{Fe}-2 \mathrm{~V}-0 \cdot 2 \mathrm{C}(\mathrm{wt}-\%)$ alloy when treated at temperatures $600-690^{\circ} \mathrm{C}$. They found a (time $)^{1 / 2}$ kinetics, which they equated to an interface reaction. 


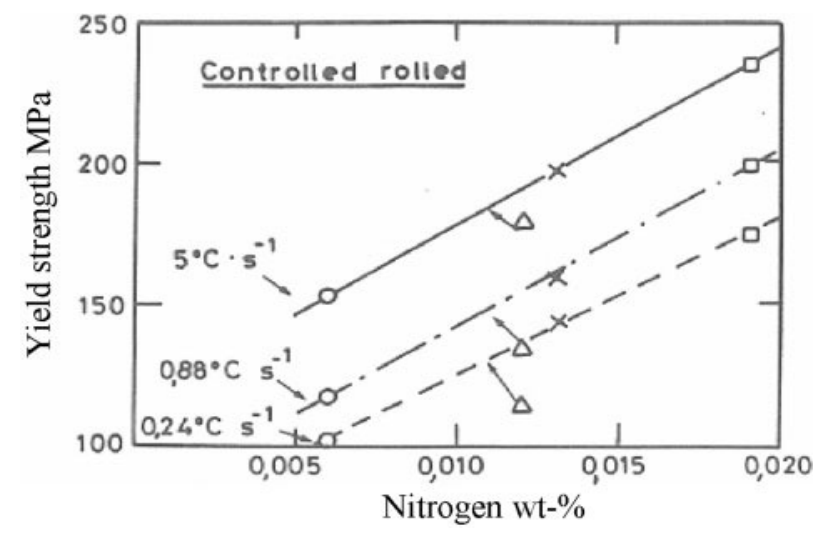

12 Dispersion strengthening contribution to yield strength $(\mathrm{MPa})$ as function of nitrogen content and cooling rate $^{2}$

Later work by Dunlop and Honeycombe ${ }^{144}$ studied a $\mathrm{Fe}-0 \cdot 4 \mathrm{~V}-0 \cdot 08 \mathrm{C}(\mathrm{wt}-\%)$ at $725^{\circ} \mathrm{C}$. They established the importance of dislocations in a (time $)^{1 / 5}$ kinetics. This work was extended by Ballinger and Honeycombe ${ }^{76}$ who compared the particle coarsening behaviour between VC and VN particles using the alloys studied earlier ${ }^{99}$ together with two additional alloys. The coarsening rates were ranked in ascending order as $\mathrm{VN} \cong$ $\mathrm{V}(\mathrm{CN}) \ll \mathrm{VC}$. A changeover in the particle kinetics was found from (time) $)^{1 / 2}$ to (time) $)^{1 / 5}$. They proposed that coarsening through pipe diffusion along static dislocations was responsible for the (time) $)^{1 / 5}$ particle kinetics. ${ }^{76}$

An investigation into the influence of vanadium and nitrogen on recystallisation following compression testing in the range $800-900^{\circ} \mathrm{C}$ was carried out by Crooks et al. ${ }^{64}$ They established that the rate of both dynamic and static work hardening increased with decreasing temperature and increasing vanadium content from $0 \cdot 10$ to $0.21 \mathrm{wt}-\%$. Dynamic hardening was considered to be due to precipitation on austenite grain boundaries, and at lower temperatures, on the substructure of the deformed austenite. On the other hand, static hardening was produced by matrix precipitation of high nitrogen vanadium carbonitrides

The Swedish Institute of Metals has a long history of investigating vanadium steels. ${ }^{2,145-148}$ Their work followed a thermodynamic analysis of the $\mathrm{Fe}-\mathrm{V}-\mathrm{C}-\mathrm{N}$ system which predicted that for $\mathrm{V}$ microalloyed steels containing less than $0 \cdot 2 \mathrm{wt}-\% \mathrm{C}$ and normal levels of $\mathrm{N}$, most of the $\mathrm{V}$ precipitated during random decomposition in $\gamma$ or $\alpha$ as particles having a composition close to VN. The experimental work involved hot compression testing as a means of simulating hot rolling. Both the nitrogen content and the cooling rate during simulated controlled rolling were shown to have a significant effect on the dispersion strengthening component of the yield strength (Fig. 12). Zajac et al. ${ }^{148}$ confirmed many of the conclusions reached earlier by Ballinger and Honeycombe. $^{76}$ They studied the effect of nitrogen in microalloyed steels with 0.05 or $0.011 \mathrm{wt}-\% \mathrm{~V}$ after either isothermal transformation or continuous cooling through the $\gamma \rightarrow \alpha$ transformation. ${ }^{148}$ It was shown that the principal factors influencing the size distribution of $\mathrm{V}(\mathrm{C}, \mathrm{N})$ precipitates were the nitrogen content and the ratio of $\mathrm{N} / \mathrm{V}$; a high $\mathrm{N}(>0.01)$ manifested itself in a smaller average particle size, a smaller interparticle spacing and a greater resistance to coarsening. It was concluded that these factors were related to the lower $\mathrm{V}$ solubility in ferrite for steels with high $\mathrm{N}$ levels. In addition to interface precipitation observed in conjunction with proeutectoid $\left(\sim 800^{\circ} \mathrm{C}\right)$ or polygonal ferrite $\left(700-750^{\circ} \mathrm{C}\right)$, random precipitates nucleated mainly on dislocations in Widmanstätten ferrite after isothermal transformation $<700^{\circ} \mathrm{C}$, were seen. Strain fields attributed to coherent precipitates were observed, and in high nitrogen steels, microtwins were reported. These latter features were not discussed in any detail. ${ }^{148}$ It was suggested by Bepari ${ }^{149}$ that precipitation from supersaturated ferrite, following the $\gamma \rightarrow \alpha$ transformation, resulted in uniformly distributed high nitrogen VCN precipitates, whereas $\mathrm{VC}$ precipitated preferentially on ferrite grain boundaries, increasing embrittlement. $\mathrm{He}$ also found that high nitrogen VCN precipitates contributed not only to a greater strength but also had a less detrimental effect on impact transition temperature and upper shelf energy than low nitrogen $\mathrm{V}(\mathrm{C}, \mathrm{N})$ precipitates. ${ }^{150} \mathrm{~A}$ comparison of the particle coarsening behaviour of $\mathrm{VN}$ and $\mathrm{TiN}$ was undertaken by Gladman, ${ }^{3}$ who explored the influence of prior or initial particle sizes of 2 and $10 \mathrm{~nm}$ at 900 and $1100^{\circ} \mathrm{C}$ for times of $30 \mathrm{~min}$ to $4 \mathrm{~h}$. His calculations indicated that $\mathrm{VN}$ has a more rapid rate of coarsening than $\mathrm{TiN}$ at both prior particle sizes. This was explained through the difference in solute concentration; the soluble $\mathrm{Ti}$ is $\sim 10^{3}$ less in the Ti steel than is the soluble V in the V steel on which the comparison was based. Gladman ${ }^{3}$ includes a useful table of diffusion data pertinent to microalloyed steels

\section{Multimicroalloyed steels}

The combined alloying of $\mathrm{V}$ with $\mathrm{Ti}, \mathrm{V}$ with $\mathrm{Nb}$, or $\mathrm{V}$ with both $\mathrm{Ti}$ and $\mathrm{Nb}$ has been explored for many years, as has the combination of $\mathrm{Al}$ and $\mathrm{V} .{ }^{2,3}$ Following Goldschmidt's ${ }^{30}$ conclusion in discussing multi-alloying that, with only a few exceptions, the transition metal carbides and nitrides are mutually soluble, it would be expected that the mutual solubility would also to be observed in the chemical analysis of mixed carbonitrides in steels. The rational behind the multi-alloying approach in microalloyed steels was to utilise both the greater solubility in austenite of $\mathrm{VN}$ and $\mathrm{VC}$ compared with $\mathrm{TiN}$ or $\mathrm{NbCN}$, and exploit the very stable particles, particularly TiN, for grain refinement of austenite, combined with the substantial dispersion strengthening provided by vanadium. $\mathrm{NbCN}$ can provide both austenite grain refinement and dispersion strengthening. ${ }^{3,4,59}$ The austenite grain refinement or conditioning during controlled rolling, is due to the ability of the microalloying addition to generate sufficiently large pinning forces to retard the motion of crystalline defects such as dislocations, subgrain boundaries and grain boundaries during recovery and recrystallisation. ${ }^{59}$ Siwecki et al. ${ }^{151}$ studied four $0.14 \mathrm{wt}-\% \mathrm{C}, 1 \cdot 2$ $1.6 \mathrm{wt}-\% \mathrm{Mn}$ steels with $\sim 0.01 \mathrm{wt}-\% \mathrm{Ti}$ and 0.03 to $0 \cdot 13 \mathrm{wt}-\% \mathrm{~V}$. Three of the steels contained $0 \cdot 011 \mathrm{wt}-\% \mathrm{~N}$ and the fourth, $0.023 \mathrm{wt}-\% \mathrm{~N}$. It was found that the addition of Ti resulted in $(\mathrm{Ti}, \mathrm{V}) \mathrm{N}$ particles precipitating in austenite which may have occurred by coprecipitation of VN nucleating on existing TiN particles, as shown in Fig. 5. Chemical analysis indicated a compositional gradient which shows that the interior of the particle is rich in $\mathrm{Ti}$ while the exterior was rich in $\mathrm{V} .{ }^{151}$ It was found that fast cooling, such as that experienced during 
continuous casting, prevented excessive growth of TiN particles, which were then suitable as nucleants for austenite grain refining. It was proposed that 'the rather weak effect of vanadium on the kinetics of static recrystallisation $>900^{\circ} \mathrm{C}$ is desirable from the point of view of effective grain refinement via recrystallisation hot rolling, in that recrystallisation can proceed to completion at a sufficiently low temperature, which is not always the case for $\mathrm{Ti}-\mathrm{Nb}$ steels'. ${ }^{151}$ However, the dispersion strengthening was lower in $\mathrm{Ti}-\mathrm{V}-\mathrm{N}$ steels than $\mathrm{V}-\mathrm{N}$, due to the presence of $\mathrm{V}$ in the $(\mathrm{Ti}, \mathrm{V}) \mathrm{N}$ grain refining particles reducing that available for precipitation as VN, following the $\gamma \rightarrow \alpha$ transformation. Similar results were found by Zeng et al. ${ }^{152}$ There are several other reports of a reduction in strength of $\mathrm{V}-\mathrm{Ti}$ steels when compared with a corresponding $\mathrm{V}$ steels. In cast $0 \cdot 10 \mathrm{~V}-0 \cdot 023 \mathrm{Ti}(\mathrm{wt}-\%)$ steels, ${ }^{153}$ the formation of large TiN particles at high temperatures was considered to be responsible for the reduction in yield strength of $\sim 35 \mathrm{MPa}$, compared with a corresponding $0.092 \mathrm{wt}-\% \mathrm{~V}$ steel, by removing nitrogen in the formation of TiN particles and therefore decreasing the driving force for the development of a high density of fine dispersion strengthening VN precipitates. A similar effect was found in a study of TSDC $0.06 \mathrm{wt}-\% \mathrm{C}$ steels where, following reheating at $1050^{\circ} \mathrm{C}$, despite the smaller ferrite grain size of an $0 \cdot 1 \mathrm{~V}-0 \cdot 010 \mathrm{Ti}-0 \cdot 017 \mathrm{~N}$ (wt- $\%$ ) steel, a reduction in yield strength of $84 \mathrm{MPa}$ was recorded compared with an $0 \cdot 1 \mathrm{~V}-0 \cdot 02 \mathrm{~N}(\mathrm{wt}-\%)$ steel. ${ }^{154}$ With a $0 \cdot 1 \mathrm{~V}-0 \cdot 03 \mathrm{Nb}-0 \cdot 007 \mathrm{Ti}(\mathrm{wt}-\%)$ steel, the reduction in yield strength was $70 \mathrm{MPa} .{ }^{154}$ The comparison of $\mathrm{V}$ and $\mathrm{V}-\mathrm{Nb}$ steels usually shows that an addition of about $0 \cdot 03-0 \cdot 04 \mathrm{wt}-\% \mathrm{Nb}$ results in a gain in yield strength but a loss in toughness. No improvement in strength was found in increasing the $\mathrm{Nb}$ content to $0.08 \mathrm{wt}-\%$ in accelerated cooled steels. ${ }^{155}$ This decrease in dispersion strengthening also occurred in Ti-Nb-V-N steels. ${ }^{154} \mathrm{~A}$ series of papers ${ }^{156-159}$ have compared in detail the precipitate morphologies and compositions of steels containing $\sim 0 \cdot 09 \mathrm{C}-0 \cdot 017 \mathrm{Ti}-0 \cdot 016 \mathrm{Nb}-0 \cdot 044 \mathrm{~V} \quad$ (wt- $\%$ ) with $\sim 0 \cdot 07 \mathrm{C}-0 \cdot 044 \mathrm{~V}$ (wt- $\%$ ) steels. Unfortunately, the $\mathrm{N}$ and $\mathrm{Si}$ levels were not given. It was observed that coarse carbonitrides precipitated at grain boundaries and fine precipitates in the matrix. EDX was used to chemically analyse the precipitates and the data claims an accuracy of $1 \%$. In the $\mathrm{Ti}-\mathrm{Nb}-\mathrm{V}$ steel, $\sim 70$ triplex and $\sim 40$ duplex particles were analysed. The triplex carbides/carbonitrides with a fine/needle morphology were $10-20 \mathrm{~nm}$ in size and had a spectral ratio (SR) of $\mathrm{Ti}_{0.51} \mathrm{Nb}_{0.35} \mathrm{~V}_{0.07}$, spherical/regular particles, $20-45 \mathrm{~nm}$ in size with $\mathrm{SR}$ of $\mathrm{Ti}_{0 \cdot 48} \mathrm{Nb}_{0 \cdot 35} \mathrm{~V}_{0 \cdot 14}$ and cuboids, 45$70 \mathrm{~nm}, \mathrm{SR}$ of $\mathrm{Ti}_{0.48} \mathrm{Nb}_{0.44} \mathrm{~V}_{0.08}$. None of the duplex precipitates $^{157}$ had an SR with $\mathrm{V}>0 \cdot 31$. All these precipitates were described as carbonitrides. Evidence of some particles with a Ti core and $\mathrm{V} / \mathrm{Nb}$ shell was presented. ${ }^{157}$ In a latter paper, ${ }^{158}$ again using EDX, the particles were described as having a core of $(\mathrm{V}, \mathrm{Nb}, \mathrm{Ti}) \mathrm{N}$ and a shell of $(\mathrm{V}, \mathrm{Nb}, \mathrm{Ti}) \mathrm{C}$. The authors noted that the density of precipitation in the $\mathrm{Ti}-\mathrm{Nb}-\mathrm{V}$ steel was significantly higher than in the $\mathrm{V}$ steel, ${ }^{157}$ but surprisingly, the difference in yield stress between the two steels was only $12 \mathrm{MPa} .{ }^{156}$ Many of the microstructural features observed in low carbon multimicroalloyed steels are also present in steels with medium carbon levels $0 \cdot 3$ to $0 \cdot 40$ wt- $\%$ C. ${ }^{160,161}$ An important paper by Prikryl et al. ${ }^{161}$ investigated an $0 \cdot 009 \mathrm{Ti}-0 \cdot 097 \mathrm{~V}-0 \cdot 011 \mathrm{~N}$ (wt-\%) steel, describing the particle morphology after casting and after processing to billet and bar. Particle compositions were analysed by EDX and electron energy loss spectroscopy (EELS), and the data compared with that predicted from thermodynamic models. They found that nitride and carbide reactions were separate events in both isothermally and continuously cooled samples. Mixed $\left(\mathrm{Ti}_{\mathrm{x}} \mathrm{V}_{1-\mathrm{x}}\right)$ nitrides were formed in as cast, isothermally heat treated and commercially processed alloys. In the as cast state, $(\mathrm{Ti}, \mathrm{V}) \mathrm{N}$ dendrites $\leqslant 600 \mathrm{~nm}$ and $(\mathrm{Ti}, \mathrm{V}) \mathrm{N}$ cuboidal $\sim 15 \mathrm{~nm}$ particles with spherical $<10 \mathrm{~nm}$, (possibly) $\mathrm{V}_{4} \mathrm{C}_{3}$ particles were replaced by (Ti,V)N cuboidal about $57-115 \mathrm{~nm}$ particles, one such EELS analysis being $\left(\mathrm{Ti}_{0 \cdot 7} \mathrm{~V}_{0 \cdot 3}\right) \mathrm{N}$, and $<10 \mathrm{~nm}$ spherical (possibly) $\mathrm{V}_{4} \mathrm{C}_{3}$ particles. No evidence for mixed $\mathrm{CN}$ particles was found in this work, a conclusion supported by their modelling, but the $\mathrm{Ti}$ rich core $/ \mathrm{V}_{4} \mathrm{C}_{3}$ shell particle structure was observed. The wide ranging and detailed review of niobium microalloyed steels undertaken by DeArdo ${ }^{59}$ unfortunately does not include a discussion of multialloying.

\section{Methods for analysis chemical composition of vanadium precipitates in microalloyed steels}

The detailed chemical composition of carbides and nitride particles in microalloyed steels, in particular the carbon and nitrogen percentages, has long been a goal for researchers. The most convenient method of analysis, using EDX analysis, is capable of detection of the elements, but the resolution of the detectors is such that quantitative analysis is not possible. While TEM studies are still valuable for understanding precipitation processes, the atom probe has been used increasingly to follow the role of alloying elements during the precipitation of carbide phases in steels. ${ }^{162-165}$ This subject has been reviewed by Thompson, ${ }^{165}$ who concentrated on the characterisation of carbides present in higher alloyed steels, including those complex carbides precipitating in secondary hardening creep resisting steels. Several papers based on atom probe work, report a chemical composition of $\mathrm{VC}_{0.84}$ for precipitates in vanadium containing steels subject to long ageing times, which were used to closely approach or reach an equilibrium state. ${ }^{162,166-168}$ Usually these precipitates were considered to be interphase precipitates. Dunlop and Turner ${ }^{162}$ used an atom probe to study precipitates as small as $2 \mathrm{~nm}$ in size in a model $\mathrm{Ti}-\mathrm{V}$ alloy, following isothermal transformation for $15 \mathrm{~min}$ at $725^{\circ} \mathrm{C}$. A precipitate composition of $0 \cdot 45 \mathrm{~V}-0.55 \mathrm{Ti}-0 \cdot 84 \mathrm{C}(\mathrm{wt}-\%)$ was recorded. Fe peaks were also observed, which were considered to originate from within the precipitates. Another combined APFIM and TEM study of fine precipitates in a microalloyed steel, albeit in a $\mathrm{Nb}$ steel, was undertaken by Burke et al. ${ }^{164} \mathrm{~A}$ satisfactory correlation between the particle size distributions using each technique was found. Using APFIM, particles with an average diameter of $1 \mathrm{~nm}$, which was below the resolution limit of the TEM, were imaged. These constituted $80 \%$ of the total particles observed in the FIM distributions, were considered to nucleate randomly in ferrite and to make a significant contribution to strengthening. 
However, the APFIM technique is only available in a few laboratories, and the probability of observing a particle in the small FIM specimen is low, which means that the statistics of particle size and distribution is poor. The application of EELS to provide a reliable level of chemical analysis has made progress over the past two decades. Crooks et al. ${ }^{64}$ used a range of techniques, which included EELS, to characterise $\mathrm{V}(\mathrm{C}, \mathrm{N})$ and $(\mathrm{V}, \mathrm{Nb})(\mathrm{C}, \mathrm{N})$ precipitates in microalloyed steels. They showed clearly that in a steel with $0.10 \mathrm{wt}-\% \mathrm{C}$, $0 \cdot 10 \mathrm{wt}-\% \mathrm{~V}$ and $0.025 \mathrm{wt}-\% \mathrm{~N}$, particles of both compounds nucleated on austenite grain boundaries, were present as $\sim 70 \mathrm{~nm}$ sized cuboids, and those which nucleated on the austenite matrix substructure, $<15 \mathrm{~nm}$ in size, contained a high concentration of N. However, they used mainly carbon replicas to extract the particles, and were therefore unable to eliminate the possibility that the particles contained some $\mathrm{C}$, which was estimated to be $<20 \mathrm{wt}-\%$. The use of aluminium replicas did not appear to eradicate this problem due to the possibility of hydrocarbon contamination. Particles in a second series of steels containing both $\mathrm{V}$ and $\mathrm{Nb}$ were studied. Again both grain boundary and matrix nucleated particles were present. Both classes of particles were $(\mathrm{V}, \mathrm{Nb})(\mathrm{C}, \mathrm{N})$ compounds, ${ }^{64}$ supporting the predictions that mutual solubility of the pure binary carbides and nitrides ${ }^{30}$ also applied to these compounds when precipitated in steels. Other early work on analysing small vanadium carbides highlighted the problems of working with particles on extraction replicas and using a serial EELS acquisition method. ${ }^{169-171}$ The carbon signal arising from the amorphous carbon ( $a-C)$ replica limited the accuracy of the data, as did specimen drift and contamination. ${ }^{170,171}$ Following Garrett-Reed ${ }^{169}$ and changing the replica material to aluminium or silicon also encountered problems. ${ }^{172,173}$ The development of parallel electron energy loss spectroscopy (PEELS) improved the acquisition of data, ${ }^{174}$ and this, combined with the ability to differentiate between the contribution to the carbon analysis from a-C of the carbon extraction replica and the crystalline carbon from the extracted carbide (c-C), ${ }^{174}$ improved the level of accuracy of the compositional analysis of the carbide and nitride particles. Using this technique to understand the evolution of precipitation in a series of six low carbon $(\sim 0.06 \mathrm{wt}-\%)$ vanadium based microalloyed steels manufactured by a laboratory simulated direct charged thin slab process, gave useful information on the chemical composition of particles $>4 \mathrm{~nm}$ in size using carbon extraction replicas. All six steels contained $\sim 0 \cdot 1 \mathrm{wt}-\% \mathrm{~V}$. Steel $\mathrm{V}$ was a baseline steel with $\sim 0.007 \mathrm{wt}-\% \mathrm{~N}$. Steel $\mathrm{V}-\mathrm{N}$ had a higher level of $\sim 0.02 \mathrm{wt}-\% \mathrm{~N}$. Steel V-Ti contained $\sim 0.01 \mathrm{wt}-\% \mathrm{Ti}$ and $\sim 0.017 \mathrm{wt}-\% \mathrm{~N}$. The three remaining steels had $\sim 0.01$ wt- $\% \mathrm{~N}$, with steel $\mathrm{V}-\mathrm{Nb}$ having $0.03 \mathrm{wt}-\% \mathrm{Nb}$, steel $\mathrm{V}-\mathrm{Nb}-\mathrm{Ti}$ having $0.03 \mathrm{wt}-\% \mathrm{Nb}$ and $0.007 \mathrm{wt}-\% \mathrm{Ti}$ and $\mathrm{V}-\mathrm{Zr}$ having $0.008 \mathrm{wt}-\% \mathrm{Zr}$. Figure 13 shows the N/ metal ratios for steels $\mathrm{V}-\mathrm{N}, \mathrm{V}-\mathrm{Ti}$ and $\mathrm{V}-\mathrm{Nb}$ are all in the region of $0 \cdot 8$, while those for steel $\mathrm{V}-\mathrm{Nb}-\mathrm{Ti}$ are $\sim 0.65 .{ }^{175}$ Allowances for some oxidation of $\mathrm{VN}$ to $\mathrm{V}_{2} \mathrm{O}_{5}$, leading to an increase in the $\mathrm{N}$ content, made little difference. The plot of $(\mathrm{N}+\mathrm{c}-\mathrm{C}) / \mathrm{M}$ represents the lower limit for the value of the non-metal to metal ratio of the precipitates. As is explained, ${ }^{175}$ adding $0 \cdot 16$ to this value gives the upper limit. The estimated maximum values of

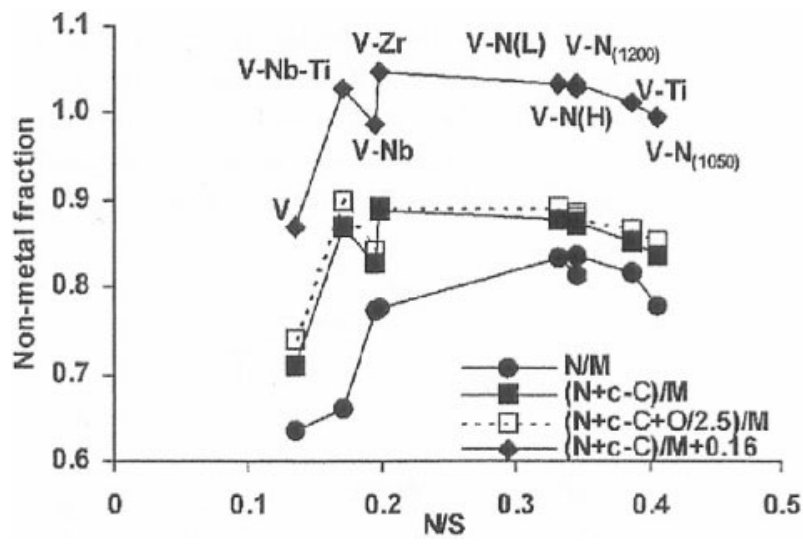

13 Plot of non-metal/metal atomic ratios in small particles versus nitrogen/metal atomic ratios for thin slab casting and direct rolling (TSDR) processed steels ${ }^{175}$

$(\mathrm{N}+\mathrm{c}-\mathrm{C}) / \mathrm{M}+0 \cdot 16$ in Fig. 13 are $\sim 1 \cdot 0$, except for steel $\mathrm{V}$, where it is 0.9 . These values are close to those predicted near to the $\gamma \rightarrow \alpha$ transformation temperature, by the corresponding ChemSage modelling for steel $\mathrm{V}_{-}$ $\mathrm{N},{ }^{176}$ and $\mathrm{V}-\mathrm{Nb}-\mathrm{Ti}$, and are shown in Fig. 14. However, these analyses are taken from the small precipitates in the final product, which the modelling predicts to contain a significant level of carbon. In fact, the work showed that sub-15 nm particles were nitrogen rich carbonitrides which do not appear to coarsen during the final stages of processing. ${ }^{154,175-178}$ The carbon extraction replica technique has the advantage of giving good contrast for extracted particles, low background for analysis using PEELS and EDX spectroscopy, and no perturbation of the optical properties of the objective lens from the ferromagnetic material in a typical foil specimen. However, there is some uncertainty about the extraction efficiency for the smallest particles, as very few were found with sizes $<4 \mathrm{~nm}$. There are some advantages in studying the particles while still in the matrix, which should reduce or remove the potential for particle modification during preparation. A number of methods have been used to investigate fine precipitates in steel and some of these are discussed by Rainforth et al. ${ }^{179}$ Several groups have used electron spectroscopic imaging or energy filtered TEM. Hättestrand and Andrén ${ }^{180}$ used a combination of energy filtered TEM and APFIM to investigate precipitates of $\mathrm{VN} \geqslant 5 \mathrm{~nm}$ in a thin foil via the $\mathrm{V}$ signal. More recently, MacKenzie et al. ${ }^{181}$ used PEELS and STEM together with a focussed ion beam lift out preparation followed by low energy ion milling which removes a small specimen of foil of a volume insufficient to affect the alignment of the microscope. These authors ${ }^{181}$ were able to show that for steel V-N, ${ }^{176} \sim 3 \mathrm{~nm}$ particles were essentially stoichiometric VN. In an extension of this work, which combined spectral imaging and three-dimensional atom probe studies, Craven et al. ${ }^{182}$ again used steel $\mathrm{V}-\mathrm{N}$ to explore the chemical analysis of particles in the range 2 $5 \mathrm{~nm}$, which were rarely extracted by the carbon replica technique. The specimen was prepared by a focussed ion beam using an ex situ lift out, and the resultant lamella was milled in a Gentle Mill. ${ }^{181}$ The resultant particle composition was $\mathrm{VN}_{0.95 \pm 0.03}$ for particle sizes of $<5 \mathrm{~nm}$. In both the spectral imaging and 3-DAP, the particle sizes were clustered below the peak of the size distribution found from the carbon replica areas, ${ }^{154}$ as 


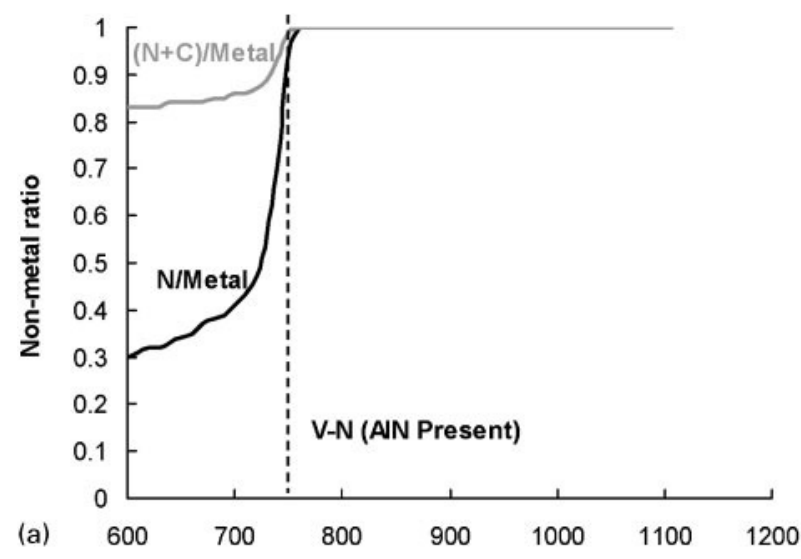

Temperature, ${ }^{\circ} \mathrm{C}$
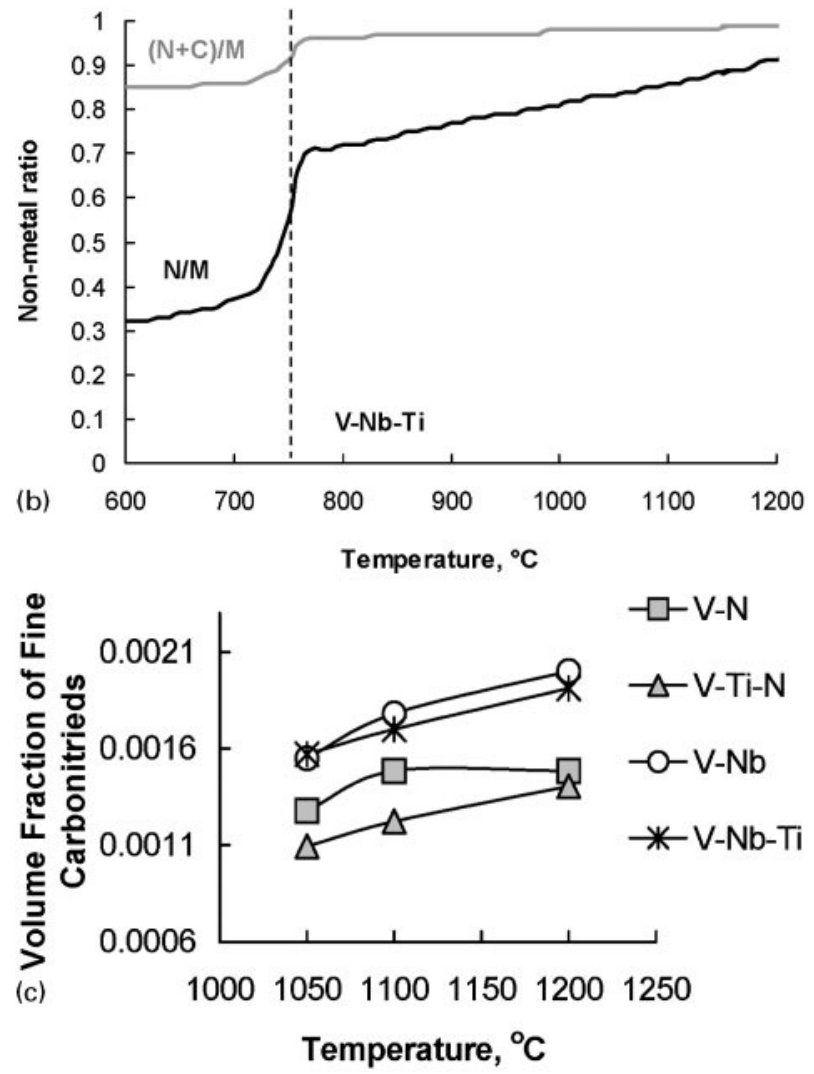

14 ChemSage predictions for a steel $\mathrm{V}-\mathrm{N}, \boldsymbol{b}$ steel $\mathrm{V}-\mathrm{Nb}-$ $\mathrm{Ti}$ and $c$ volume fractions of dispersion strengthening particles in TSDR processed steels, as function of equalisation temperature ${ }^{176}$

seen in Fig. 15, confirming that the efficiency of the replica extraction of small particles is low. ${ }^{182}$ The work also found a significant content of $\mathrm{Cr}, \mathrm{Mn}, \mathrm{Si}$ and $\mathrm{C}$ close to the particle, indicating an 'atmosphere' of segregated atoms around the particle core. ${ }^{182}$ It should be emphasised that while significant advances have been made in the level of accuracy of the quantitative analysis of light elements in small transition metal carbide and nitride precipitates in microalloyed steel, and in particular VN, the techniques are relatively slow, require a high degree of skill in the preparation of suitable specimens and a considerable understanding of the physics underpinning the chosen analytical methods. The transforming of raw data to give an accurate analysis involves a number of correction factors, so the

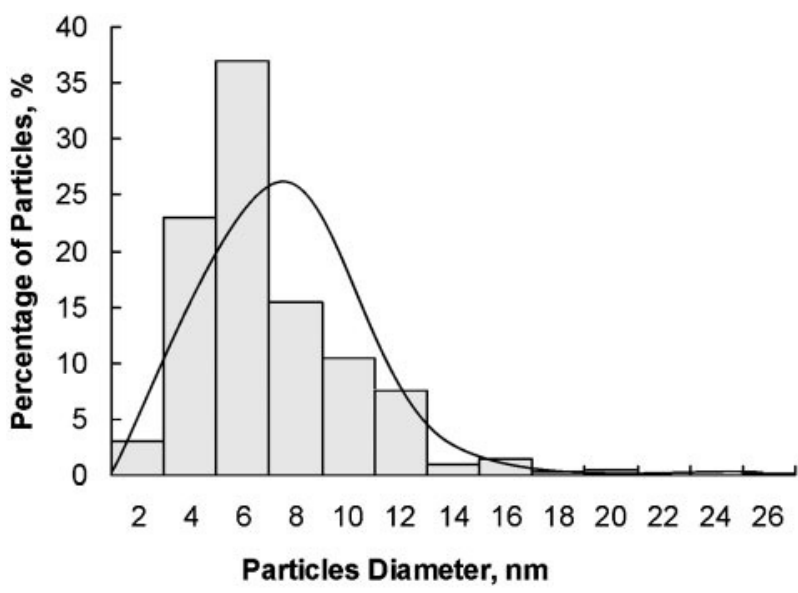

15 Experimentally determined size distribution for small particles of $\mathrm{V}(\mathrm{C}, \mathrm{N})$ (Ref. 154)

particle chemical analysis at this level is anything but routine.

\section{Effect of vanadium during processing by continuous casting, controlled rolling and thin slab direct rolling of microalloyed steels}

\section{Continuous casting transverse cracking}

One of the main problems encountered in slabs of microalloyed steels produced by a continuous casting process is that of transverse cracking, which manifests itself as fine cracks penetrating up to $5-8 \mathrm{~mm}$ below the surface of the slab. The cracking is associated with the straightening operation which occurs at $700-1000^{\circ} \mathrm{C}$, a temperature range in which steel is known to exhibit a minimum ductility in hot tensile laboratory tests, usually as percentage reduction in area (\% RA). The cracks have been shown to be intergranular, meandering along the prior austenite grain boundaries. This topic of hot ductility related to transverse cracking has been reviewed up to 1991 by Mintz et al., ${ }^{183}$ who have made a significant contribution in this area, particularly in work on niobium steels. Peritectic steels containing $\mathrm{Nb}$ are very prone to transverse cracking during the straightening operation in both conventional, ${ }^{184,185}$ and TSDR processing. ${ }^{186}$ It is now well established that niobium precipitates as $\mathrm{NbCN}$ at austenite grain boundaries preventing dynamic recrystallisation and encouraging grain boundary sliding, leading to a low ductility intergranular failure. ${ }^{187}$ Far less work has been undertaken on vanadium HSLA steels. The work reported by Mintz and Arrowsmith ${ }^{184}$ showed that vanadium behaved in similar manner to plain $\mathrm{C}-\mathrm{Mn}$ steels, which show good ductility. However, Mintz and Abushosha ${ }^{188}$ found that if the product of vanadium and nitrogen weight percentage exceeds $1.2 \times 10^{-3}$, corresponding to a steel composition of $0 \cdot 1 \mathrm{wt}-\% \mathrm{~V}$ and $0 \cdot 012 \mathrm{wt}-\% \mathrm{~N}$, then the ductility levels approached the low values of $\%$ RA exhibited by a steel containing $0.03 \mathrm{wt}-\% \mathrm{Nb}$. In both steels, this was accompanied by a significant volume fraction of fine particles. With a composition of $0.05 \mathrm{~V}-0.005 \mathrm{~N}$ (wt- $\%$ ), little precipitation was observed, and the steel exhibited corresponding higher RA values. A more recent study by Mohamed, ${ }^{187}$ who provided a useful succinct review of the literature, 


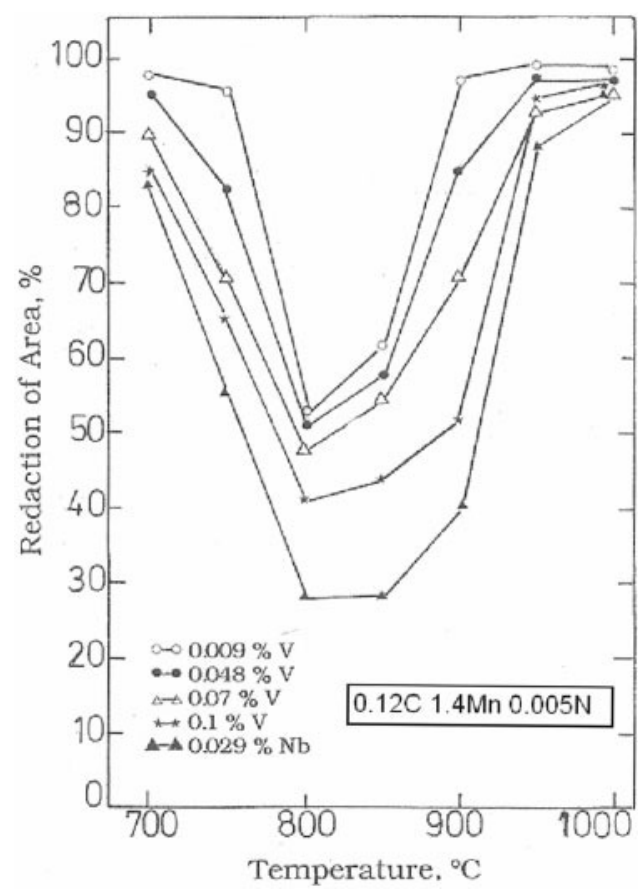

16 Hot ductility curves for $\mathrm{V}$ and $\mathrm{Nb}$ steels ${ }^{187}$

compared the hot ductility of a $\mathrm{Nb}$ steel with a series of steels containing 0.009 to $0.10 \mathrm{wt}-\% \mathrm{~V}$, all having approximately $0 \cdot 12 \mathrm{wt}-\% \mathrm{C}$ and $0 \cdot 005 \mathrm{wt}-\% \mathrm{~N}$. The curves generated in this work are given in Fig. 16 where the $\% \mathrm{RA}$ is plotted against the test temperature. It can be seen that increasing the $\mathrm{V}$ content lowered the ductility from 53 to $41 \% \mathrm{RA}$ at $800^{\circ} \mathrm{C}$ and from 96 to $52 \% \mathrm{RA}$ at $900^{\circ} \mathrm{C}$. Thus the minimum ductility of the highest V steel (41\%) does not come close to the minimum ductility of the $\mathrm{Nb}$ steel $(28 \%)$. It was concluded that VN particles are less detrimental to hot ductility than $\mathrm{NbCN}$, probably because $\mathrm{NbCN}$ are finer and precipitate preferentially at austenite grain boundaries, which indicated the importance of size and location of the particles. Another reason for the reduced effect on hot ductility is considered to be due to the higher solubility in austenite of $\mathrm{VN}$ than $\mathrm{NbCN}{ }^{189}$ In most of the above work, the precipitates were extracted on to carbon replicas to carry out TEM, but the research did not involve chemical analysis of the particles. Therefore the $\mathrm{C}$ and $\mathrm{N}$ contents of the particles were unknown and it was not known if vanadium was present as VN or VCN. However the general trend of the results provided by Mohamed ${ }^{187}$ give encouragement for the replacement of $\mathrm{Nb}$ by $\mathrm{V}$, in cases where transverse cracking is a problem. This is also supported by the study of Banks et al., ${ }^{190}$ which considered steel compositions typical of those used in TSDR processing, where the $\mathrm{C}$ percentage is reduced to $\sim 0.05 \%$ to avoid the peritectic reaction during casting. As explained, ${ }^{190}$ 'in conventional cold charging, test scarfing is a common operation to remove small surface defects inherited from casting. The processing of thin slabs by the hot charging routine precludes surface inspection and a defect free surface is a prime requirement for economic production'. Thus the straightening of thin slabs of microalloyed steels must be maintained at temperatures in excess of those, below which the ductility deteriorates. A stress relaxation test of in situ melted $\mathrm{V}-\mathrm{N}, \mathrm{V}-\mathrm{Nb}$, and
$\mathrm{V}-\mathrm{Nb}-\mathrm{N}$ steels was used, and again the ductility of $0.87 \mathrm{wt}-\% \mathrm{~V}$ and $0.83 \mathrm{~V}-0.015 \mathrm{Nb}$ (wt- $\%$ ) steels was found to be superior to $0.038 \mathrm{wt}-\% \mathrm{Nb}$ steels. ${ }^{190}$ The most critical factor was considered to be the upper temperature at which the ductility deteriorates, since bending of the steels must be completed before any part of it (face, edge or corner) falls below this temperature. ${ }^{2}$

\section{Conventional controlled rolled (CCR) steels}

As described by Llewllyn, ${ }^{191}$ the traditional route to a fine grain size in ferrite pearlite structural steels was to incorporate grain refining elements, such as aluminium, and after rolling, to normalise the materials from $\sim 920^{\circ} \mathrm{C}$. With the introduction of niobium, which increased strength in the as rolled condition compared to plain carbon steels, a significant reduction in toughness was reported compared with aluminium grain refined steels. However, the microalloyed steels could be normalised to improve their impact properties, but the strength advantage was then forfeited. There was therefore a need for an alternative route to a fine grain size in structural plate which would overcome the cost and strength penalties associated with traditional normalising. It has been known for many years, and described as early as 1928 by Berry, ${ }^{192}$ that improvements in the mechanical properties of structural steels could result from rolling to finishing temperatures in the range $1000-800^{\circ} \mathrm{C}$, which are lower than those normally used for hot rolling of mild steels. Vanderbeck in 1958, reported that European steels producers, mainly German, were adopting lower than normal finishing temperatures during rolling, to improve mechanical properties. ${ }^{193}$ This practice became known as controlled rolling and more recently, thermomechanical processing, which embraces both modified hot rolling and inline accelerated cooling operations. ${ }^{191}$ Conventionally, rolling of plain or unalloyed C-Mn steel is carried out at high temperatures to change the shape of the billet, starting at $\sim 1250^{\circ} \mathrm{C}$ and terminating at $>1100^{\circ} \mathrm{C}$, which gives sufficient time at high temperatures for grain growth to take place on cooling after rolling. Consequently, the final austenite grain sizes are large and transform to ferrite grains, which at room temperature are usually in the range $50-250 \mu \mathrm{m}$ diameter. Grange ${ }^{194}$ was among the first to point out that the full potential of hot rolling was not being realised and initiated research into the determination of rates of recrystallisation during rolling, considering such variables as the temperature of deformation and amount of deformation per pass. This was at the start of considerable research worldwide, and a full account is given of the situation to 1988 in the book by Tamura et al. ${ }^{195}$ Among the main changes were:

(i) the use of lower slab reheating temperatures based on the need to take into solution the microalloying carbides and nitrides but to avoid significant austenite grain growth ${ }^{137}$

(ii) the introduction of a time delay between the roughing and finishing passes to allow the final deformation to be carried out below the recrystallisation start temperature

(iii) lowering of the finish rolling temperatures down to $800^{\circ} \mathrm{C}$ and an increase in the total reduction below $900^{\circ} \mathrm{C}$ of up to $30 \%$.

In addition the carbon content was reduced from $0 \cdot 15$ to closer to $0 \cdot 05 \%$, to lower the percentage of pearlite and 
aid weldability by reducing the carbon equivalent. ${ }^{196}$ The main purpose of controlled rolling is to refine the microstructure of the steel. This is carried out in stages by deformation in a falling temperature range and the rearrangement and removal of the dislocations is by dynamic and static recovery and recrystallisation of austenite which can result in a small ferrite grain size. To understand the development of microstructure and the relation to properties, the interaction of dislocations, sub and high angle grain boundaries with precipitates of the transition metal carbides and nitrides [carbonitrides], has been studied extensively in niobium steels. ${ }^{197,198}$ However, much less work has been reported on vanadium steels.

Unlike steels with $\mathrm{Nb}$ additions, no difference is found in the ferrite grain size for $\mathrm{V}$ steels which are formed from unrecrystallised or deformed austenite grains. ${ }^{199}$ One of the main explanations for this difference lies in the solubility of $\mathrm{Nb}$ and $\mathrm{V}$ carbonitrides in austenite. Figure 6 shows the relative recrystallisation stop temperatures for steels with different alloy additions. A $0.04 \mathrm{wt}-\% \mathrm{Nb}$ steel will form carbonitrides over most of the temperature range in which rolling in austenite takes place. Because of the higher solubility of VCN in austenite, precipitation in a $0.5 \mathrm{wt}-\% \mathrm{~V}$ steel will not commence until the temperature has decreased to $\sim 800^{\circ} \mathrm{C}$. In addition, the kinetics of precipitation of VCN in austenite are slow. This means that strain induced precipitation of vanadium carbonitrides in austenite is not an important process in the evolution of microstructure in low $\mathrm{N}$ steels. Therefore, for normal steel compositions, processed by finishing rolling $\sim 1000^{\circ} \mathrm{C}$, only a small fraction of the available $\mathrm{V}$ will precipitate in austenite, and the remainder will be available for nucleation in ferrite. ${ }^{2}$ Irvine et al. ${ }^{137}$ were among the first to study the influence of $\mathrm{V}$ in a microalloyed controlled rolled steel. They found that for any specific reheating temperature, the properties improved after a low finishing rolling temperature and a faster cooling rate. Also, they considered that $\mathrm{V}$ contributed to both austenite grain refining and dispersion strengthening. However, Hannerz and JonssonHolmquist ${ }^{131}$ were more specific and considered that on cooling a $0.15 \mathrm{wt}-\% \mathrm{C}, \quad 1.3 \mathrm{wt}-\% \mathrm{Mn},>0.10 \mathrm{wt}-\% \mathrm{~V}$, $0 \cdot 005-0.013 \mathrm{wt}-\% \mathrm{~N}$ steel from a high temperature, precipitation of $\mathrm{VN}$ will take place which will block grain growth in austenite, thus producing, a fine grain austenite, which on transformation encourages the formation of fine ferrite grains.

In other work, Brown et al. ${ }^{61}$ studied the microstructure of a hot rolled and isothermally held $0 \cdot 16 \mathrm{C}-$ $1 \cdot 3 \mathrm{Mn}-0 \cdot 12 \mathrm{~V}-0 \cdot 21 \mathrm{~N}-0 \cdot 041 \mathrm{Al}(\mathrm{wt}-\%)$ steel. They found that after soaking at $1288^{\circ} \mathrm{C}$ and cooling to $1038^{\circ} \mathrm{C}$ before rolling, only AlN on austenite sub-boundaries was present. Lowering the start rolling to $871^{\circ} \mathrm{C}$ coincided with copious precipitation of $\mathrm{V}(\mathrm{C}, \mathrm{N})$ again on austenite sub-boundaries, both compounds being 'identified' by SAED. The precipitation in the deformed austenite was considered to indicate that dynamic recrystallisation had occurred. Following three different rolling schedules, a comparison of the influence of vanadium and niobium on the precipitation mode and dislocation substructures was undertaken by Morrison et $a .^{200}$ It was found that dispersion strengthening was strongly influenced by nitrogen content and transformation temperature, with large increases as the transformation temperature decreased. Also, when rolling was extended into the ferrite phase field, higher strengths were obtained in the vanadium steels and both interphase and random precipitation were observed.

\section{Thin slab cast and direct rolling processed steels}

Thin slab casting and direct rolling technology has brought about global changes to the manufacture of hot rolled coil, due to its higher productivity and lower energy requirements. ${ }^{201}$ Post-cast processing of thick cast slabs (200-250 mm thickness) of structural steels which use CCR schedules, is usually considered to remove most of the features of the as cast microstructure. In CCR processing, the austenite is metallurgically conditioned by the phase transformation that occurs during slab cooling and reheating. The austenite grain size after soaking and at the start of the rolling process is usually smaller than it was in the original cast slab, being affected by any undissolved inclusions and carbonitrides.

However, in the TSDR process, known also as compact strip processing, the as cast product which has a thickness of $50-80 \mathrm{~mm}$, the cooling rates are faster, the equalisation times shorter and the amount of deformation introduced during rolling less than in conventional practice. With TSDR methods, the continuously cast steel is hot rolled following direct charging to an equalisation tunnel furnace, without the intermediate stages of cooling to room temperature before rolling, as in CCR. Therefore the $\gamma \rightarrow \alpha \rightarrow \gamma$ phase transformation, which takes place during cooling down of the conventional as cast slab to ambient temperature and reheating before rolling, does not occur. With direct charging the initial as cast austenite grains before rolling are considerably coarser than those after reheating with cold charging. Also, some aspects of the microstructural features from the as cast condition are therefore more likely to be inherited in the later stages of processing or even in the final product. ${ }^{154,202-205}$ For example, the as cast structure prior to rolling is generated at the peritectic transformation temperature, in excess of $1450^{\circ} \mathrm{C}$, where equilibrium solubility of microalloyed carbonitrides is very much greater than that at the soaking temperatures used in CCR. Therefore the as cast phase may be more highly supersaturated with respect to microalloying elements than the reheated phase in the CCR processing. This is predicted to have an effect on precipitation during the processing. ${ }^{206}$

Compared with thick slabs, thin slabs are cast at higher speeds, up to $6 \mathrm{~m} \mathrm{~min}^{-1}$, and the rapid solidification results in reduced secondary dendrite arm spacing, and this in turn reduces the degree of interdendritic segregation. ${ }^{206}$ The faster cooling rates may result in an austenite phase which is more supersaturated with alloying elements while the final product may have mechanical and toughness properties which are different from steels which have undergone conventional processing. ${ }^{207}$ In addition, the process route, which is depicted schematically in Fig. 17, means that the as cast billet, after shearing, is reheated without transformation to ferrite.

Processing of TSDC was reviewed by RodriguezIbabe. $^{208}$ The vanadium steels he considered were all 


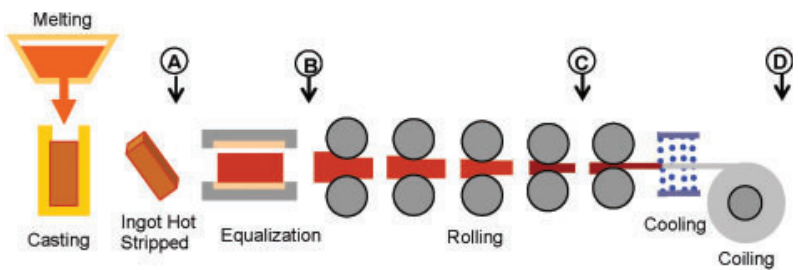

17 Schematic diagram showing process route used for simulating thin slab direct rolling ${ }^{177}$

studied by Li et al. ${ }^{56,176,177}$ It is of interest to note that no observations of interphase precipitation were recorded in this work. In $\mathrm{V}-\mathrm{N}$ steel $(0 \cdot 10 \mathrm{~V}-0 \cdot 022 \mathrm{~N}$, $\mathrm{wt}-\%$ ), following a low equalisation treatment at $1050^{\circ} \mathrm{C}$, cuboidal precipitates were observed along austenite grain boundaries (Fig. 8). Further work ${ }^{154,175}$ on these carbonitride particles, using PEELS and the procedures discussed above, ${ }^{173,174,181}$ showed that they were essentially nitrides with very little carbon content. They would persist and grow through subsequent processing stages, becoming increasingly $\mathrm{V}$ rich thereby depleting bulk $\mathrm{V}$ and $\mathrm{N}$ levels, before the fine dispersion hardening particles could form. Cuboidal particles containing both $\mathrm{V}$ and $\mathrm{Nb}$ were also found in a V$\mathrm{Nb}-\mathrm{N}$ steel $(0 \cdot 11 \mathrm{~V}-0 \cdot 03 \mathrm{Nb}-0 \cdot 011 \mathrm{~N}$, wt- $\%)$, after equalisation at $1100^{\circ} \mathrm{C}$. They were also found after equalisation at temperatures between 1050 and $1200^{\circ} \mathrm{C}$ in steel $\mathrm{V}-\mathrm{Nb}-\mathrm{Ti}-\mathrm{N}$. Steels $\mathrm{V}-\mathrm{Ti}-\mathrm{N}$ and $\mathrm{V}-\mathrm{Nb}-\mathrm{Ti}-\mathrm{N}$ also contained cruciform or star-like particles (Fig. 18). Around 25 cruciform particles in steel $\mathrm{V}-\mathrm{Ti}-\mathrm{N}$, were analysed by EDX after equalisation at $1050^{\circ} \mathrm{C}$, and gave an average $\mathrm{Ti} /(\mathrm{Ti}+\mathrm{V})$ atomic ratio of 0.30 which increased to $0 \cdot 40$ after equalisation at $1100^{\circ} \mathrm{C}$. Analysis using PEELS on another set of eight cruciforms after the $1100^{\circ} \mathrm{C}$ equalisation provided the data shown in Fig. 19. Here it can be seen that the $\mathrm{N} /(\mathrm{V}+\mathrm{Ti})$ atomic ratio for both core and arms were in the range $0 \cdot 90-1 \cdot 1$, with an average value of $0 \cdot 99$. The average $\mathrm{Ti} /$ $(\mathrm{Ti}+\mathrm{V})$ atomic ratio was 0.44 compared with 0.40 given above for EDX analysis. These compositional results from the cruciforms show that they are stoichiometric nitrides. Some cruciforms had a core rich in Ti with arms $\mathrm{V}$ rich. The Ti level is normally greater in the arms but there were a significant number of cases where it is the same in the core as the arms (Fig. 20). ${ }^{177}$ TiN acting as a core nucleant for $\mathrm{V}$ and $\mathrm{Nb}$ precipitates is now a well established observation and has attracted some

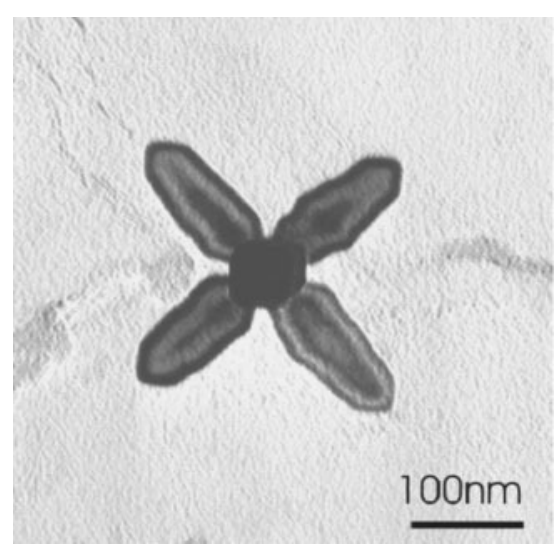

18 Cruciform particle in steel $\mathrm{V}-\mathrm{Ti}-\mathrm{N}$ steel: equalisation at $1100^{\circ} \mathrm{C}$ (Ref. 178)

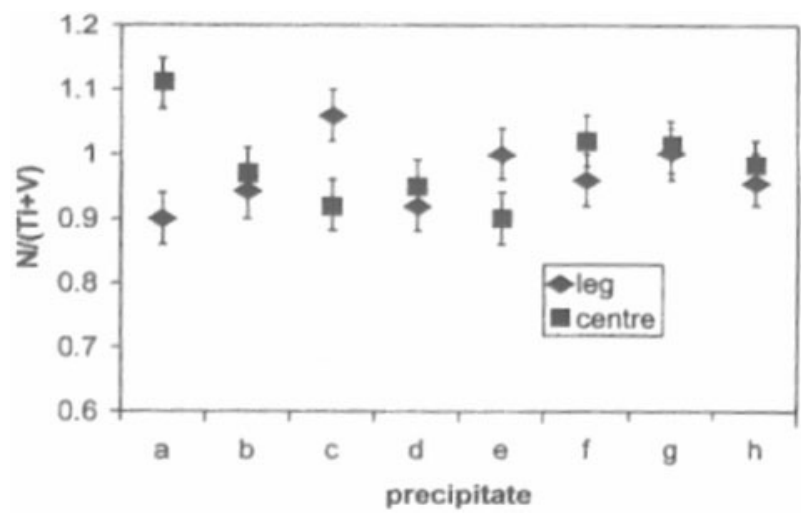

19 Graphs showing $\mathrm{N} /(\mathrm{V}+\mathrm{Ti})$ compositional ratios for eight cruciform particles at core and arms ${ }^{177}$

modelling, ${ }^{209}$ based on the $\mathrm{N}$ rich core and $\mathrm{C}$ rich shell. This approach does not fit the above experimental data but does mirror the results of Hong et al. ${ }^{210}$ They analysed cruciforms present in an as cast steel containing $0.06 \mathrm{wt}-\% \mathrm{C}, \quad 0.03 \mathrm{wt}-\% \mathrm{~V}, \quad 0.039 \mathrm{wt}-\% \mathrm{Nb}$, $0.018 \mathrm{wt}-\% \mathrm{Ti}$ and $0.004 \mathrm{wt}-\% \mathrm{~N}$ after reheating at $1100-1400^{\circ} \mathrm{C}$, followed by water quenching. ${ }^{210}$ While they were unable to undertake quantitative analysis of the $\mathrm{C}$ and $\mathrm{N}$ in their particles, the EDX spectra clearly show a higher $\mathrm{N}$ peak relative to the $\mathrm{C}$ peak in the core than in the arms of the cruciform. The analyses for the fine particles are discussed in detail above. Figure 21 shows details of eight particles from two areas analysed for steel $\mathrm{V}-\mathrm{Nb}-\mathrm{Ti}$. Here the average value of $\mathrm{c}-\mathrm{C} / \mathrm{m}$ of $0 \cdot 21$ is much higher than the steels with binary additions (Fig. 13), and it was observed that the particles, on average were smaller, as were the particle volume fractions as predicted by ChemSage (Fig. 14c). Similar

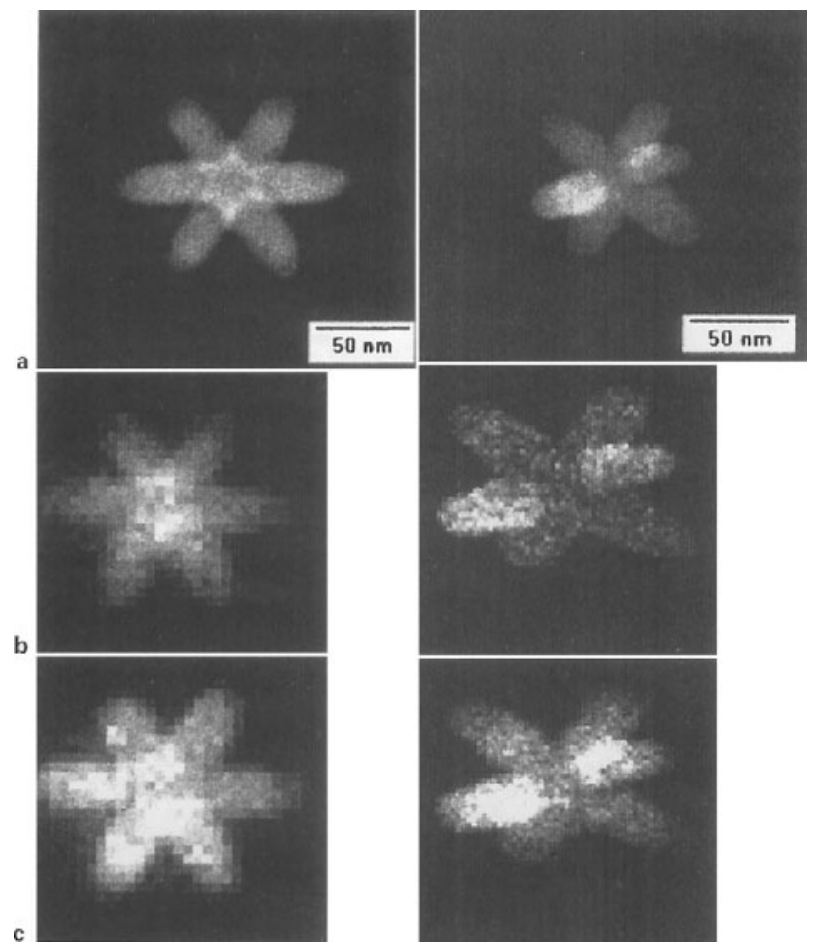

a annular dark field STEM image; $b$ Ti $K_{\alpha}$ counts; c $V$ $K_{\alpha}+$ Ti counts $^{177}$

20 Concentration maps for particles showing high $\mathrm{Ti}$ counts at the centre high Ti counts at edges of arms 


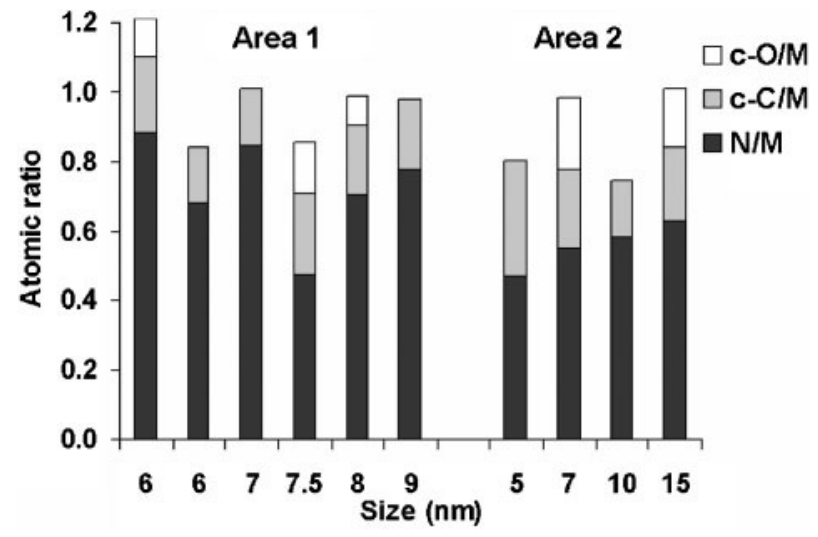

21 Non-metal/metal ratios for small particles in $\mathrm{V}-\mathrm{Ti}-\mathrm{Nb}$ steel $^{175}$

precipitate morphologies to those described above, with the exception of cruciforms, were observed in TSDR processed $\sim 0.06$ wt- $\% \mathrm{C}-\mathrm{V}-\mathrm{Nb}$ and $\mathrm{V}-\mathrm{Nb}-\mathrm{Ti}$ steels by Reip et al. ${ }^{159}$ who used STEM/SAED/EDX techniques to identify the fine particles as carbides containing $\mathrm{V}, \mathrm{Nb}$ and Ti. However, unlike others, ${ }^{161,175,177}$ who used standards to overcome problems with overlapping peaks such as V $K_{\alpha}$ which overlaps Ti $K_{\beta}$, and both Ti $L_{\alpha}$ and V $L_{\alpha}$ which overlap $\mathrm{N} K_{\alpha}$, plus EELS to analyse C and $\mathrm{N}$ contents, some of the above papers ${ }^{159,210}$ did not comment on these omissions.

\section{Development of strength and toughness in vanadium microalloyed steels}

The mechanical properties and toughness developed in microalloyed steels have been considered in terms of the influence of grain size and precipitation. Traditionally the approaches developed by Hall and Petch for yield strength and Cottrell and Petch for predicting the ductile-brittle transition, have been followed since the 1960s, commencing with their application by Morrison and Woodhead ${ }^{135}$ to niobium microalloyed steels. Without this application, the fundamental approach of Petch might have remained as one of many hypotheses gathering dust. Woodhead and Morrison's work showed conclusively that the research of Hall and Petch, initiated by Orowan and Bragg at Cambridge ${ }^{211,212}$ in the 1950 s, provided a powerful tool to understand how microstucture controlled mechanical and toughness properties. Later, this was expanded by others, through the use of regression equations, which showed how the steel composition together with the steel processing route developed the microstructure. ${ }^{136}$

The original Hall-Petch equation is

$$
\sigma_{\mathrm{y}}=\sigma_{\mathrm{o}}+k_{\mathrm{y}} d^{-1 / 2}
$$

where $\sigma_{\mathrm{y}}$ is the yield strength, $\sigma_{\mathrm{o}}$ the friction stress opposing dislocation motion, $k_{\mathrm{y}}$ a term relating to the grain boundary resistance to dislocation motion and $d$ the grain diameter. To apply this equation to estimate the yield strength of a microalloyed steel, it was realised that the friction stress must include opposition to dislocation motion from atoms in solid solution and precipitates together with a term associated with the symmetry of a dislocation, the Peierls-Nabarro force.

Pickering and Gladman ${ }^{136}$ were among the first to expand $\sigma_{\mathrm{o}}$ by the regression equation approach to included these terms, which have since been refined by many others, for example. ${ }^{213-217}$

Pickering and Gladman's equation ${ }^{136}$ is

$$
\sigma_{\mathrm{y}}=105+84[\mathrm{Si}]+33[\mathrm{Mn}]+17 \cdot 5 d^{-1 / 2}
$$

where $\sigma_{\mathrm{y}}$ is in $\mathrm{MPa}, d$ in $\mathrm{mm}, k_{\mathrm{y}}$ in $\mathrm{MPa} \mathrm{mm}^{-3 / 2}$ and the alloying contents in wt- $\%$. Mintz ${ }^{218}$ has examined several regression equations given in the literature and considered the reasons for the variability of $k_{\mathrm{y}}$. He found that $k_{\mathrm{y}}$ may vary between 14 and $24 \mathrm{MPa} \mathrm{mm}^{-3 / 2}$ for ferrite-pearlite or pearlite free steels. In principle, this may have a marked effect on the yield strength. For example, for a steel having an average ferrite grain size of $5 \mu \mathrm{m},\left(d^{-1 / 2}=14 \cdot 1 \mathrm{~mm}^{-1 / 2}\right)$, a change of $k_{\mathrm{y}}$ from $18 \cdot 1$ to $24 \mathrm{MPa} \mathrm{mm}{ }^{-3 / 2}$ would have a calculated increase in yield strength of $115 \mathrm{MPa}$. Generally, however, the lower yield strength is only marginally influenced by this variation in the $k_{\mathrm{y}}$ value because of a strong interrelationship between the $k_{\mathrm{y}}$ and $\sigma_{\mathrm{o}}$ values, such that high $k_{\mathrm{y}}$ values are associated with low $\sigma_{\mathrm{o}}$ values, and vice versa. ${ }^{218}$ The regression equation favoured by Corus and utilised by used by Li et al. ${ }^{176}$ is a modification of that developed by Morrison et al. ${ }^{217}$

$$
\begin{aligned}
\sigma_{\mathrm{y}}= & 45+32[\mathrm{Mn}]+84[\mathrm{Si}]+680[\mathrm{P}]+38[\mathrm{Cu}]+ \\
& 43[\mathrm{Ni}]+18 \cdot 1 d^{-1 / 2}
\end{aligned}
$$

It is noteworthy, that none of the regression equations used in discussing microalloyed steels contains any terms associated with transition metals. The regression equations allow an estimate of the lower yield strength from the steel composition and average ferrite grain size. However, when the components of the friction stress involve dispersion strengthening and dislocation strengthening, then another approach is necessary. Now the contribution to yield strength from dispersion and dislocation strengthening $\sigma_{\mathrm{d}}$ was calculated by subtracting the components of yield strength $\sigma_{\mathrm{y}}$ due to ferrite lattice fraction stress and $\mathrm{C}+\mathrm{N}$ in solution $\sigma_{\mathrm{o}}$, solid solution strengthening $\sigma_{\mathrm{s}}$, and ferrite grain size strengthening $\sigma_{\mathrm{g}}$ from the measured value of the lower yield stress, with the units in MPa, using a modified version of the Hall-Petch equation. In this analysis, ${ }^{176}$ it was assumed that strengthening from dislocations and texture was low and similar for all the steels examined.

$$
\begin{aligned}
& \sigma_{\mathrm{P}}+\sigma_{\mathrm{d}}=\sigma_{\mathrm{y}}-\left(\sigma_{\mathrm{o}}+\sigma_{\mathrm{s}}+\sigma_{\mathrm{g}}\right) \\
& \sigma_{\mathrm{o}}=45 \mathrm{MPa} \\
& \sigma_{\mathrm{s}}=84[\mathrm{Si}]+32[\mathrm{Mn}]+38[\mathrm{Cu}]+43[\mathrm{Ni}] \\
& \sigma_{\mathrm{g}}=18 \cdot 1 d^{-1 / 2}
\end{aligned}
$$

The justification for combining $\sigma_{\mathrm{P}}+\sigma_{\mathrm{d}}$ is based on the strong interaction of dislocations and particles, as seen in Fig. 22.Microalloyed steels with yield strengths up to $600 \mathrm{MPa}$ have been developed based on a ferritepearlite grain structure and higher strengths with a bainitic matrix. The major contributions in the ferritepearlite steels would be due to a $5 \mu \mathrm{m}$ ferrite grain size providing $\sim 250 \mathrm{MPa}$, while $\sigma_{\mathrm{P}}+\sigma_{\mathrm{d}}$ could make a contribution in the range of $100-200 \mathrm{MPa},{ }^{145,176,200}$ as shown in Fig. 23. This level of yield strength has usually entailed rolling to $<10 \mathrm{~mm}$ steel thickness, finishing 


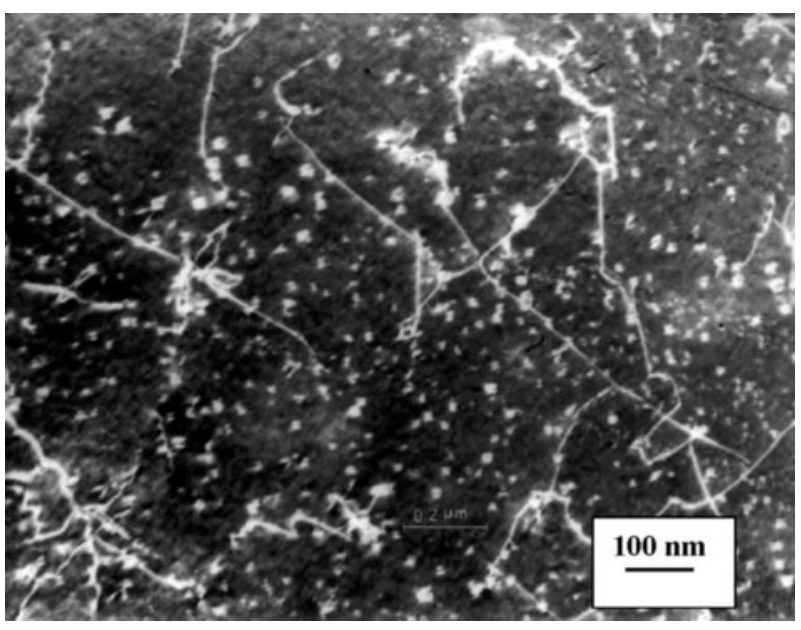

22 Dislocations and vanadium carbonitride precipitates

rolling at low temperatures, possibly in ferrite ${ }^{77,200}$ and/ or applying water cooling. ${ }^{176}$ The effect of end water cool temperature is evident in Fig. 23. This parameter in TSDR processing has a similar effect to equalisation temperature. ${ }^{176}$ The effect of nitrogen additions on the yield strength of vanadium microalloyed steels has been shown to be some $6 \mathrm{MPa}$ for every $0.001 \mathrm{wt}-\% \mathrm{~N}$, essentially independent of processing conditions. ${ }^{137,148}$ Another interesting aspect of the precipitation in $\mathrm{V}-\mathrm{N}$ structural steels has been highlighted by Zajac et al. ${ }^{219}$ They demonstrated that 'the effective carbon for precipitation in ferrite during the period of the phase transformation is much greater than the very small carbon content in solution in ferrite at equilibrium'. This, they considered, is due to 'the abnormally high activity of carbon in ferrite in the presence of under cooled austenite and before cementite nucleation, so that profuse nucleation of vanadium carbonitride is encouraged'. As the carbon content increased from 0.04 to $0 \cdot 22 \mathrm{wt}-\%$, the average size of the precipitates decreased, the profusion of precipitates and the yield strength increased. $^{219}$ An interesting observation was made by Morrison et al., ${ }^{217}$ who estimated that $\sigma_{\mathrm{p}}$ in practice for $\mathrm{V}$ as $\mathrm{VN}, \mathrm{Nb}$ and $\mathrm{Ti}$ additions is $1500 \mathrm{MPa} / \mathrm{wt}-\%$ and for $\mathrm{V}$ as $\mathrm{VC}$ is $500 \mathrm{MPa} / \mathrm{wt}-\%$ and that these figures represent $50 \%$ of $\sigma_{\mathrm{p} \text { (max) }}$, which is calculated from the steels composition. This loss of potential dispersion strengthening, is in part, to account for the precipitation

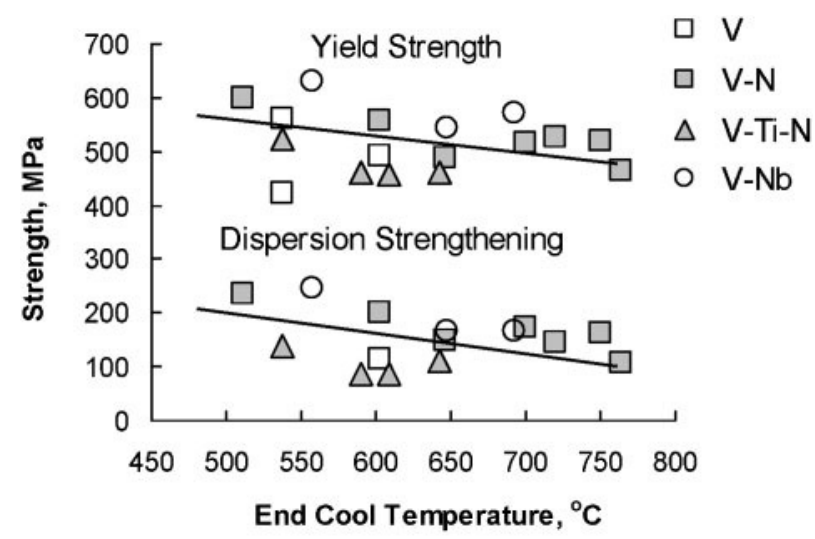

23 Effect of end water cool temperature on lower yield strength and dispersion strengthening in TSDC steels $^{176}$

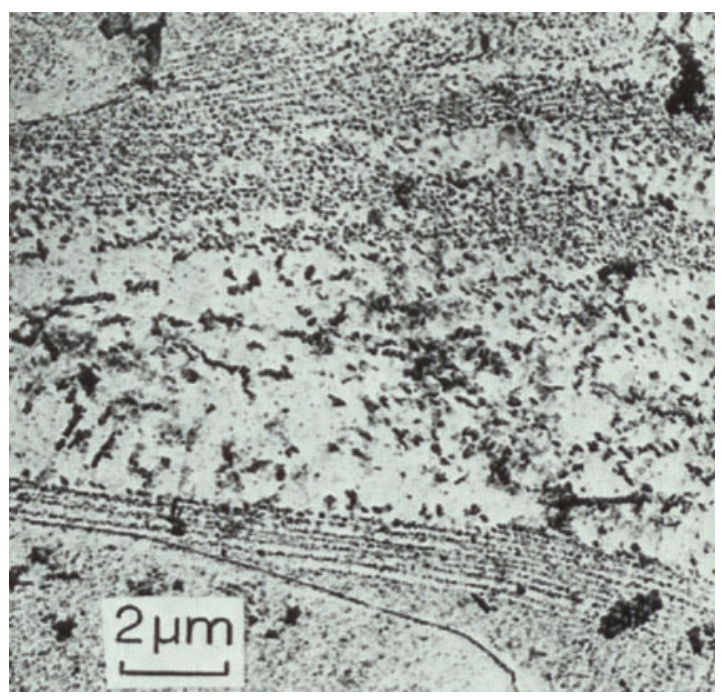

24 Carbon extraction replica showing small number of rows typical as rolled vanadium steels ${ }^{220}$

which occurs in austenite during controlled rolling ${ }^{217}$ and in part due to solute remaining in solution. Support for this view was provided by Baker, ${ }^{220}$ who tempered some of the controlled rolled model vanadium steels studied previously ${ }^{77,141}$ and obtained up to $50 \%$ increase in $\sigma_{\mathrm{y}}$ In addition, the hypothesis proposed by Zajac et al. ${ }^{219}$ could also explain the loss in strength recorded by Baker, ${ }^{220}$ as his alloys had carbon levels in the region of $0.02-0.03 \mathrm{wt}-\%$ C. More recently, Pereloma et al. ${ }^{221}$ have discussed loss of particle strengthening in $\mathrm{Nb}$ steels, as being due in part to strain induced precipitation in austenite, while Kestenbach et al. ${ }^{222}$ have considered loss in strength, associated with interface precipitation removing dispersion strengthening particles.

An increase in the friction stress is known to have a deleterious effect on toughness. Several papers reviewed by Morrison et al. ${ }^{200}$ developed equations to calculate the impact transition temperature (ITT) as a function of cementite thickness $t$, ferrite grain size and dispersion strengthening. ${ }^{213,217,218}$ A current version of these equations is

$$
\begin{aligned}
54 \mathrm{~J} \operatorname{ITT}\left({ }^{\circ} \mathrm{C}\right)= & 192 t^{1 / 2}-10 \cdot 1 d^{-1 / 2}+ \\
& K\left(\sigma_{\mathrm{P}}+\sigma_{\mathrm{d}}\right)-23
\end{aligned}
$$

Recent research has shown that vanadium steels processed by the TSDR route which offers both metallurgical, environmental and economic advantages, can achieve similar properties to CCR processed steels, with yield strengths of $450-550 \mathrm{MPa}$ and acceptable levels of toughness. ${ }^{154,159,176,205}$

Differing views on the role played by precipitation of carbonitrides in developing strength in microalloyed steels have been expressed in the literature. For example, it is considered by some, that interphase precipitation does not contribute a major dispersion strengthening component to the yield stress. This is thought to be due mainly to random precipitation formed in ferrite after a few rows of interphase precipitation, ${ }^{2,3,223}$ as shown in Fig. 24. Much of the earlier work on interphase precipitation was carried out on model alloys using isothermal conditions. The intersheet spacing $\lambda$, decreased with a lowering of transformation temperature. $\lambda$ has been related to dispersion strengthening $\sigma_{\mathrm{p}}$ by empirical 


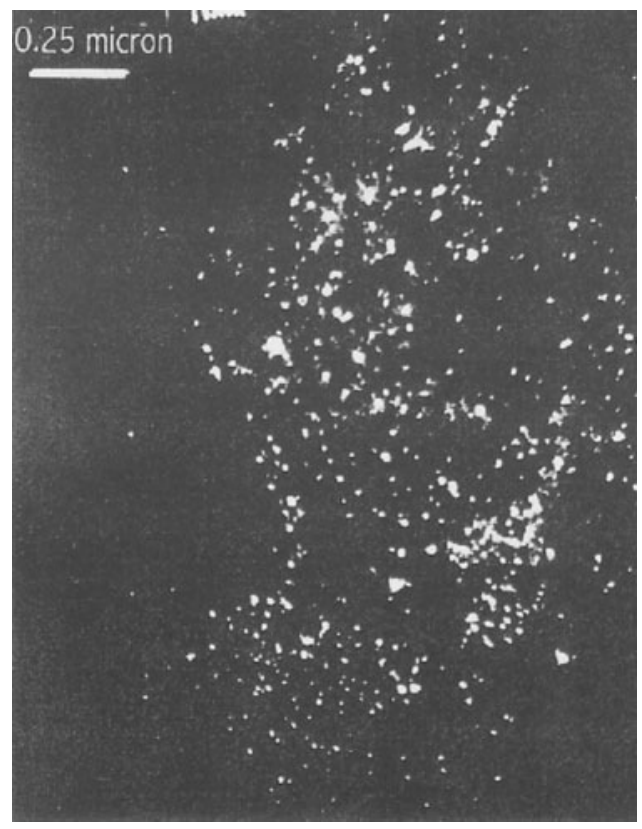

25 Inhomogeneous distribution of $\mathrm{V}(\mathrm{C}, \mathrm{N})$ particles showing precipitate free region adjacent to dense precipitation $^{225}$

equations ${ }^{80,92}$ of the form $\sigma p \approx \lambda^{-\mathrm{n}}$, where $n$ is in the range $0 \cdot 5-1 \cdot 1$. Interphase precipitation is known to be subject to heterogeneous particle distributions. Crooks et al. ${ }^{64}$ commented on the non-uniform distribution of matrix precipitates and many areas where the interphase sheet spacing was $<100 \mathrm{~nm}$, which is required for significant dispersion hardening, a spacing often recorded. ${ }^{80,87}$ This observation of a non-uniform distribution has recently been reinforced by the work of Kestenbach et al., ${ }^{222}$ who undertook quantitative studies of the heterogeneous particle distributions in $\mathrm{Nb}$ and $\mathrm{Nb}+\mathrm{Ti}$ steels, to assess the strengthening potential due to interphase precipitation. The work was motivated by descriptions of particles being "not evenly distributed, but confined to certain areas, ${ }^{85}$ or 'having been found in only two of a total of 20 grains investigated'. ${ }^{223}$ Campos et $a l^{224}$ found that in the particular case of an industrially processed, highly microalloyed hot strip steel, interphase precipitation was present in $\sim 50 \%$ of the ferrite grains. The inhomogeneous distribution of precipitates in microalloyed steels is not confined to interphase precipitates. ${ }^{222}$ Work on vanadium steels by Douse and Baker $^{225}$ reported a quantitative assessment of the number of fields containing fine random particles, as seen in Fig. 25, and the data given in Table 4. Here it can be seen that $\sim 60 \%$ of the fields of view contain particles, but only $\sim 5 \%$ have a high density of particles. The absence of the smallest particles may be due the problems of extraction on carbon replicas mentioned

Table 4 Precipitate distributions on carbon extraction replicas taken from vanadium steel V-N (Ref. 225)

\begin{tabular}{llllrr}
\hline Replica & Empty & Low & Medium & High & Total \\
\hline 1 & 35 & 27 & 18 & 5 & 85 \\
2 & 25 & 31 & 11 & 2 & 69 \\
3 & 13 & 23 & 18 & 3 & 57 \\
Total fields & 73 & 81 & 47 & 10 & 211 \\
\hline
\end{tabular}

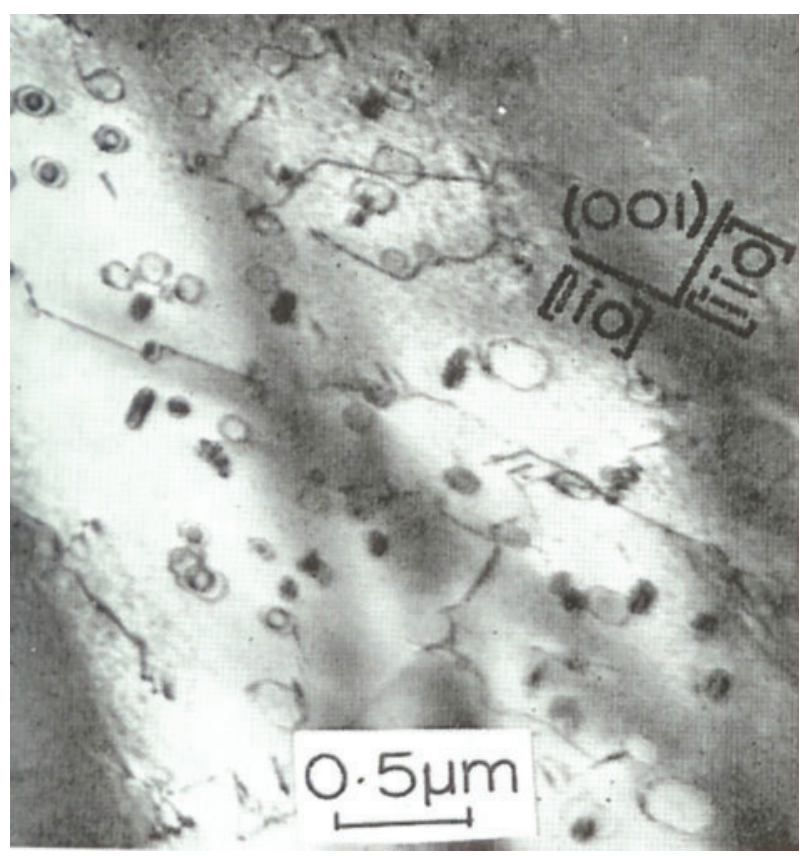

26 Dislocation-particle interactions in low C-V-N steel ${ }^{220}$

earlier. ${ }^{181,182}$ Other examples of inhomogeneous distribution of precipitates and practical problems associated with the use of carbon extraction replicas to obtain quantitative particle assessments have been considered. ${ }^{226}$ As far as is known, no detailed study on the effect of non-uniform particle distribution on the lower yield strength has been undertaken. Most modelling assumes a uniform distribution of particles of equilibrium stoichiometric composition, while the calculated dispersion strengthening component is based on the Orowan strengthening mechanism, which applies strictly to incoherent particles. The mechanisms for particle coherency loss discussed in the classic paper by Brown and Woolhouse, ${ }^{27}$ including that due to external dislocations, such as may be present in Figs. 22 and 26 , suggest that the critical mismatch $\varepsilon_{\text {crit }}$, lies between $0 \cdot 013<\varepsilon_{\text {crit }}<0 \cdot 077$. The data in Table 3 for $\varepsilon_{1}$ span this range while that for $\varepsilon_{2}$ do not. Also, as the ratio of $\varepsilon_{2 \text { crit }} /$ $\varepsilon_{1 \text { crit }} \infty$ particle length/particle thickness, ${ }^{228}$ and in Table 3, this ratio increases from $\mathrm{NbC}$ at 4.5 to $\mathrm{VN}>19$,which accounts for the plate-like growth particularly noticeable for vanadium carbonitrides in microalloyed steels. While the authors ${ }^{227}$ compared data derived from both theory and experiment, all the experimental data was obtained from non-ferrous systems, as none was available at the time from steels.

The uncertainty of the state of coherency together with the inhomogeneous distribution of precipitates which is now becoming more widely recognised, suggests that a regression equation approach for estimating particle and dislocation strengthening in microalloyed steels, overcomes many of the problems associated with the experimental determination of $\sigma_{\mathrm{P}}+\sigma_{\mathrm{d}}$, and is useful in ranking steels, but provides no information on the mechanisms of strengthening. One of the main shortcomings in the prediction of the components of strengthening has been reliable data on the volume fraction of the microalloyed precipitates. Chemical methods $^{138-140}$ and TEM $^{168,214,215,226}$ have been the main techniques used to obtain particle volume 


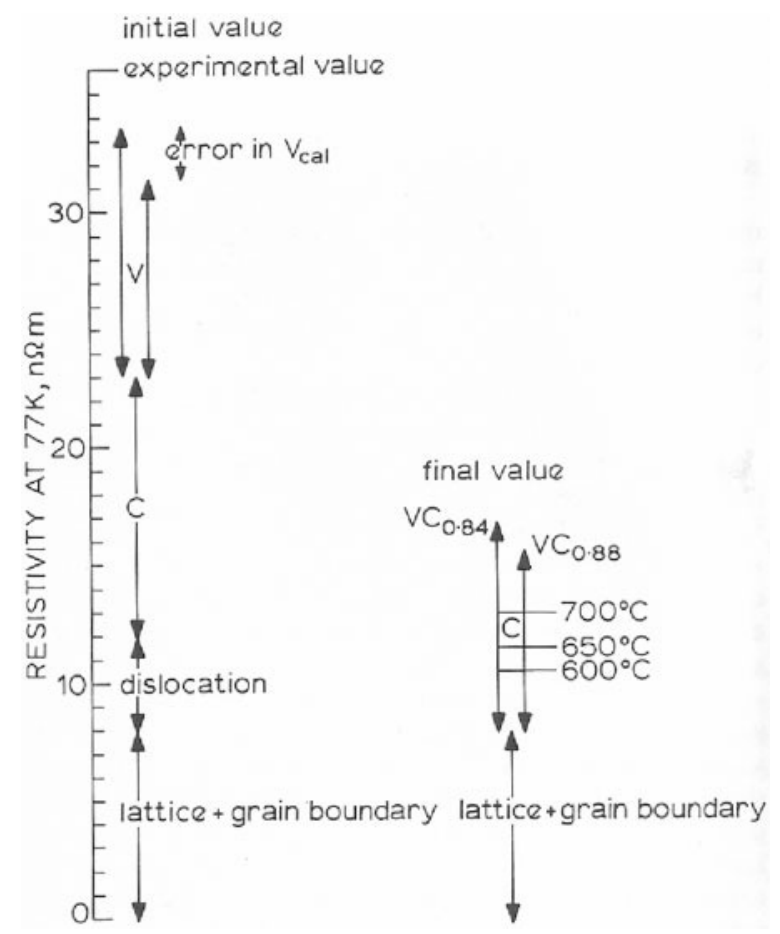

27 Calculated resistivity contribution at $77 \mathrm{~K}$, totalling $31 \mathrm{n} \Omega \mathrm{m}$ at short aging times and $16 \mathrm{n} \Omega \mathrm{m}$ for longer aging times $\left(\mathrm{VC}_{0.84}\right)$ (Ref. 231)

fractions. A major concern with both approaches has been the possible loss of contribution from the smallest particles $^{181,182}$ appoximatly $\leqslant 5 \mathrm{~nm}$. The use of resistivity and dilatometry measurements as a means of determining the kinetics of phase transformations, ${ }^{122}$ in particular of vanadium carbide precipitation, ${ }^{229-231}$ and the contributions of the microstructural features to strength has been explored in only a few instances. Figure 27 shows the breakdown of the contribution of various microstructural components to the total resistivity, which can then be used to calculate the precipitate volume fraction. ${ }^{231}$ There is now a possibility of obtaining microstructural information online during steel production in a non-destructive and remote manner. Impedence spectroscopy using electromagnetic sensors has been developed which monitor phase transformations on the run-out table in hot rolled steels production. ${ }^{232}$ The development of similar sensors for use online to record resistivity changes should be possible in the future.

\section{Summary}

Vanadium has been an important element in steels for over 80 years, commencing with a role in tempered $\mathrm{Cr}-$ Mo-V steels for creep resistant applications. The use of vanadium as a single alloying element was considered as nucleating small $\mathrm{FeV}$ precipitates, followed by use in microalloyed steels from the late 1950s. Here, the importance of transition metal carbides, nitrides and carbonitrides in controlling properties was recognised. Microalloying in low carbon steels $(<0 \cdot 15 \mathrm{wt}-\%)$ was rapidly followed by the development of controlled rolling. 4,191,195 The high levels of solubility of vanadium carbide, and to a lesser extent vanadium nitride, compared with other transition metal carbides and nitrides, allowed the use of lower soaking temperatures in the controlled rolling of vanadium microalloyed steels than was normally used in hot rolling of niobium steels. ${ }^{3}$ Compared with niobium, vanadium in solid solution in austenite has little influence on recrystallisation through solute drag processes. ${ }^{68}$ Under constant activity nitriding conditions, the nucleation of vanadium nitride involves the formation of coherent disc shaped zones on $\{100\}$ matrix ferrite planes with attendant strain field contrast in TEM specimens. ${ }^{107}$ Similar contrast has been reported in steels containing the normal levels of $\mathrm{C}$ and $\mathrm{N}$ found in microalloyed steels, ${ }^{108}$ although the mechanism for the presence of coherent precipitation is not accepted universally. ${ }^{124}$ While vanadium nitrides produce grain refinement of austenite, ${ }^{2,137,177}$ this is usually less effective than $\mathrm{AlN},{ }^{233} \mathrm{NbN}$ or $(\mathrm{V}, \mathrm{Nb}) \mathrm{N} .^{234,235}$ Vanadium carbide is usually seen as interphase precipitation $^{53,75,80,81}$ or random precipitation in ferrite, ${ }^{77,89,141}$ conferring significant dispersion strengthening as can vanadium nitride and vanadium carbonitrides, ${ }^{154}$ the latter being known to be particularly resistant to particle coarsening. ${ }^{76}$ In recent times, the use of nitrogen as an important alloying element has gained acceptance, ${ }^{145,146,201}$ and this is timely for thin slab direct rolling processes, were the steel is directly charged to an equalisation furnace following continuous casting. ${ }^{202-208,236}$ Thus there is a requirement to avoid the peritectic transformation ${ }^{206}$ by lowering the carbon level in the cast steel to $\leqslant 0.06 \mathrm{wt}-\%$. While vanadium is often regarded as an alternative addition to niobium, there are occasions when a combined addition is beneficial. $^{3,4,237,238}$ Vanadium steels are known to experience less deleterious transverse cracking than those with niobium additions alone, but $\mathrm{V}-\mathrm{Nb}$ steels show the least loss in hot ductility. ${ }^{187}$ Recently, STEM/ PEELS techniques have been developed which can provide quantitative analysis of the $\mathrm{C}$ and $\mathrm{N}$ levels in particles $<5 \mathrm{~nm}$ in size. ${ }^{181,182}$ As a result, dispersion strengthening in V-N TSDR steels has been clearly shown to depend on fine, nearly stoichiometric, vanadium nitride particles. ${ }^{175}$ The earlier view that vanadium precipitates were just described as compounds ${ }^{239}$ or carbides $^{231}$ even in steels containing $0 \cdot 010 \mathrm{wt}-\% \mathrm{~N}, 137,240$ is no longer the case. In more complex $\mathrm{V}-\mathrm{Nb}$ steels, a larger volume fraction of high nitrogen carbonitrides are dispersed, compared with $\mathrm{V}-\mathrm{N}$ steels, resulting in greater dispersion strengthening, which together with a fine ferrite grain size can lead to lower yield strengths in the range 450-600 $\mathrm{MPa}$, combined with satisfactory toughness properties. ${ }^{56,205}$ The importance of relating processing parameters to microstructure and to properties of alloys arose in the main, through the research associated with the development of microalloyed steels. Another parallel development which had a major effect on microstructural studies was the progress in analytical electron microscopy, particularly that involving EDX analysis and EELS. Newer techniques such as electron spectroscopic imaging, energy filtered TEM and threedimensional atom probe microscopy, ${ }^{179,182}$ will undoubtedly play an important role in the future unravelling of the complex microstructures observed in modern microalloyed steels, possibly online. ${ }^{232}$

\section{Acknowledgements}

The author was introduced to the subject of microalloyed steels in 1962 while employed as a project leader 
at Tube Investments Research Laboratories, Hinxton Hall near Cambridge, where he worked with Dr P. E. Brookes on the evolution of Thirty Oak, a niobium controlled rolled microalloyed steel, designed initially for transmission towers. He wishes to acknowledge the unheralded contribution of Mr B.W. Berry of the former Round Oak Steel Works Ltd for his vision and perspicacity in the initial stages of this work. Also the continuous collaboration with Professor Alan J. Craven, University of Glasgow, for over 25 years in the development of EELS analysis of vanadium carbides and nitrides is acknowledged as is the collaboration with Dr Yu Li, now of Vanitec. The support given by Mr P. E. Mitchell, the former Chairman of Vanitec and the collaboration with Drs D. N. Crowther and W. B. Morrison, Swinden Laboratories, British Steel/Corus over many years is acknowledged. Aileen Petrie is thanked for her help with formatting some of the micrographs.

\section{References}

1. J. H. Woodhead: 'The physical metallurgy of vanadium steels', Proc. Semin. Vanadium'79, 3-10; 1979, Vanitec, Chicago, IL; also available as Vanadium Award Paper no. V0284, London, 1983.

2. R. Lagneborg, T. Siwecki, S. Zajac and B. Hutchinson: Scan. J. Metall., 1999, 28, 186-242.

3. T. Gladman: 'The physical metallurgy of microalloyed steels'; 1997, London, Institute of Materials.

4. F. B. Pickering: Proc. Conf. Microalloying '75, 9-31; 1977, New York, Union Carbide Corp.

5. H. B. Knowlton: 'Heat treatment, uses and properties of steel', 105; 1929, Cleveland, OH, American Society for Steel Treating.

6. H. H. Abram: J. Iron Steel Inst., 1934, 130, 351-375.

7. G. Oakes and K. C. Barraclough: in 'The development of gas turbine materials', (ed. G.W. Meethem), 31-61; 1981, London, Applied Science Publishers.

8. J. H. Woodhead and A. G. Quarrell: J. Iron Steel Inst., 1965, 203, 605-620.

9. B. A. Senior: Mater. Sci. Eng. A, 1988, A103, 263-271.

10. in 'Materials properties handbook: titanium alloys', 483-636; 1994, Materials Park, OH, ASM International.

11. G. Brauer and W. D. Schnell: J. Less Common Met., 1964, 6, 23-30.

12. G. Brauer and W. D. Schnell: J. Less Common Met., 1964, 6, 326.

13. A. T. Davenport, L. C. Brossard and R. E. Milner: J. Met., 1975, 27, 21-27.

14. R. G. Baker and J. Nutting: in 'Precipitation processes in steels', Special report no. 64, 1-22; 1959, London, The Iron and Steel Institute.

15. G. Kurdjumov and G. Sachs: Z. Phys., 1930, 62, 592.

16. K. Narita: Trans. ISIJ, 1975, 15, 145-152.

17. E. T. Turkdogan: Trans. ISS Iron Steelmaker, May 1989, 61-75.

18. H. A Wriedt and H. Hu: in 'Chemical metallurgy: a tribute to Carl Wagner, (ed. N. A. Gokcen et al.), 171-194; 1981, Warrendale, PA, The Metallurgical Society of AIME.

19. T. Wada, H. Wada, J. Chipman and J. F. Elliott: Metall. Trans., 1972, 3, 2865-2872.

20. N. A. Savost'yanova and L. A. Shvartsman: Phys. Met. Metall., 1960, 9, 35-39.

21. K. Bungardt, K. Kind and W. Oelsen: Arch. Eisenhuttenw., 1956, 27, 6.

22. H. Sekine, T. Inoue and M. Ogasawara: Trans. ISIJ, 1968, 8, 101-102.

23. K. A. Taylor: Scr. Metall. Mater., 1995, 32, 7-12.

24. M. G. Frohberg and H. Graf: Stahl Eisen, 1960, 80, 539-541.

25. A. Rose: British steel report no. SL/PM/R/S2971/4/97/A, 1979.

26. W. Roberts and A. Sandberg: 'The compositions of $C(V, N)$ as precipitated in HSLA steel micoalloyed with vanadium', Report no. IM-1489, Swedish Institute for Metals, Stockholm, Sweden, 1980.

27. V. Raghavan: Bull. Alloy Phase Diagr., 1984, 5, 194-198.

28. B. Aronsson: Proc. Symp. on 'Steel strengthening mechanisms', 77-88; 1969, Zurich, Climax Molybdenum Company.

29. J. Strid and K. E. Easterling: Acta Metall., 1985, 33, 2057-2074.

30. H. J. Goldschmidt: 'Interstitial alloys', 238; 1957, London, Butterworths

31. D. C. Houghton: Acta Metall. Mater., 1993, 41, 2993-3006.
32. V. V. Popov and I. I. Gorbachev: Phys. Met. Metall., 2005, 99, 286-299.

33. V. V. Popov and I. I. Gorbachev: Philos. Mag., 2005, 85, 2449-2467.

34. M. J. Crooks, A. J. Garrett-Reed, J. B. Vander Sande and W. S. Owen: Metall. Trans. A, 1982, 13A, 1347-1353

35. R. W. K. Honeycombe: 'Steels, microstructure and properties', 140-165; 1981, London, Arnold.

36. A. M. Sage, J. H. Woodhead and D. W. Evans: 'Vanadium structural steels, 2-quenched and tempered'; 1971, Witbank, Highveld Steel and Vanadium Corporation.

37. E. Smith and J. Nutting: J. Iron Steel Inst., 1957, 157, 314-329.

38. A. K. Seal and R. W. K. Honeycombe: J. Iron Steel Inst., 1958, 158, 9-15.

39. A. K. Seal and R. W. K. Honeycombe: J. Iron Steel Inst., 1958, 158, 343-356.

40. W. Crafts and J. L. Lamont: Trans. AIME, 1950, 188, 561-574

41. K. J. Irvine and F. B. Pickering: J. Iron Steel Inst., 1960, 194, 137-153.

42. E. Tekin and P. M. Kelly: J. Iron Steel Inst., 1965, 203, 715-720.

43. E. Tekin and P. M. Kelly: Proc. Conf. on 'Precipitation from ironbased alloys', 173-221; 1965, New York, AIME, Gordon and Breach.

44. D. Raynor, J. A. Whiteman and R. W. K. Honeycombe: J. Iron Steel Inst., 1966, 204, 349-354.

45. M. Tanino and T. Nishida: Trans. JIM, 1968, 9, 103-110.

46. K. Miyata, T. Omura, T. Kusida and Y. Komizo: Metall. Mater. Trans. A, 2003, 34A, 1565-1573.

47. S. Yamasaki and H. K. D. H. Bhadeshia: Mater. Sci. Technol., 2003, 19, 1335-1343.

48. B. D. Jana, A. K. Chatrabarti and K. K. Ray: Mater. Sci. Technol., 2003, 19, 80-86.

49. I. M. Robinson: Mater. Sci. Technol., 1993, 9, 1031-1036.

50. E. Orowan: Proc. Symp. on 'Internal stresses in metals and alloys', 451; 1948, London, The Institute of Metals.

51. P. B. Hirsch: J. Inst. Metals, 1957, 86, 7 appendix.

52. A. J. Ardell: Metall. Trans. A, 1985, 16A, 2131-2165.

53. D. V. Edmonds and R. W. K. Honeycombe: Proc. Conf. on 'Precipitation processes in solids', (ed. K. C. Russell and H. I. Aaronson), 121160; 1978, Warrendale, PA, Metallurgical Society of AIME.

54. W. J. Lui and J. J. Jonas: Proc. Conf. on 'Processing, microstructure and properties of HSLA steels', (ed. A. J. De Ardo et al.), 39; 1988, Warrendale, PA, Metallurgical Society of AIME.

55. F. D. Richardson and J. H. E. Jeffes: J. Iron Steel Inst., 1948, 160, 261-265.

56. Y. Li, D. N. Crowther, P. S. Mitchell and T. N. Baker: ISIJ Int., 2002, 42, 636-644.

57. Y. Li, $\bar{D}$. N. Crowther, P. S. Mitchell and T. N. Baker: Proc. 4th Int. Conf. on 'HSLA steels', (ed. G. Liu et al.), 326-332; 2000, Beijing, The Metallurgical Press.

58. L. J. Cuddy: in 'Themomechanical processing of microalloyed austenite', (ed. A. J. DeArdo et al.), 129-140; 1982, Warrendale, PA, The Metallurgical Socociety of AIME

59. A. J. DeArdo: Int. Met. Rev., 2003, 48, 371-402.

60. E. J. Palmiere, C. L. Garcia and A. J. DeArdo: Metall. Trans. A, 1996, 27A, 951-960.

61. E. L. Brown, A. J. DeArdo and H. H. Bucher: 'Hot deformation of austenite', 250-285; 1977, New York, The Metallurgical Society of AIME.

62. J. N. Cordea and R. E. Hook: Metall. Trans., 1970, 1, 11-17.

63. M. J. White and W. S. Owen: Metall. Trans. A, 1980, 11A, 597-604.

64. M. J. Crooks, A. J. Garrett-Reed, J. B. Vander Sande and W. S Owen: Metall. Trans. A, 1981, 12A, 1999-2013.

65. L. J. Cuddy, J. J. Bauwin and J. C. Raley: Metall. Trans. A, 1980, 11A, 381-386.

66. C. Garcia-Mateo, B. Lopez, J. M. Rodriguez-Ibabe: Mater. Sci. Eng. A, 2001, A303, 216-225.

67. K. He and D. V. Edmonds: Mater. Sci. Technol., 2002, 18, 289-296.

68. H. L. Andrade, M. G. Akben and J. J. Jonas: Metall. Trans. A, 1983, 14A, 1967-1977.

69. R. W. K. Honeycombe: Metall. Sci., 1980, 14, 201-214.

70. R. W. K. Honeycombe: in 'Processing, microstructure and properties of HSLA steels', (ed. A. J. DeArdo et al.), 1-38; 1988, Warrendale, PA, Metallurgical Society of AIME.

71. A. T. Davenport, F. G. Berry and R. W. K. Honeycombe: Metall. Sci., 1968, 2, 104-106.

72. F. G. Berry and R. W. K. Honeycombe: Metall. Trans., 1970, 1, 3279-3286.

73. H. C. Sutton and J. A. Whiteman: J. Iron Steel Inst., 1971, 209, 220-225.

74. D. V. Edmonds: J. Iron Steel Inst., 1972, 210, 363-365.

75. A. D. Batte and R. W. K. Honeycombe: J. Iron Steel Inst., 1973, 211, 284-289. 
76. N. K. Ballinger and R. W. K. Honeycombe: Metall. Trans. A, 1980, 11A, 421-429.

77. T. N. Baker: J. Iron Steel Inst., 1973, 211, 502-510.

78. F. G. Berry, A. T. Davenport and R. W. K. Honeycombe: Proc. Conf. on 'Mechanism of phase transformations in crystalline solids', 288-292; 1969, London, The Institute of Metals.

79. A. T. Davenport and R. W. K. Honeycombe: Proc. Roy. Soc. Lond. A, 1971, 332A, 191-205.

80. D. V. Edmonds: Metall. Trans., 1973, 4, 2527-2533.

81. D. V. Edmonds and R. W. K. Honeycombe: J. Iron Steel Inst., 1973, 211, 209-216.

82. K. Campbell and R. W. K. Honeycombe: Metall. Sci. J., 1974, 8, 197-203.

83. G. Fourlaris, A. J. Baker and G. D. Papadimitriou: Acta Metall. Mater., 1995, 43, 2589-2604.

84. W. B. Morrison: Mater. Sci., Technol., 1985, 1, 954-960.

85. W. B. Morrison: J. Iron Steel Inst., 1963, 201,

86. W. B. Leslie: Proc. Conf. on 'The relationship between structure and mechanical properties of metals', 334; 1963, London, HMSO.

87. J. M. Gray and R. B. G. Yeo: Q. Trans. ASM, 1968, 61, 225-269.

88. T. Sakama and R. W. K. Honeycombe: Metall. Sci., 1984, 18, 449-454.

89. E. T. Stephenson, G. M. Karchner and P. Stark: Trans. Am. Soc. Metall., 1964, 57, 208-216.

90. M. Tanino, T. Nishida, T. Ooka and K. Yoshikawa: J. Jpn Inst. Metall., 1965, 29, 728-734.

91. J. H. Woodhead and D. Webster: J. Iron Steel Inst., 1969, 207, 51-53.

92. S. Freeman: Proc. Conf. on 'Effect of second phase particles on the mechanical properties of steel', 152-156; 1971, London, The Iron and Steel Institute.

93. R. W. K. Honeycombe: Metall. Trans. A, 1976, 7A, 915-936.

94. R. W. K. Honeycombe: Proc. Int. Conf. on 'Technology and applications of HSLA steels', 243-250; 1983, Philadelphia, PA, ASM.

95. W. Roberts: Internal report no. IM-1333, Swedish Institute for Metals Research, Stockholm, Sweden, 1978

96. R. Lagneborg and S. Zajac: Metall. Mater. Trans. A, 2001, 32A, 39-50.

97. F. A. Khalid and D. V. Edmonds: Mater. Sci. Technol., 1993, 9 , 384-395.

98. T. N. Baker: Proc. Conf. on 'Effect of second phase particles on the mechanical properties of steel', 204; 1971, London, The Iron and Steel Institute.

99. N. K. Ballinger and R. W. K. Honeycombe: Metall. Trans. A, 1980, 11A, 421-429.

100. K. H. Jack: Scand. J. Metall., 1972, 1, 195-202.

101. D. L. Speirs: 'Precipitation in iron molybdenum nitrogen alloys', PhD thesis, University of Newcastle, England, UK, 1969.

102. J. H. Driver and J. M. Papazian: Acta Metall., 1973, 21, 1139-1149.

103. M. Wada, A. Fujii, T. Komazaki and T. Mori: Acta Metall., 1989, 37, 2349-2355.

104. D. H. Jack: Acta Metall.,1976, 24, 137-146.

105. N. G. Chechenin, A. R. Chezan, C. B. Craus, D. O. Beorma, D. M. Bronsveld, J. T. M. de Hosson and L. Niesen: Metall. Mater. Trans. A, 2002, 33A, 3075-3087.

106. V. A. Phillips and A. U. Seybolt: Trans. Met. Soc. AIME, 1968, 242, 2415-2422.

107. M. Pope, P. Grieveson and K. H. Jack: Scand. J. Metall., 1973, 2, 29-34.

108. T. N. Baker and A. J. Lapointe: Proc. Conf. EMAG, (ed. D. L. Misell), 195-198; 1977, London, Institute of Physics.

109. V. A. Philips and J. D. Livingstone: Philos. Mag., 1962, 7, 969-980.

110. M. F. Ashby and L. M. Brown: Philos. Mag., 1963, 8, 1083-1103.

111. S. L. Sass, T. Murs and J. B. Cohen: Philos. Mag., 1967, 16, 679-690.

112. A. T. Davenport: J. Iron Steel Inst., 1968, 206, 499-501.

113. J. J. Irani and R. W. K. Honeycombe: Proc. 5th Int. Conf. on 'Electron microscopy', Paper HH-9; 1962, New York, Academic Press.

114. S. R. Keown and D. J. Dyson: J. Iron Steel Inst., 1966, 204, 832-836.

115. R. B. Nicholson and J. Nutting: Phil. Mag., 1958, 3, 531-535.

116. E. Smith: Acta Metall., 1966, 14, 583-593.

117. E. Hornbogen: Acta Metall., $1962,10,525-533$.

118. E. Hornbogen: Acta Metall., 1962, $\overline{\mathbf{1 0}}, 1187-1189$

119. M. Tanino and T. Nishida: Trans. JIM, 1968, 9, 103-110.

120. K. H. Jack and D. H. Jack: Mater. Sci. Eng., 1973, 11, 1-27.

121. R. W. K. Honeycombe: Iron Steel Spec. Rpt 1964, 86, $\frac{1-14 .}{1-14}$

122. G. R. Speich: Trans. Met. Soc. AIME, 1969, 245, 2553-2564.

123. E. Smith: Proc. 5th Int. Conf. on 'Electron microscopy', Paper CC-10; 1962, New York, Academic Press.

124. E. V. Morales, J. Gallego and H.-J. Kestenbach: Philos. Mag. Lett., 2003, 83, 79-87.
125. T. D. Mottishaw and G. D. W. Smith: Proc. 29th Int. Symp. on 'Field emission', 465-472; 1982, Stockholm, Almqvist and Wilksell.

126. D. Hernandez, B. Lopez and J. M. Rodriguez-Ibabe: Mater. Sci. Forum, 2005, 500-501, 411-418.

127. F. Ishikawa, T. Takahashi and T. Ochi: Metall. Mater. Trans. A 1994, 25A, 929-936.

128. T. Kimura, A. Ohmori, F. Kawabata and K. Amano: Proc. Themec '97, 645-651; 1997, Warrendale, PA, TMS

129. T. Furuhara, J. Yamaguchi, N. Sugita, G. Miyamoto and T. Maki: ISIJ Intl., 2003, 43, 1630-1639.

130. T.-K. Lee, H. J. Kim, B. Y. Kang and S. K. Hwang: ISIJ Int., 2000, 40, 1260-1268.

131. N. E. Hannerz and B. M. Jonsson-Holmquist: Met. Sci., 1974, 8, 228-234.

132. C. L. Davis and J. E. King: Mater. Sci. Technol., 1993, 9, 8-15.

133. P. H. M. Hart and P. S. Mitchell: Weld. J., 1995, 74, S239-S248.

134. Y. Li, D. N. Crowther, M. J. W. Green, P. S. Mitchell and T. N. Baker: ISIJ Int., 2001, 41, 46-55

135. W. B. Morrison and J. H. Woodhead: J. Iron Steel Inst., 1963 201, 43-46.

136. F. B. Pickering and T. Gladman: 'Metallurgical developments in carbon steels', 10-20; 1963, London, Iron and Steel Institute.

137. K. J. Irvine, F. B. Pickering and T. Gladman: J. Iron Steel Inst., 1967, 205, 161-182.

138. H. J. Wiester, H. A. Vogels and H. Olmer: Stahl Eisen, 1959, 79, $1120-1129$.

139. P. Konig, W. Scholz and H. Ulmer: Arch. Eisenh., 1961, 32, 541-556.

140. H. A. Vogels: P. Konig and K.-H. Piehl: Arch. Eisenh., 1964, 35, 339-351.

141. T. N. Baker: Met. Technol., 1974, 1, 126-131.

142. T. N. Baker: Acta Metall., 1973, 21, 261-266.

143. D. M. Schwartz and B. Ralph: Philos. Mag., 1969, 19, 1069-1074.

144. G. L. Dunlop and R. W. K. Honeycombe: Philos. Mag., 1975, 32 61-72.

145. T. Siwecki, A. Sandberg, W. Roberts and R. Langeneborg: in 'Themomechanical processing of microalloyed austenite', (ed. A J. DeArdo et al.), 163-194; 1982, Warrendale, PA, Metallurgical Society of AIME.

146. W. Roberts: Proc. Int. Conf. on 'Technology and applications of HSLA steels', (ed. M. Korchynsky), 33-65; 1983, Philadelphia, PA, ASM.

147. W. Roberts T. Siwecki and A. Sandberg: Proc. Int. Conf. on 'Technology and applications of HSLA steels', (ed. M. Korchynsky) 67-84; 1983, Philadelphia, PA, ASM.

148. S. Zajac, T. Siwecki and M. Korchynsky: Proc. Conf. on 'Low carbon steels for the 90's', (ed. R. Asfahani and G. Tither), 139 149; 1993, Warrendale, PA, TMS.

149. M. M. Bepari: Mater. Sci. Technol., 1989, 5, 13-19.

150. M. M. Bepari: Mater. Sci. Technol., 1990, 6, 338-348.

151. T. Siwecki, A. Sandberg and W. Roberts: Proc. Int. Conf. on 'Technology and applications of HSLA steels', (ed. M. Korchynsky), 619-634; 1983, Philadelphia, PA, ASM.

152. Y.-Z Zheng, A. J. DeArdo, R. M. Fix and G. Fitzsimons: Proc. Int. Conf. on 'Technology and applications of HSLA steels', (ed. M. Korchynsky), 85-94; 1983, Philadelphia, PA, ASM

153. H. Najafi, J. Rassizadehghani and A. Halvaaee: Mater. Sci. Technol., 2007, 23, 699-705.

154. Y. Li, J. A. Wilson, A. J. Craven, P. S. Mitchell, D. N. Crowther and T. N. Baker: Mater. Sci. Technol., 2007, 23, 509-518.

155. D. M. Fegredo, J. D. Boyd and M. J. Stewart: Proc. Int. Conf. 'Technology and applications of HSLA steels', (ed. M. Korchynsky) 95-105; 1983, Philadelphia, PA, ASM.

156. M. Tanniru, S. Shanmugam, R. D. K. Misra, D. Panda and S. Jansto: Mater. Sci. Technol., 2005, 21, 159-164.

157. S. Shanmugam, M. Tanniru, R. D. K. Misra, D. Panda and S. Jansto: Mater. Sci. Technol., 2005, 21, 165-177.

158. S. Shanmugam, M. Tanniru, R. D. K. Misra, D. Panda and S. Jansto: Mater. Sci. Technol., 2005, 21, 883-892.

159. C. P. Reip, S. Shanmugam and R. D. K. Misra: Mater. Sci. Eng. $A, 2006, \mathbf{A 4 2 4}, 307-317$.

160. S. W. Thompson and G. Krauss: Metall. Trans. A, 1989, 20A, 2279-2288.

161. M. Prikryl, A. Kroupa, G. C. Weatherly and S. V. Subramanian: Metall. Mater. Trans. A, 1996, 27A, 1149-1165.

162. G. L. Dunlop and P. J. Turner: Met. Sci., 1975, 9, 370-374.

163. P. J. Turner and J. M. Papazian: Met. Sci., 1973, 7, 81-86.

164. M. G. Burke, L. J. Cuddy, J. Piller and M. K. Miller: Mater. Sci. Technol., 1988, 4, 113-116.

165. R. C. Thompson: Mater. Charact. 2000, 44, 219-233. 
166. G. E. Hollox, J. W. Edington and R. B. Scarlin: J. Iron Steel Inst., 1971, 209, 837-841.

167. G. L. Dunlop and D. A. Porter: Scan. J. Metall., 1977, 6, 19-20.

168. G. L. Dunlop and R. W. K. Honeycombe: Met. Sci., 1978, 12, 367-371

169. A. J. Garrett-Reed: Proc. Conf. on 'Quantitative microanalysis with high spatial resolution', 165-168; 1981, London, The Metals Society.

170. T. N. Baker, A. J. Craven, S. P. Duckworth and F. Glas: Proc. Conf. EMAG, 239-242; 1981, London, Institute of Physics.

171. S. P. Duckworth, A. J Craven and T. N. Baker: Proc. Conf. EMAG, 339-342; 1983, London, Institute of Physics.

172. S. P. Duckworth, A. J. Craven and T. N. Baker: Proc. Conf. on 'Analytical electron microscopy 1984', (ed. D. B. Williams and D. C. Joy), 235-238; 1984, San Francisco, CA, San Francisco Press.

173. A. J. Craven, M. M. Cluckie, S. P. Duckworth and T. N. Baker: Ultramicroscopy, 1989, 28, 330-334

174. J. A. Wilson and A. J. Craven: Ultramicroscopy, 2003, 94, 197207.

175. J. A. Wilson, A. J. Craven, Y. Li and T. N. Baker: Mater. Sci. Technol., 2007, 23, 519-527.

176. Y. Li, J. A. Wilson, D. N. Crowther, P. S. Mitchell, A. J. Craven and T. N. Baker: ISIJ Int., 2004, 44, 1093-1120.

177. T. N. Baker, Y. Li, J. A. Wilson, A. J. Craven and D. N Crowther: Mater. Sci. Technol., 2004, 20, 720-730.

178. Y. Li and T. N. Baker: Mater. Sci. Forum, 2005, 500-501, 237 243.

179. W. M. Rainforth, M. P. Black, R. L. Higginson, E. J. Palmiere, C. M. Sellars, I. Prabst, P. Warbichler and P. F. Hofer: Acta Mater., 2002, 50, 735-747.

180. M. Hättestrand and H.-O. Andrén: Micron, 2001, 32, 789-797.

181. M. MacKenzie, A. J. Craven and C. L. Collins: Scr. Mater., 2006, 54, 1-5.

182. A. J. Craven, M. MacKenzie, A. Cerezo, T. Godfrey and P. H. Clifton: Mater. Sci. Technol., 2008, 24, 641-650.

183. B. Mintz, S. Yue and J. J. Jonas: Int. Mater. Rev., 1991, 36, (5), 187-217.

184. B. Mintz and J. M. Arrowsmith: 'Hot working and forming processes', 99-103; 1980, London, The Metals Society.

185. Y. Maehara, K. Yasumoto, H. Tomono, T. Nagamichi and Y. Ohmori: Mater. Sci. Technol., 1990, 6, 793-806.

186. P. J. Lubensky, S. L. Wigman and D. J. Johnson: Proc. Conf. Microalloying '95, 225-233, 1995, Pittsburgh, PA, ISS/AIME.

187. Z. Mohamed: Mater. Sci. Eng. A, 2002, A326, 255-260.

188. B. Mintz and R. Abushosha: Iron Steel, 1993, 20, 445-452.

189. C. Offerman, C. A. Daker and C. Enstron: Scan. J. Met., 1981, 10, 115-120.

190. K. Banks, A. Koursaris, F. Verdoon and A. Tuling: Mater. Sci. Technol., 2001, 17, 1596-1604.

191. D. T. Llewellyn: 'Steels, metallurgy and applications'; 1992 , Oxford, Butterworths-Heinemann

192. W. J. Berry: Iron Coal Trade Rev., 1928, 66, 900-902.

193. R. W. Vanderbeck: Weld. J., 1958, 37, 114S

194. R. A. Grange: in 'Fundamentals of deformation processing', (ed W. A. Backoffen), 299-310; 1964, New York, Syracuse University Press,

195. I. Tamura, C. Ouchi, T. Tanaka and H. Sekine: 'Thermomechanical processing of high strength low alloy steels', 1988, London, Butterworths.

196. W. E. Duckworth, R. Philips and J. A. Chapman: J. Iron Steel Inst., 1965, 203, 1108-1114.

197. J. J. Jonas and C. M. Sellars: Proc. Conf. on 'Future developments of metals and ceramics', (ed. J. A. Charles et al.), 147-177; 1992, London, Institute of Materials.

198. B. Datta, E. J. Palmiere and C. M. Sellars: Acta Mater., 2001, 49, 785-794.

199. T. Siwecki, B. Hutchinson and S. Zajac: Proc. Int. Conf. Microalloying '95, 120-135; 1995, Pittsburgh, PA, Iron and Steel Society.

200. W. B. Morrison, R. C. Cochrane and P. S. Mitchell: ISIJ Int, 1993, 33, 1095-1103.

201. M. Korchynsky: Scan. J. Metall., 1998, 28, 40-45.

202. E. Hofken, P. Kappes and H. Lax: Stahl Eisen, 1986, 106, 27-33.

203. G. Flemming, P. Knappes, W. Rohde and L. Vogtmann: Stahl Eisen, 1988, 108, 25-35.

204. G. Flemming, F. Hofman, W. Rohde and D. Rosenthal: Met. Plant Technol. Int., 1993, 2, 84-89.
205. D. N. Crowther, P. S. Mitchell and W. B. Morrison: Proc. 39th Int. Conf. on 'Mechanical working and steel processing', 839-848; 1998, Warrendale, PA, ISS/AIME.

206. R. Priestner: Mat. Sci. Forum, 1998, 284-286, 95-104.

207. R. Kasper and O. Pawelski: Proc. METEC Cong., 90-93; 1994, Dusseldorf, VDEH.

208. J. M. Rodriguez-Ibabe: Mater. Sci. Forum, 2005, 500-501, 49-62.

209. P. Maugis and M. Gouné: Acta Mater., 2005, 53, 3359-3567.

210. S. G. Hong, H. J. Jun, K. B. Kang and C. G. Park: Scr. Mater. 2003, 48, 1201-1206

211. R. W. Armstrong: in 'Yield, flow and fracture of polycrystals', (ed. T. N. Baker), 1-31; 1983, London, Applied Science Publishers.

212. R. W. K. Honeycombe: Biographical Memoirs of Fellows of the Royal Society, 1995, 41, 341-357.

213. J. H. Little, J. A. Chapman, W. B. Morrison and B. Mintz: Proc. 3rd Int. Conf. on 'Strength of metals and alloys', 80-84; 1973, London, Institute of Metals

214. J. Irvine and T. N. Baker: Met. Sci., 1979, 13, 228-237.

215. T. N. Baker (ed.): in 'Yield, flow and fracture of polycrystals', 253-273; 1983, London, Applied Science Publishers.

216. J. Li, F. Sun and W. C. Xu: Scr. Metall. Mater., 1990, 24, 1393 1398

217. W. B. Morrison, B. Mintz and R. C. Cochrane: Proc. Conf. on 'Product technology on controlled processing of HSLA steels', Paper 1, 1976, York, University of York.

218. B. Mintz: Met. Technol., 1984, 11, 265-272.

219. S. Zajac T. Siwecki, W. B. Hutchinson and R. Langneborg: Mater. Sci. Forum, 1998, 284-286, 295-302.

220. T. N. Baker: Proc. Conf. on 'Heat treatment', 13-18; 1975, London, The Metals Society.

221. E. V. Pereloma, B. R. Crawford and P. D. Hodgson: Mater. Sci. Eng. A, 2001, A299, 27-31.

222. H.-J. Kestenbach, S. S. Campos and E. V. Morales: Mater. Sci. Technol., 2006, 22, 615-626.

223. A. J. DeArdo: Mater. Sci. Forum, 1998, 15, 284-286.

224. S. S. Campos, E. V. Morales and H.-J. Kestenbach: Metall. Mater. Trans. A, 2001, 32A, 1245-1249.

225. K. Douse and T. N. Baker: 'Thermomechanical processing of steels', 573-580; 2000, London, IoM.

226. T. N. Baker: in 'Quantitative microscopy of high temperature materials', (ed. A. Strang and J. Crawley), 161-189; 2001, London, IoM Communications.

227. L. M. Brown and G. R. Woolhouse: Philos. Mag., 1970, 21, 329 345.

228. D. A. Porter and K. E. Easterling: 'Phase transformations in metals and alloys', 2nd edn, 160-163; 1992, London, Chapman and Hall.

229. P. Wilkes: Met. Sci., 1968, 2, 6-11.

230. J. M. Derbyshire and J. Barford: Proc. Conf. on 'Mechanism of phase transformations in crystalline solids', 65-71; 1969, London, The Institute of Metals.

231. W. G. Hall and T. N. Baker: Met. Sci., 1981, 15, 447-454.

232. C. L. Davis, S. J. Dickinson and A. J. Peyton: Iron Steelmaking, 2005, 32, 381-384

233. R. K. Amin and F. B. Pickering: in 'Themomechanical processing of microalloyed austenite', (ed. A. J. DeArdo et al.), 1-30; 1982, Warrendale, PA, Metallurgical Society of AIME.

234. I. Weiss, G. L. Fitzsimons, K. Mielityinen and A. J. DeArdo: in 'Themomechanical processing of microalloyed austenite', (ed. A. J. DeArdo et al.), 33-56; 1982, Warrendale, PA, Metallurgical Society of AIME.

235. T. Gladman: 'Grain size control'; 2004, London, Maney/IoM Commumications.

236. J. M. Rodriguez-Ibabe: in 'Materials science foundations', Vol. 33, 'Thin slab direct rolling of microalloyed steel'; 2007, Stafa- Zurich, Trans Tech Publications Ltd.

237. V. J. Pogorzhelskyj, Y. J. Matrosov and A. G. Nasibov: Proc. Conf. Microalloying '75, 100-106; 1977, New York, Union Carbide Corp.

238. T. Greday and M. Lambergits: Proc. Conf. Microalloying '75, 172-185; 1977, New York, Union Carbide Corp.

239. W. E. Duckworth and J. D. Baird: J. Iron Steel Inst., 1969, 207, 854-871.

240. T. Gladman, I. D. McIvor and F. B. Pickering: J. Iron Steel Inst., $1971,209,380-390$ 